أثر تطوير معايير المحاسبة السعودية على جودة المعلومات المحاسبية

إعداد

أ.د/ توفيق بن عبدالمحسن الخيّال أ.د/ صلح بن عبدالرحمن السعد

\author{
الملكة العربية السعودية - جدة \\ جامعة الملك عبد العزيز المادية \\ كلية الاقتصاد والإدارة ـ قسم المحاسبة العزبة \\ جدة- الملكة العربية السعودية
}


الملخص

هافت الدراسة إلي توثيق الوضع الحالي لمهنة المحاسبة في المملكة العربية السعودية

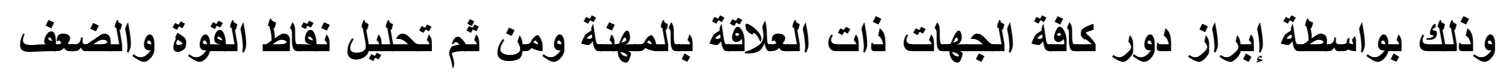

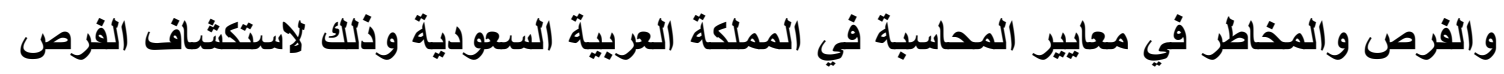
المتاحة والأفاق المستقبلية التي يمكن الاستفادة منها لتطوير معايير المحاسبة في المملكة

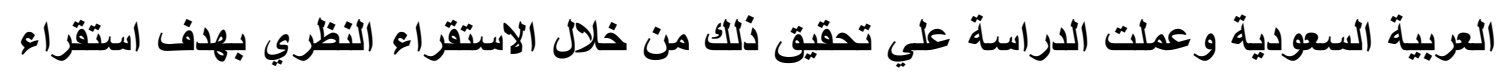
وتصنيف كل ما توصل إليه الباحثان من مراجع ومؤتمرات وأبحاث بهاف الوصول إلي إطار نظري شامل لموضوع الدراسة . 


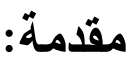

تكمـن الوظيفـة الأساسية للمحاسبة في تقديم المعلومـات الملائهـة وإضـفاء التقـة على المعلومات التي تحتوي عليها التقارير المالية، حيث تعد هذه التقارير المصدر الأساسي للحصول على المعلومات للأطراف الخارجية مثل الستثمرون الحاليون والمحتملون، ومؤسسات الإقراض،

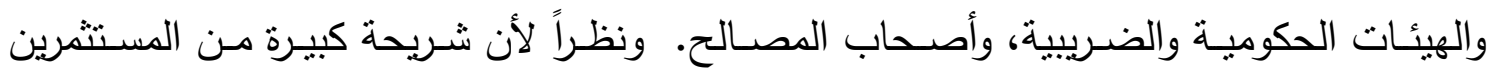

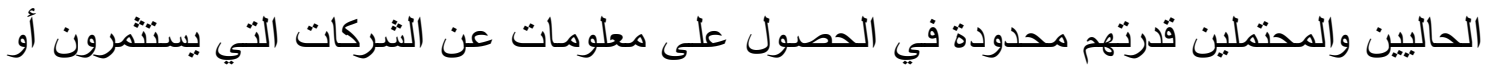
يرغبون الاستثمار فيها وبالتالي اعتمادهم على المعلومات المنشورة في التقارير المالية عند اتخاذ

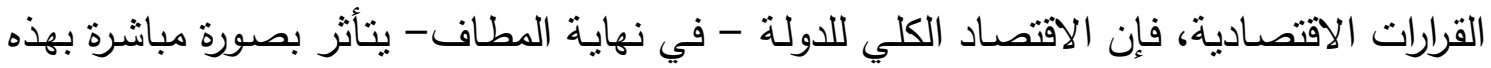

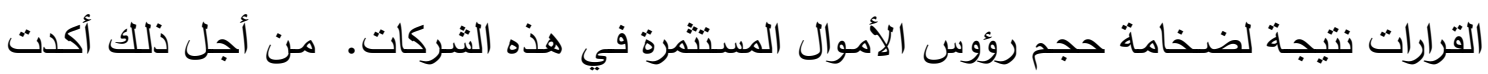

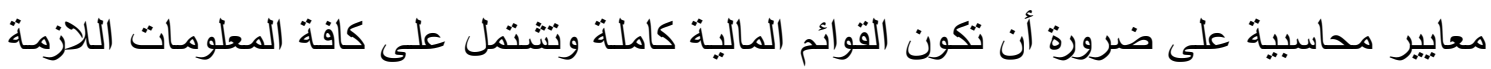

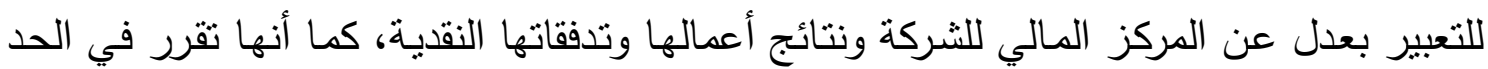
الأدنى كمية ونوعية هذه المعلومات بما يساعد مستخدميها على اتخاذ قرارات اقتصادية رشيدة. وتساعد المعلومات المحاسبية الفئات المستفيدة في تقويم المبادئ المختلفة التي تعد في

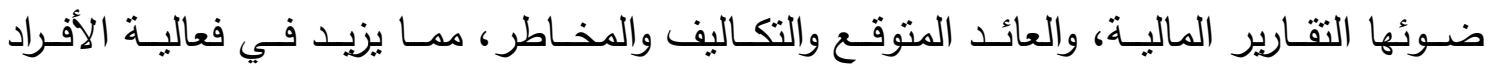

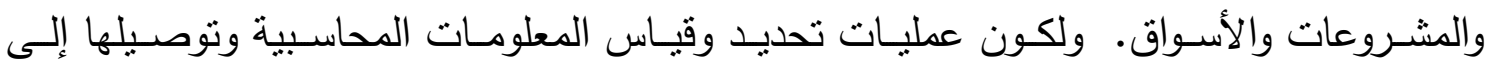
المستخدم النهائي قد تتخذ صورا مختلفة فإن ذلك يتطلب وجود معايير محاسبية مرتبطة ارتباطا

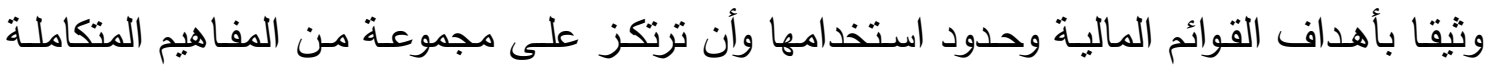

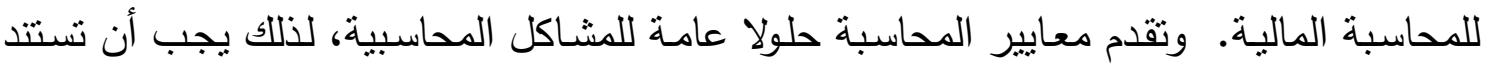
إلى مفاهيم راسخة حتى تتسم بالتجرد، وحتى تسنطيع تقديم الحلول للمشاكل ذات الطبيعة الخاصة

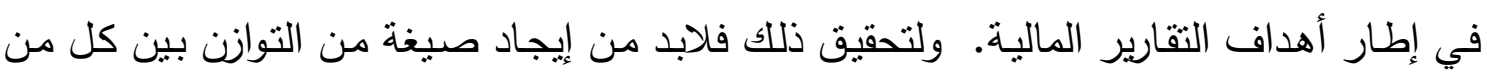
المنفعة المفترضة وقابلية النطبيق العملي، وتوازن بين ملائمة المعلومات وإمكانية الاعتماد عليها،

$$
\text { وتوازن بين التكلفة والعائد. }
$$

ويعد التزام المحاسبين القانونيين بتطبيق المعايير المحاسبية اعترافا من مهنة المحاسبة

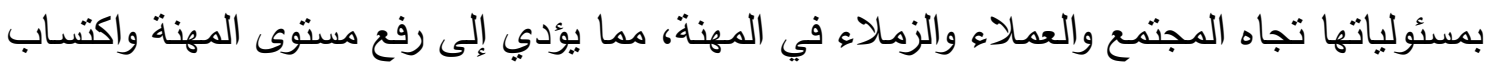
تقة المجتمع مما يزيد من فاعليتها وكفاءتها.

وفي المملكة العربية السعودية تعد الهيئة السعودية للمحاسبين القانونيين (SOCPA) الجهة المسؤلة عن تطوير معايير المحاسبة، وهي جهاز شبه حكومي مستقل، حيث صدر المرسوم 
الملكي رقم (م/12) و تاريخ 13-5-1412هـ (1991م) الذي تم بموجبه إلغاء نظام المحاسبين

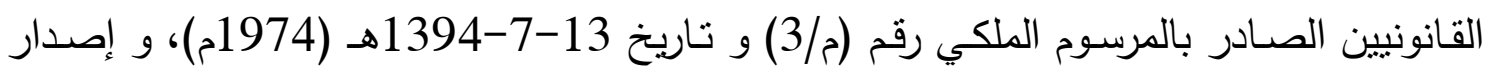

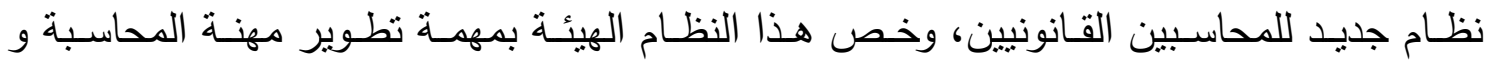

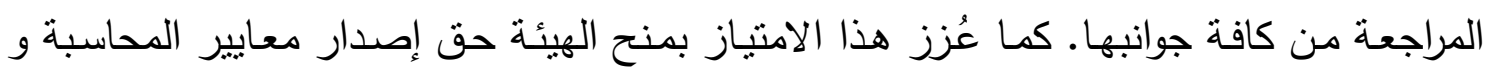

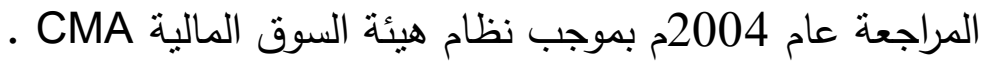

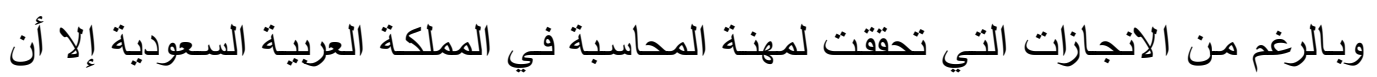
المهنة تواجه في الوقت الراهن تحديات جديدة نظرا للتغيرات والتحولات الهامة في الاقتصاد العالمي

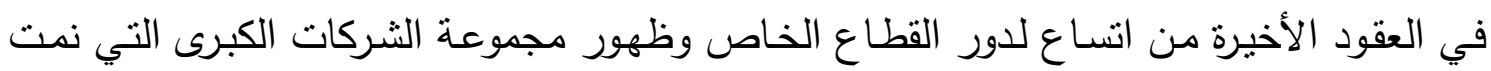
وتوسعت عن طريق ما يعرف باسم انضمام الثركات واندماجها، وكذا تثعب وتعقد بيئة الأعمال

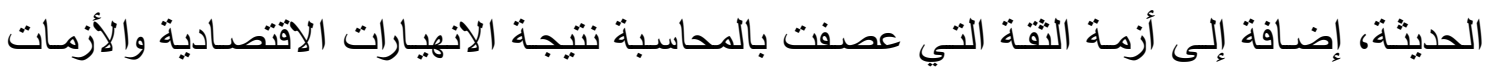
المالية التي شهدها عدد من دول شرق آسيا وأمريكا اللاتينية وروسيا في عقد التسعينات من القرن

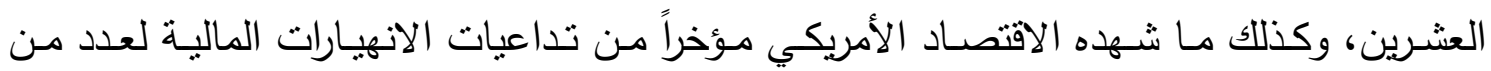

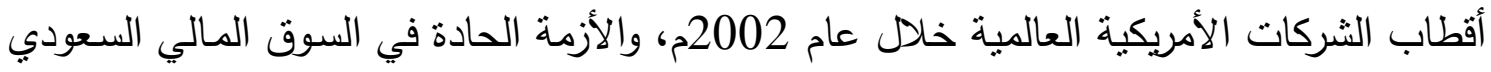

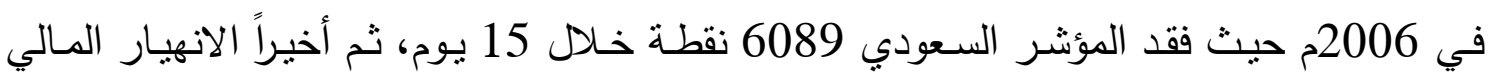
العالمي الذي أطاح بالاقتصاد العالمي في عام 2008م، هذه الظروف مجتمعة الزمت الهيئات

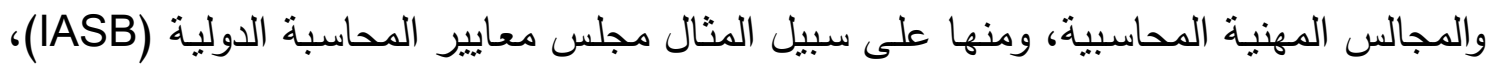

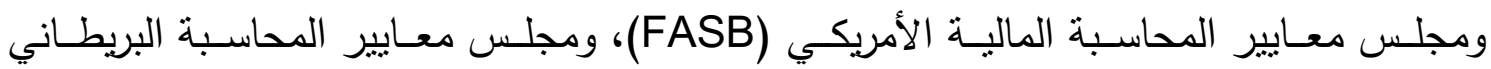

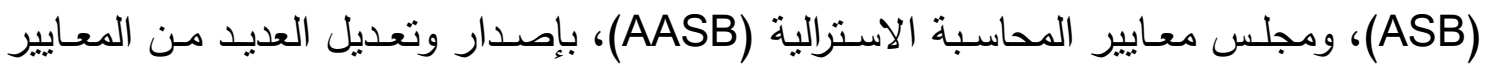

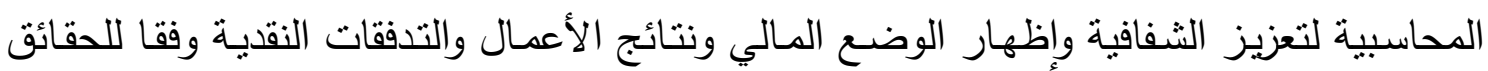
الاقتصادية.

وقد ظهرت الحاجة إلى إصدار وتعديل العديد من المعايير المحاسبية بعد تعرض العديد من الثركات أثناء الأزمة المالية الآسيوية (1997م) للإفلاس نتيجة حصولها على قروض كبيرة

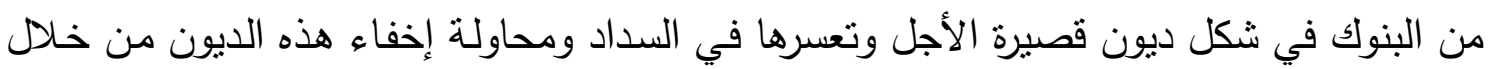

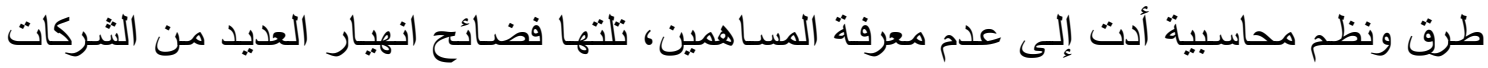

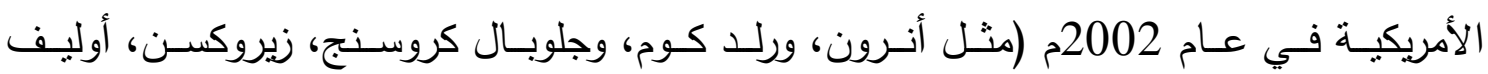

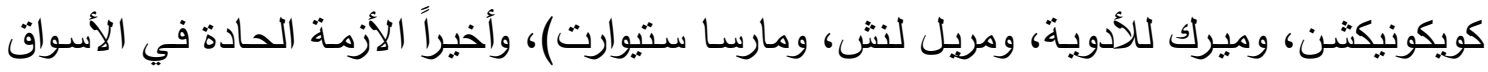

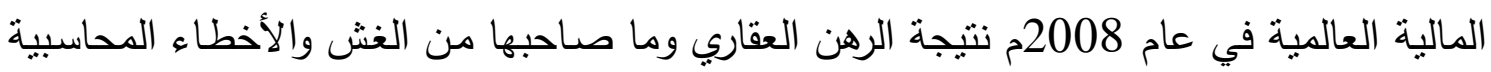


والمعلومات الداخلية والتضليل، ونتج عن ذلك أن فقد المجتمع الثقة في الأنظمة الإدارية والرقابية

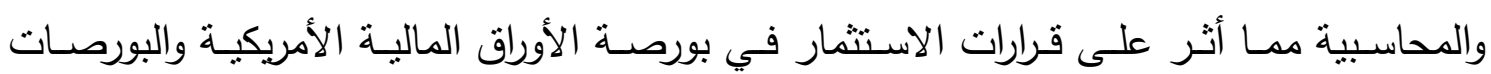

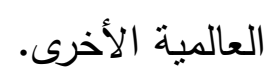

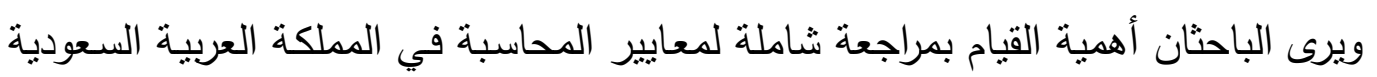
حيث اتضح أن من أهم الأسباب التي أدت إلى حدوث الألى الأزمات المالية الحادة في الأسواق المالية

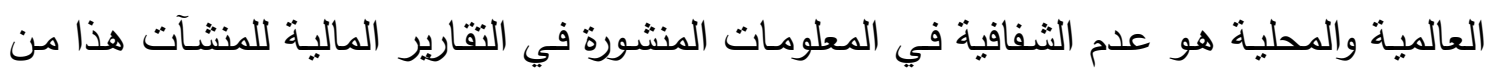

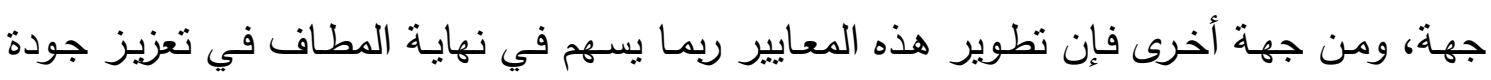
المعلومات المحاسبية وبالتالي في رفع كفاءة الأسواق المالية وتحديد السعر العادل للأوراق المالية فيها وذلك بهدف ترشيد القرارات الاقتصادية.

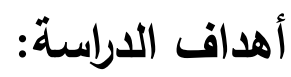

1- توثيق الوضع الحالي لمهنة المحاسبة في المملكة العربية السعودية وذلك بواسطة إبراز دور كافة الجهات ذات العلاقة بالمهنة. 2- تحليل نقاط القوة والضعف والفرص والمخاطر في معايير المحاسبة في المملكة العربية السعودية.

3- إلقاء الضوء على الفرص المتاحة والأفاق المستقبلية التي يمكن الاستفادة منها لتطوير معايير المحاسبة في المملكة العربية السعودية

أهمية الاراسة:

ترجع أهية هذه الدراسة للاعنبارات التالية:

1- تعزيز المساحة المعرفية لموضوع معايير المحاسبة باعنباره احد مجالات التطوير في المحاسبة

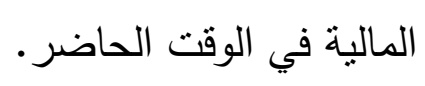

2- ندرة الأبحاث العلمية والدراسات المتخصصة التي قامت بدراسة أثر تطوير معايير المحاسبة

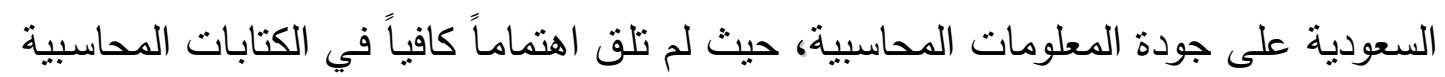
في المملكة العربية السعودية.

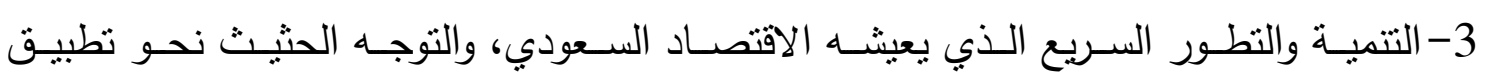

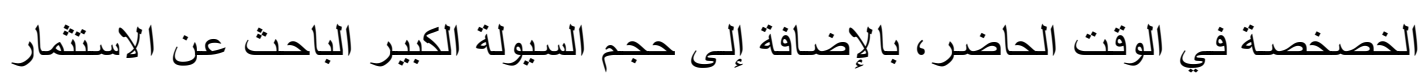
لدى الأفراد. 
4- النمو المتزايد، وخصوصاً في السنوات القليلة الماضية، في عدد شركات المساهمة السعودية وضخامة الأموال المستثمرة فيه، وتعاظم الحاجة إلى مزيد من الثفافية في التقارير المالية.

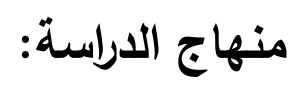

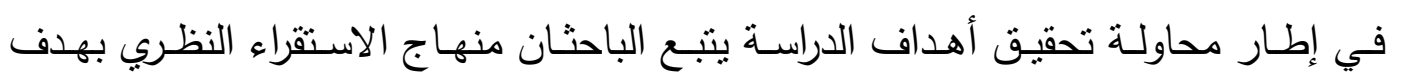

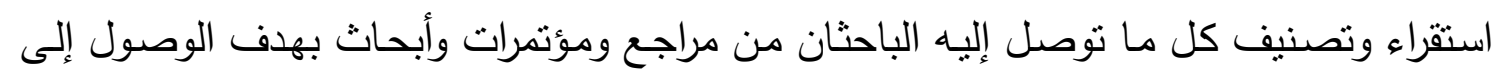

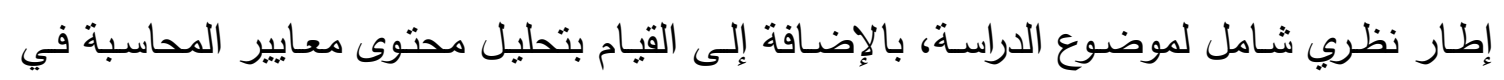

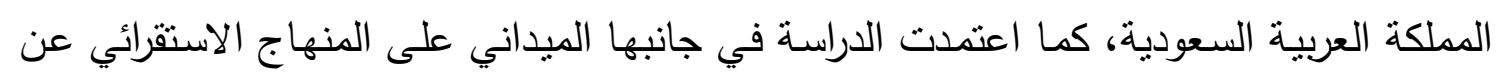

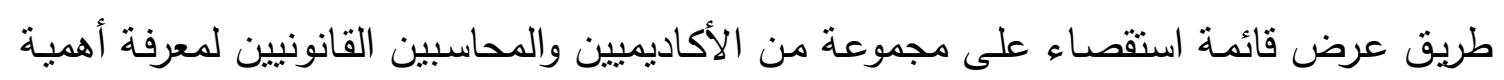
تطوير معايير المحاسبة السعودية وأثزها على جودة المعلومات المحاسيبة عندية. خطة الاراسةة: في ضوء منهج البحث والأهداف الدحددة مسبقاً سوف يتم تقسيم خطة الدراسة إلى قسمين

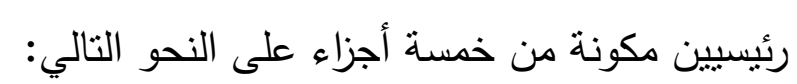

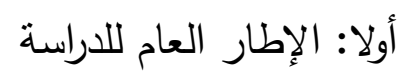
ثانيا: الإطار النظري للدراسة ثالثا: الدراسة الميدانية رابعا: نتائج الدراسة والتوصيات

ثانيا: الإطار النظري للادراسة

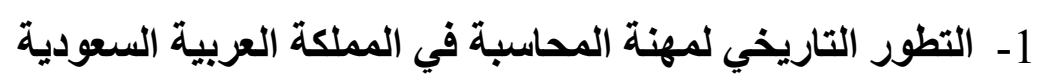

حظيت المهنة في منتصف القرن الرابع عثر الهجري باهتمام المسئولين في المملكة العربية السعودية فقد تضمن النظام التجاري الصادر عام 1350هـ بعض الأحكام التي تتظم مسك الدفاتر

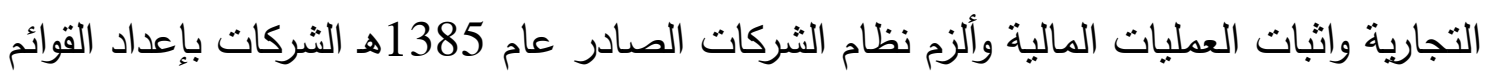

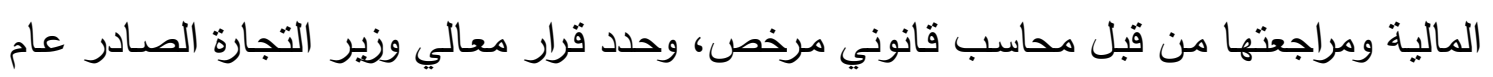

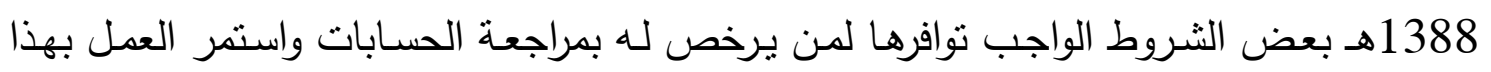

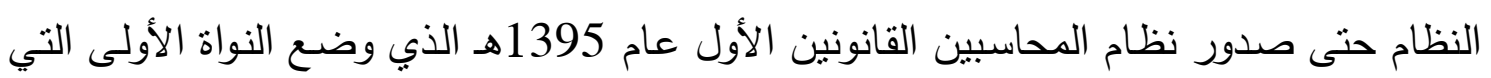


تتظم عمل المهنة في المملكة وأوجد لجنة عليا للمحاسبة القانونية وأوكل إليها مهمة الإثراف على المهنة .

وفي منتصف عام 1399هـ تقدم مكتب الراشد ببحث مفصل يوضح طرق تطوير المهنة

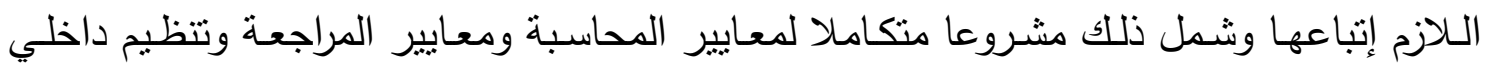

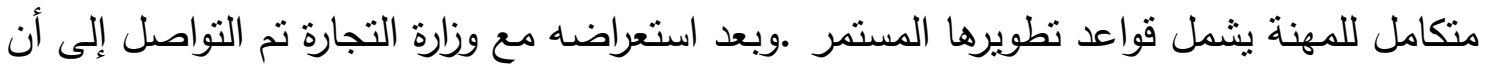

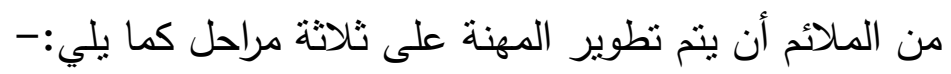

المرحلة الأولى: الدراسة المقارنة لوضع المهنة في عدد من الدول (1400-1401هـ):

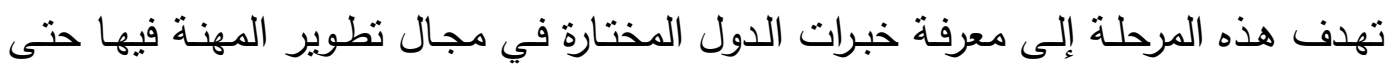

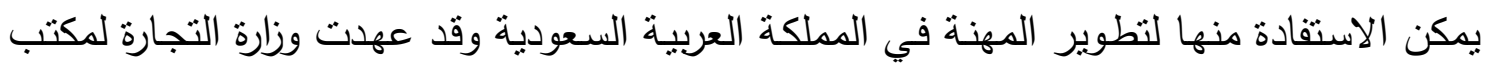
الراثد للبدء في المرحلة الأولى من المشروع وذللك بعد دراسة متعقةة للتصور المبدئي المقترح ،وقد

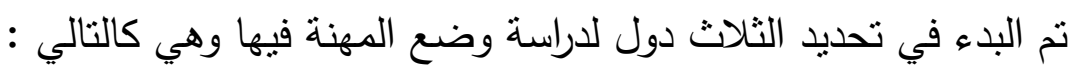
1- المجموعة الأولى : الولايات المتحدة الأمريكية ، بريطانيا وكندا. 2- المجموعة الثانية : فرنسا ، ألمانيا الغربية والسويد . 3- المجموعة الثالثة : تونس فنزويلا والبرازيل . 20.

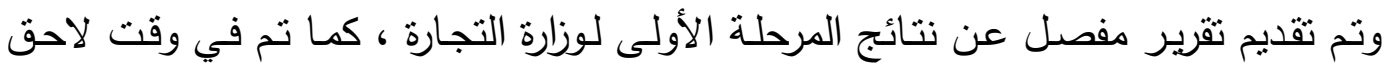

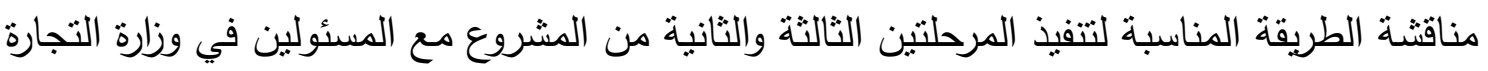
في حينه وتبين وجود خيارين " الأول : جمع المرحلتين الثانية والثالثة في مرحلة واحدة وذلك بإجراء دراسة شاملة لتطوير أوضاع

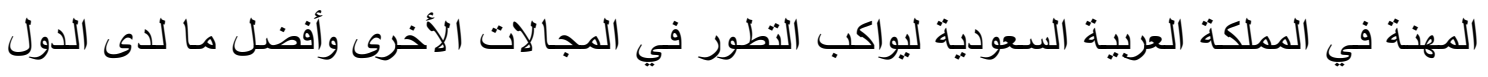

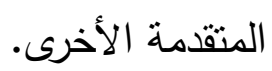
الثاني : القيام بتتفيذ المرحلة الثانية من المشروع في الوقت الراهن وخاصـة فيما يتعلق بالعناصر

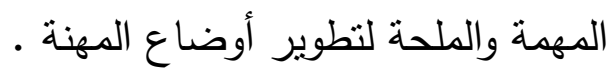


المرحلة الثانية: إعداد التظور النظري لمهنة المحاسبة والمراجعة (1402-1406هـ):

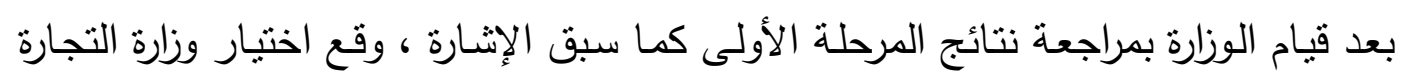

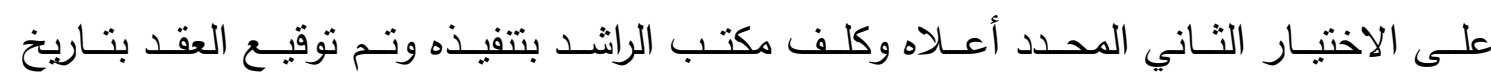

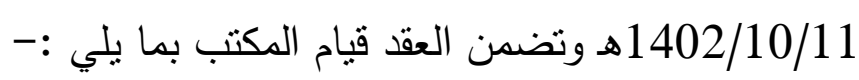

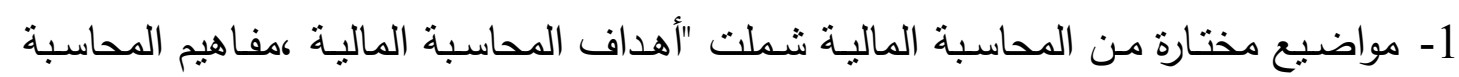

$$
\begin{aligned}
& \text { المالية، معيار العرض والإفصاح العام". } \\
& \text { 2- معيار المراجعة } \\
& \text { 3- التنظيم الداخلي للمهنة }
\end{aligned}
$$

وجرى بحث مستقيض وجرت عدة طرق لتحديد السبل الأمثل لتتفيذ هذه المرحلة بحيث

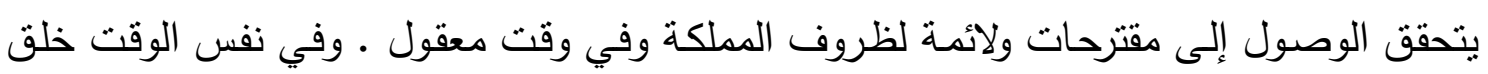

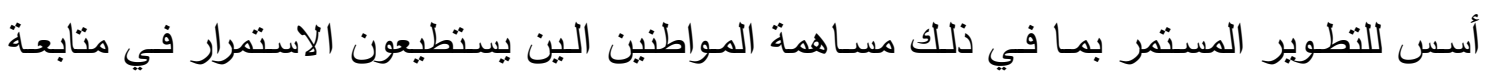

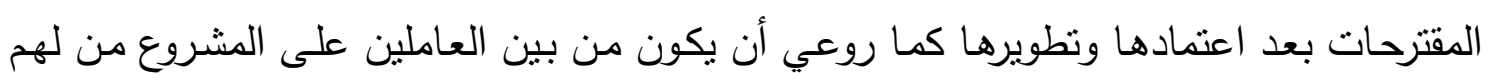

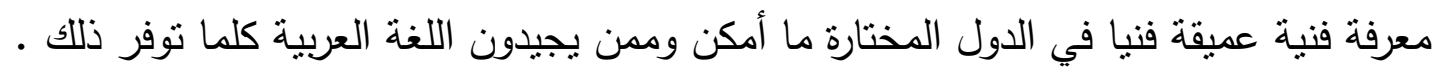
المرحلة الثالثة : إنثاء الهيئة السعودية للمحاسبين القانونيين (1412هـ - حتى تاريخه):

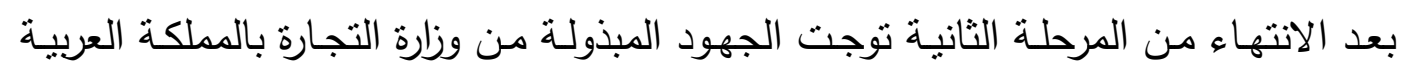
السعودية بصدور المرسوم الملكي رقم م/12 وتاريخ 1412/5/13هـ والذبي تم بموجبـه الموافقة على نظام المحاسبين القانونيين، وعلى أنثاء الهيئة السعودية للمحاسبين القانونيين وهي هيئة تهنت

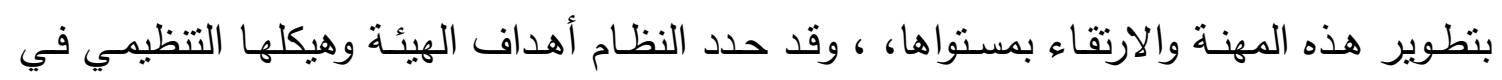

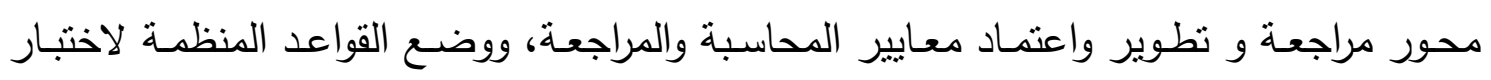

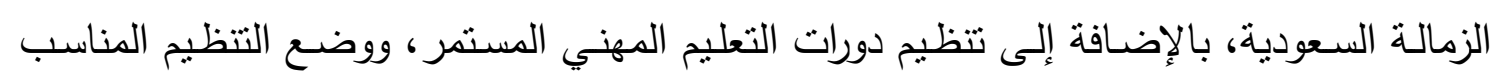

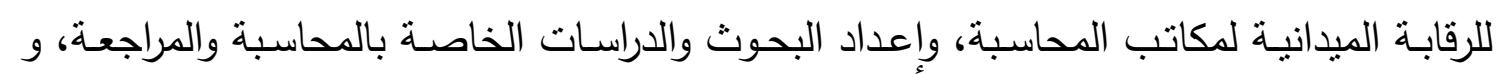

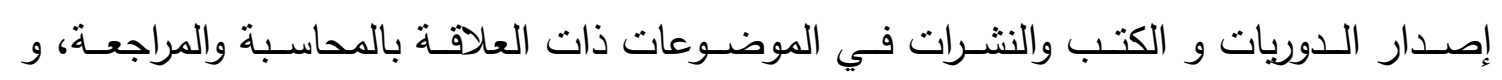
المشاركة في الندوات و اللجان المحلية و الدولية المتعلقة بمهنة المحاسبة والمراجعة.

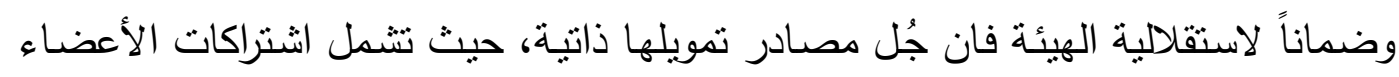

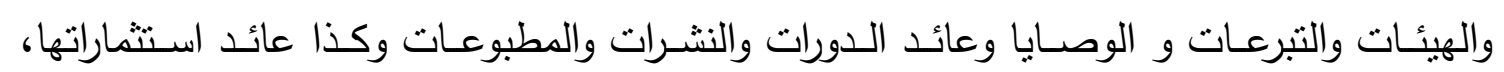

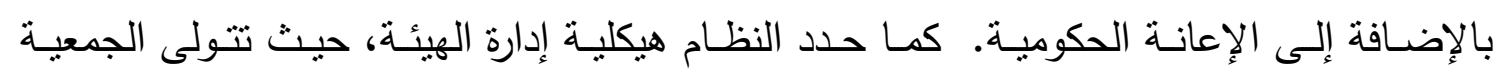
العمومية الإتشراف على كافة أنشطة الهيئة وانتخاب نصف العضاء العضاء مجلس إدارة الهيئة وكذا إقرار 
تقاريرها السنوية. وتتكون الجمعية العمومية للهيئة من جميع الأعضـاء الأساسيين، وهم الذين

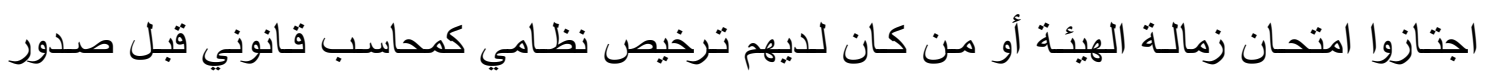

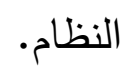

وثُدار الهيئة من قبل مجلس مهمته الأساسية تصريف شؤونها لتحقيق أغراضها المحددة في

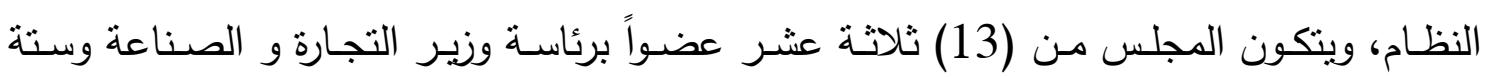

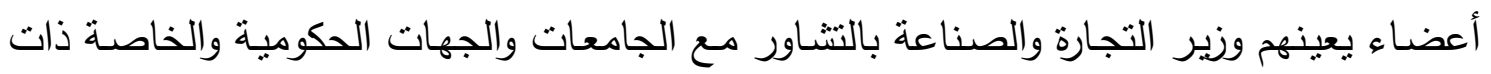

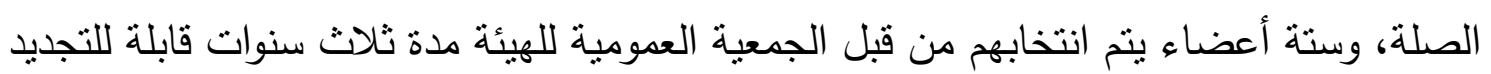
مرة واحدة، أما الأعضاء الستة المعنيون فيشملون ثلاثثة ممثلين للحكومة (من وزارة التجارة، ووزارة

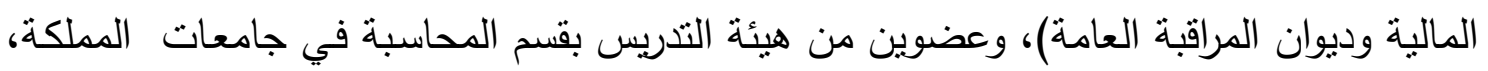

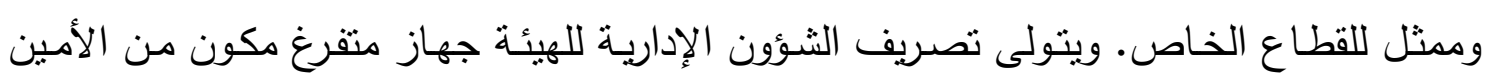
العام و مساعده وإدارات تتفيذية. ولقد شكل مجلس إدارة الهيئة لجاناً فنية كان لها الدور الههم في إصدار نوصيات لبناء

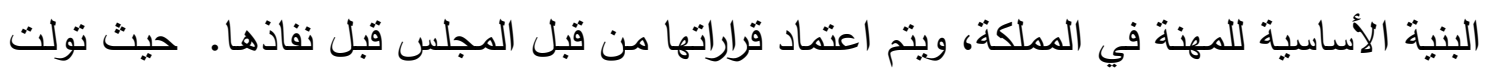

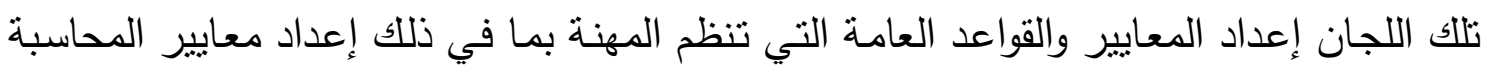
للقياس والعرض والإفصساح المحاسبي، ومعايير المراجعة، وقواعد سلوك و آداب المهنة، وتنظيم

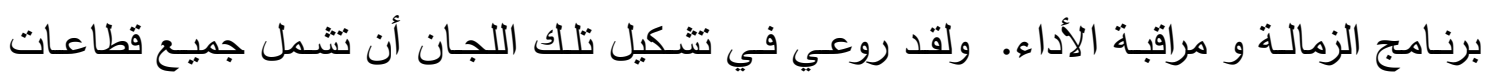
المجتمع وممتلين عن القطاع الخاص.

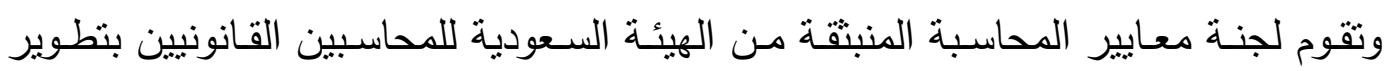

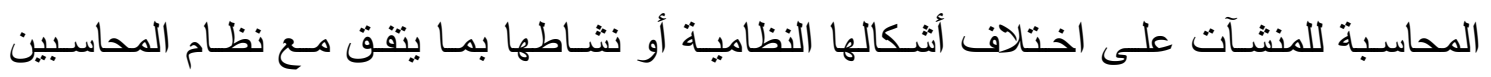

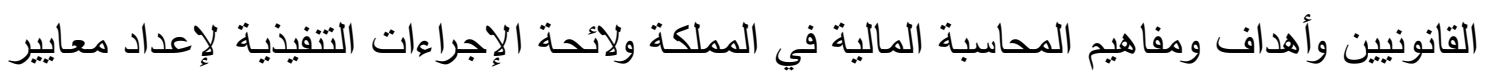
المحاسبة وتعديلها. وقد صدر عن اللجنة حتى الآن إحدى وعشرون معيار وسبعة أراء وتفسيرات

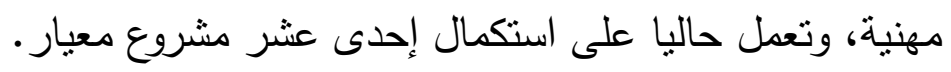
أ- الوظائف المناطة بالهيئة :

مراجعة وتطوير واعتماد معايير المحاسبة. مراجعة وتطوير واعتماد معايير المراجعة.

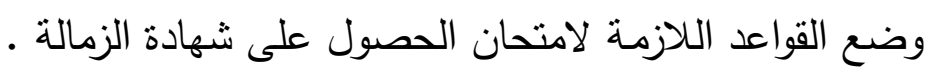

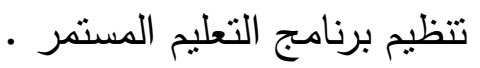


وضع التنظيم المناسب للرقابة الميدانية للتأكد من قيام المحاسب القانوني بتطبيق المعايير المهنية والثقييد بأحكام نظام المحاسبين ولوائحه .

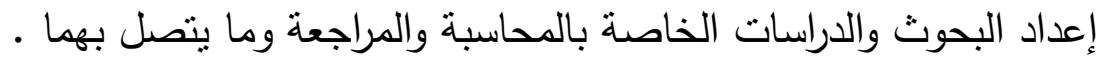
إصدار الدوريات والكتب والنشرات في موضوعات المحاسبة والمراجعة .

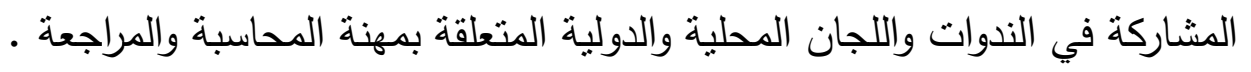

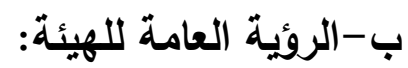

الريادة في خدمة المنتسبين والمستقفينين من مهنـة المحاسبة والمراجعة في المملكة العربية السعودية والتواصل المهني الفاعل إقليميا وعالميا. ج- الرسالة الأساسية الهيئة:

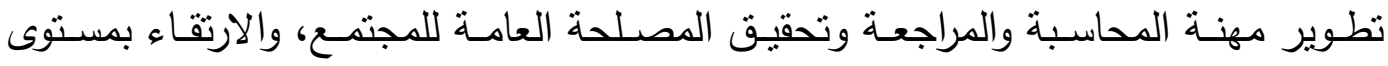

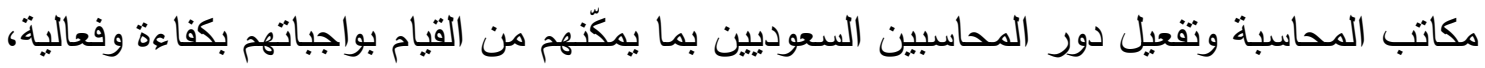
والتفاعل مـع الجهات التعليميـة ومؤسسـات القطاعين العام والخـاص والجهات المهنيـة الإقليميـة والدولية.

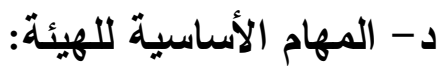

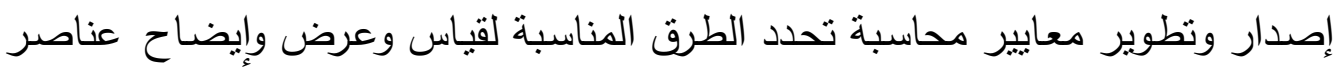
القوائم المالية وتأثير العمليات والأحداث والظروف على المركز المالي ونتائج الأعمال ـ إصدار وتطوير معايير مراجعة موضوعية محددة ومقبولة يلتزم بها المحاسبون القانونيون

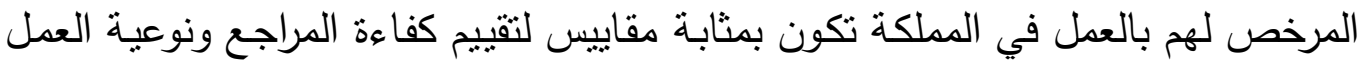

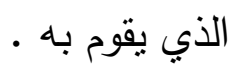
تطوير وتتفيذ برنامج مراقبة أداء المحاسبين القانونيين بغرض التأكد من التزامهم بالمعايير

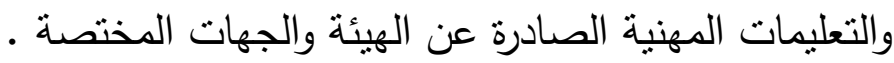

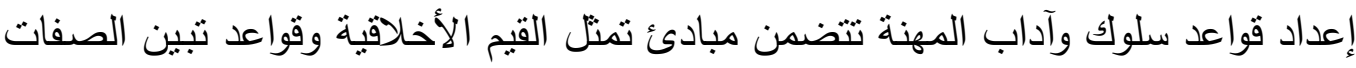
السلوكية التي يتعين على العضو التحلي بها عند ممارسة أعماله وعند تعامله مع زملاء

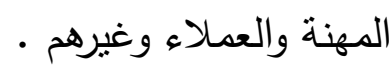
إعداد وتتظيم اختبار زمالة الهيئة السعودية للمحاسبين القانونيين ؛ وقد اشترط النظام لمن

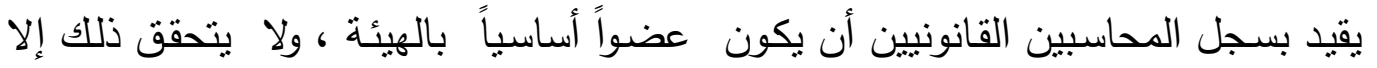
باجتياز اختبار زمالة الهيئة. وخطت الهيئة بمجلس إدارتها ولجانها المختلفة والأمانة العامة بكانة 
خطوات حثيتة لإعداد اختبار الزمالة انتهت باعتماد القواعد العامـة لاختبار زمالة الهيئة بموجب قرارا بتاريخ 1413 هـ. وقد أخذ في الاعتبار عند إعداد تلك القواعد الاستفادة من تجارب من سبقنا في هذا المجال وعلى الأخص تجربـة الولايات المتحدة الأمريكية ، وأن يكون برنامج الزمالة منلائماً مع البيئة المحلية. ويشارك في الإعداد لهذا الاختبار نخبة مختارةً من ذوي الاهتمام والاختصاص بمواد برنامج الزمالة . تتظيم البرامج التي تكفل تطوير المستوى المهني وعلى الأخص البرامج التالية : - زمالة الهيئة السعودية للمحاسبين القانونيين.

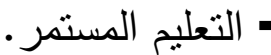
- دورات خاصة بمواضيع أو جهات معينة. إنشاء مركز معلومات شامل وفقاً لأحدث الأساليب يشتمل على الكتب والأبحاث والنشرات المتخصصة في مجال المحاسبة والمراجعة ؛ وما تصدره الجهات المهنية في مختلف دول العالم من معايير وقواعد مهنية ، كما يشتثل المركز على قاعدة معلومات عن العاملين في

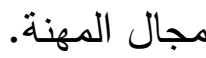

إعداد نشرة مهنية متخصصة تعني بالمواضيع التي تهم مهنة المحاسبة والمراجعة . تتظيم عدد من الندوات المتخصصة في مجال المحاسبة والمراجعة بغرض رفع الوعي - المحاسبي

ومـن المفيـد هنـا الإشـارة إلـى أن الإتحـاد الـدولي للمحاسبين (IFAC) قد اختـار الهيئة السعودية للمحاسبين القانونيين من ضمن ست عشر هيئة مهنية على مستوى العالم يمكن الاستفادة من خبراتها في مجال تطوير مهنة المحاسبة والمراجعة وذلك تقديراً لما وصلت إليه مهنة المحاسبة والمراجعة في المملكة العربية السعودية من تطور ، وكذلك تقديراً للدور الذي تقوم بـه الهيئة في تطوير المعايير والأنظمة ذات العلاقة بالمهنة، جاء ذلك في دليل إنشاء الهيئات المهنية الصسادر عن الاتحاد في طبعة نوفمبر 2007م، والذي نص على أن "الهيئة السعودية للمحاسبين القانونيين هي هيئة محاسبية مهنية راسخة الأساس تضم موظفين وأعضاء تتوفر فيهم مهارات وخبرات عالية وهي قادرة على تقديم الدعم والمشورة والمساعدة للهيئات المهنية الأخرى في الدول المتحدثة باللغة 
المرحلة الرابعة إنثاء الجمعية السعودية للمراجعين الداخليين: (1432- حتى تاريخه)

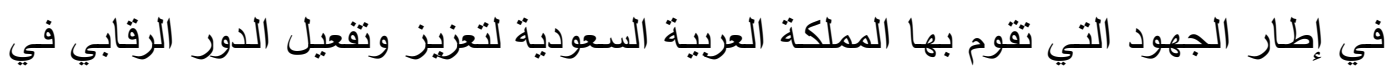

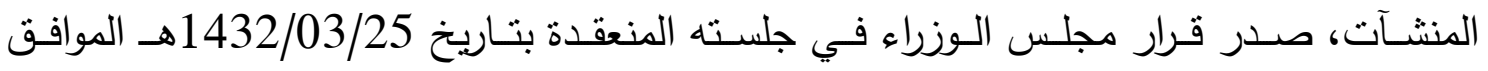
2011/02/28 بالموافقة على تتظيم الجمعية السعودية للمراجعين الداخليين، وتهدف الجمعية إلى لى لهني تطوير مهنة المراجعة الداخلية في المملكة العربية السعودية. أ- الوظائف المناطة بالجمعية:

1- توفير معايير المراجعة الداخلية الدولية وقواعد آداب المهنة والإششادات المهنية الأخرى ذات

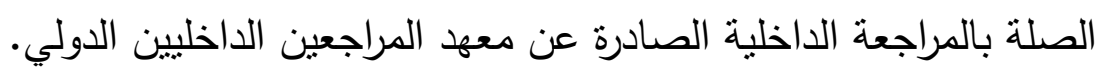

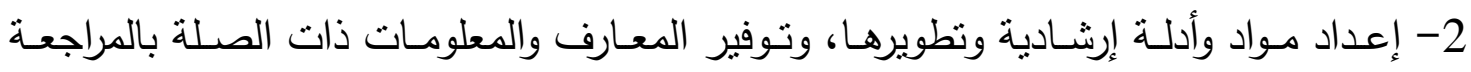

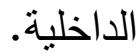

3- عقد الاختبارات المؤهلـة للحصـول على الثـهادات المهنيـة التي يمنحهـا معهد المـراجعين الداخليين الدولي.

4- تطوير البرامج التدريبية وبرامج التعليم المهني المستمر والدبلومات المتعلقة بالمراجعة الداخلية وتتفيذها، من أجل رفع المستوى العلمي والمهني لممارسي مهنة المراجعة الداخلية، وإصدار الثهادات المتعلقة بها.

5- تقديم الدعم الفنـي لمراقبـة جودة الأداء المتعلق بمهنـة المراجعـة الداخليـة، وتطوير وسـائل تحسين الأداء المهني.

6- إعداد الدراسات المتعلقة بالأنظمة، واللوائح، والمعايير ذات الصلة بأعمال المراجعة الداخلية، وتقديم المقترحات في شأنها للجهات ذات الاختصاص. 7- عقد المؤتمرات واللقـاءات المهنيـة في مجـال المراجعـة الداخليـة وفقاً للإجـراءات النظاميـة المنبعة. - مان.

8- السعي إلى رفع وعي الجمهور بأعمال المراجعة الداخلية. 9- توطيد أواصر الصلة مـع الجهات ذات العلاقة بالمراجعة الداخلية داخل المملكة وخارجها، وتحديد مجالات الاهتمام المشتركة وتفعيلها.

هذا وتجدر الإثـارة إلى أن المراجعة الداخلية وظيفة رقابية تمارس في المنشآت المختلفة.

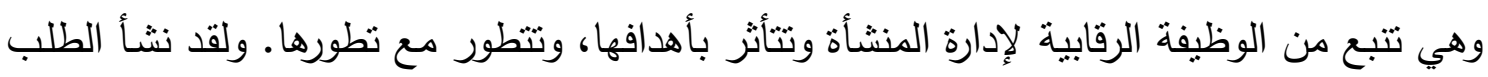


على المراجعة الداخلية نتيجة الحاجة لوجود وسيلة تحقق مستقلة بغرض الحد من الغش، والأخطاء

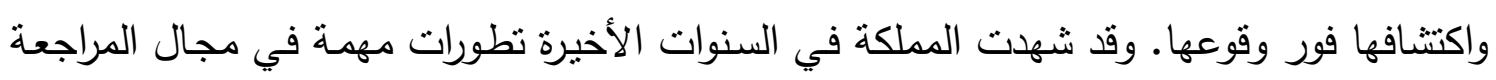

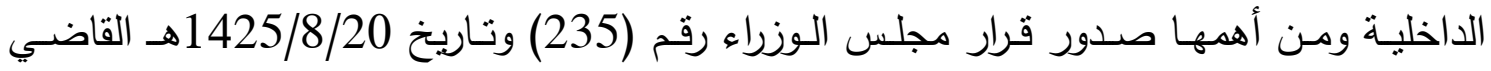

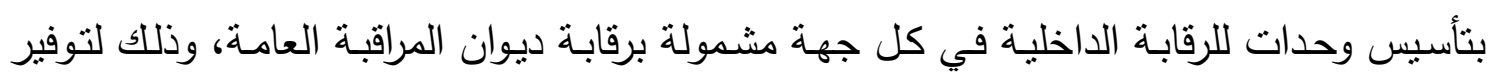

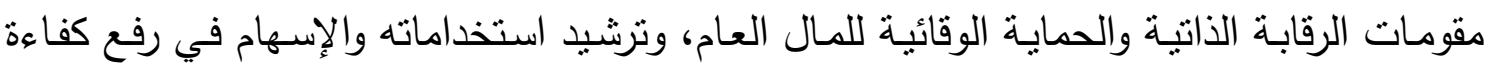

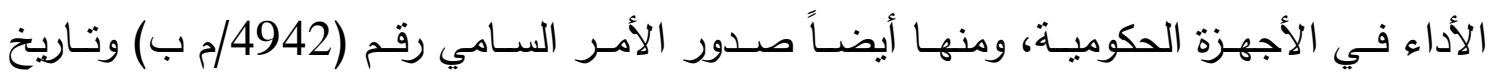

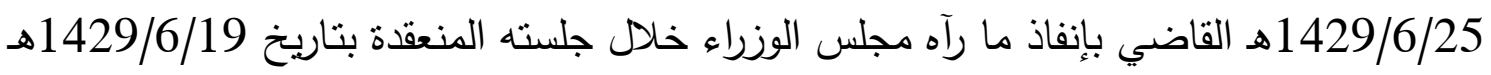
بأن يوقع أمين عام الهيئة السعودية للمحاسبين القانونيين برنامج التعاون الفني بين الهيئة السعودية الهية للمحاسبين ومعهر المراجعين الداخليين الأمريكي لإنشاء جهة للمراجعة الداخلية في المملكة العربية

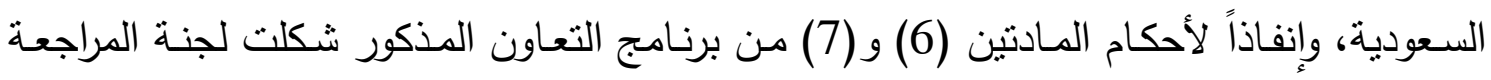

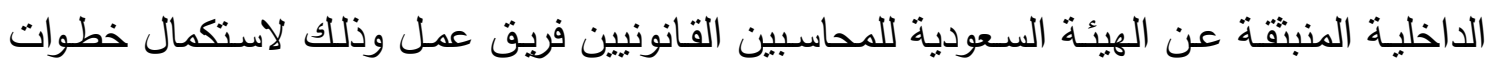

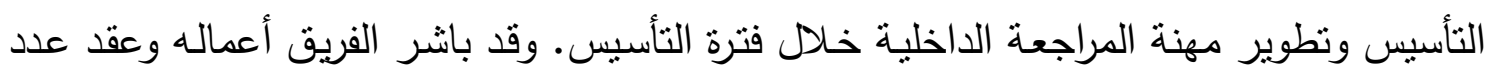

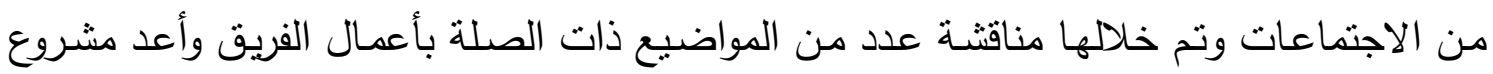

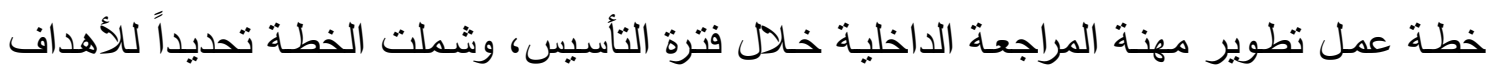
المرحلية ومبادرات تحقيقها. كما أعد الفريق مشروع تتظيم الجمعية السعودية للمراجعين الداخليين، وبعد مناقشته مع ذوي الاهتمام والاختصاص تم رفعه لمجلس الوزراء للنظر في الموافقة عليه.

2- الحاجة إلى تطوير معايير المحاسبة في المملكة العربية السعودية لتحقيق التوافق مع معايير

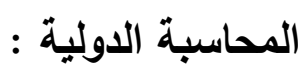

أن أهميـة المملكة العربيـة السعودية الاقتصادية والماليـة تعزز عالميـا حيث أنها من أهم

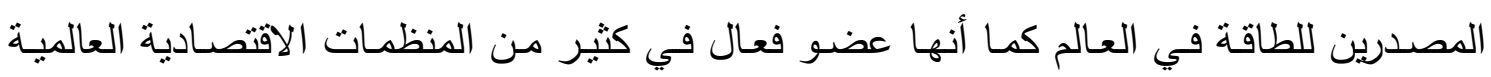

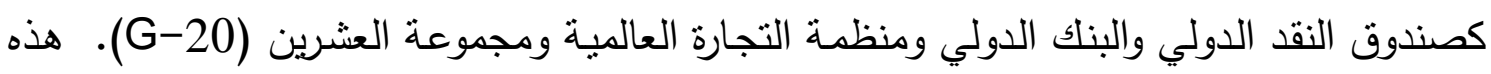

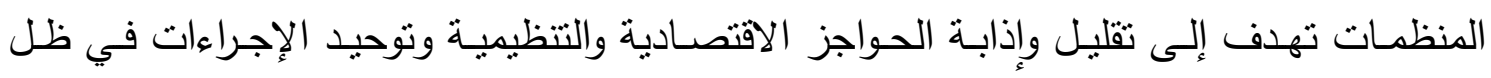
منظومة من منطلبات العولمة التي تستلزم من الدول تكيف أنظمتها الاقتصادية والمالية في اتجاه

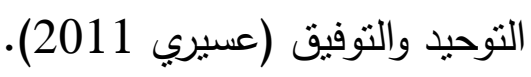


أن انضمام المملكة العببية السعودية إلى منظمة التجارة العالمية افرز تحديات كبيرة للمهنة المحاسبة في المملكة وسوف يؤدي إلى تغييرات جوهرية على طبيعة ومكونات وآليات تتظيم مهنة المحاسبة والتي من أهمها: 1- المتابعة المستمرة من قبل الجهة المنظمة للمهنة للنطورات المهنية على المستوى الدولي و

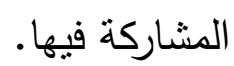

2- التسيق والتواصل مع الجهات المنظمة التابعة للاول الأعضاء .

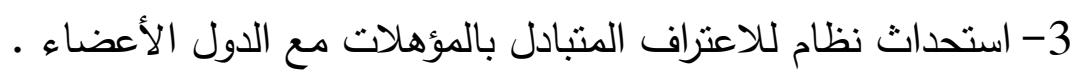

4- زيادة الثفافية و الوضوح لآلية عمل الجهة المنظمة للمهنة داخلياً .

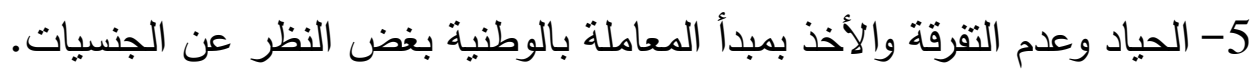
6- الارتباط مع لجان وهيئات مهنية دولية. 7- ت تغيير متطلبات التعليم والتدريب المستمر . 8- تطبيق المعايير الدولية بالإضافة إلى المعايير المحلية والاستمرار في إصدارها. أن تأثير انضمام السعودية إلى منظمة التجارة العالمية وما يصاحبه من تغيرات جوهرية ونقلة نوعية في طبيعة ومتطلبات ممارسة مهنة المحاسبة ربما يساهم في: 1- اندماج المكاتب المحلية الصغيرة. 2- زيادة عدد الملاك في الثركات المهنية الكبرى . 3-زيادة الطلب على خدمات المحاسبة والمراجعة مع زيادة عدد الثركات التجارية العاملة في

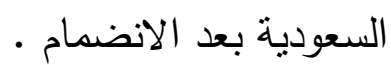

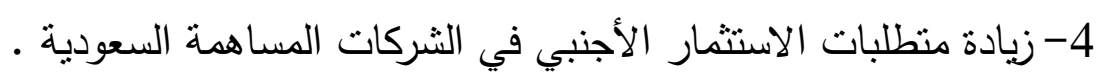

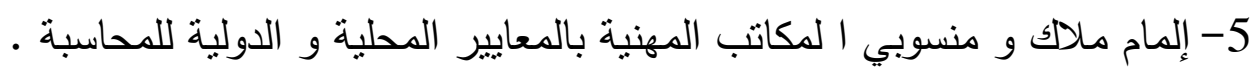
6- دخول مكاتب أجنبية كبيرة لسوق المهنة السعودي •

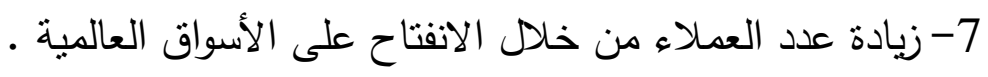

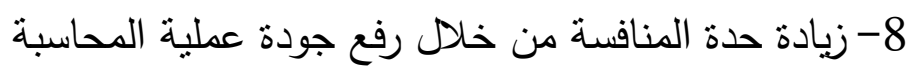
أن هناك نتزايد في الحاجة لتحقيق التوافق بين المعايير المعدول بها في في إعداد التقارير

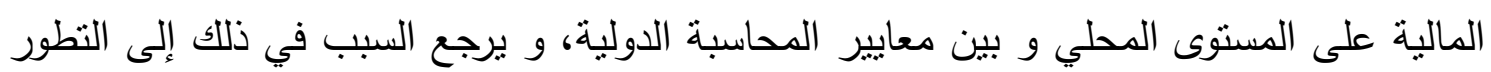

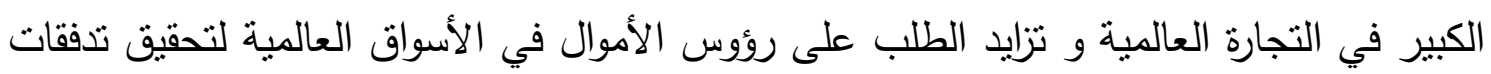

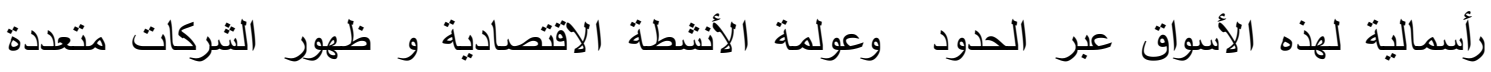


الجنسية و انتثار أنشطتها في دول مختلفة تتتوع من حيث الظروف الاقتصادية والاجتماعية والسياسية والثقافية. وتعد المعايير المحاسبية دالة في عدد من المتغيرات المحاسبية والاقتصادية والاجتماعية والتشريعية والسياسية. وقد كانت المملكة العربية السعودية من المبادرين لصياغة فئنة

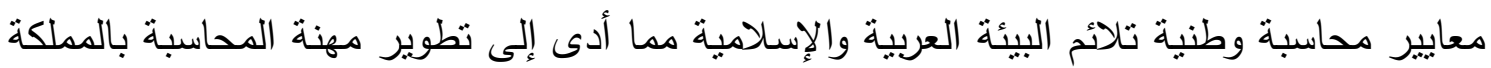
إلا أن هناك تحولات كبيرة في الوقت الحاضر حول الكثير من الدول للأخذ بمعايير المحاسبة الدولية وذللك لتحقيق الكثير من المزايا ومن أهمها: 1- قابلية المقارنة ويقصد به مقارنة البيانات الواردة في القوائم المالية المعدة للشركات في مختلف الفهات الدول وذلك لمساعدة المستخدمين لهذه القوائم عل فهمها واتخاذ القرارات الاقتصادية الرشيدة. 2-توحيد نتائج الأعمال للفروع المختلفة في دول مختلفة بقوائم موحدة بإتباع معايير موحدة. 3- تعد قوائم مالية واحدة للشركات التي تدرج أسهوها في أسواق مالية مختلفة بدلا من فوائم مالية متمانثية مع المعايير المحاسبية لكل سوق مالي.

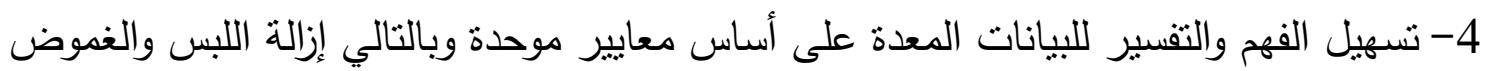
واختلاف التفسير للبيانات من فبل مستخدمي القوائم المالية. 5- الوفر في الزمن والجه والتكاليف وبالذات في الدول النامية للاستفادة مما وصلت إليه الدول المتقدمة من معايير. 6- إمكانية المقارنة لبيانات الثركات المعدة قوائمها على أساس معايير موحدة وهذا بدوره يساعد

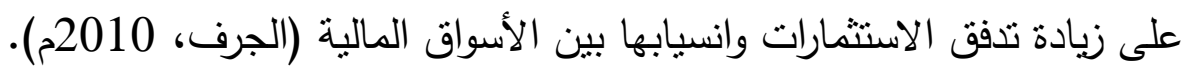

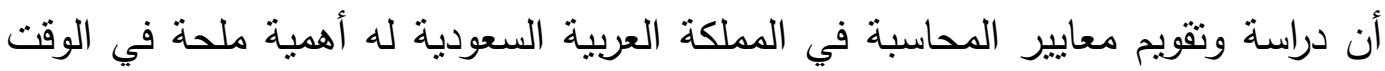

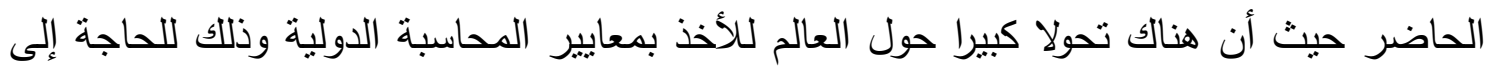

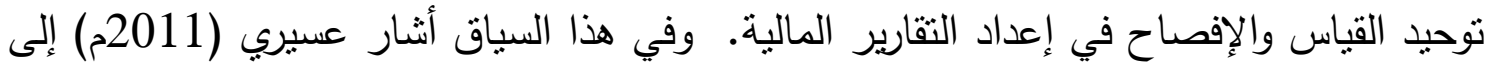

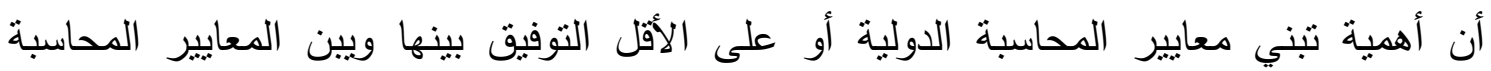

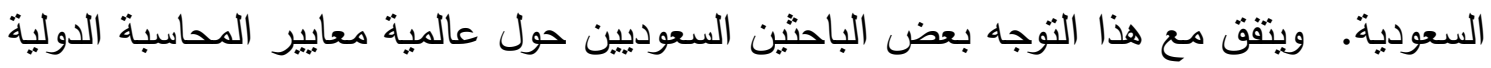

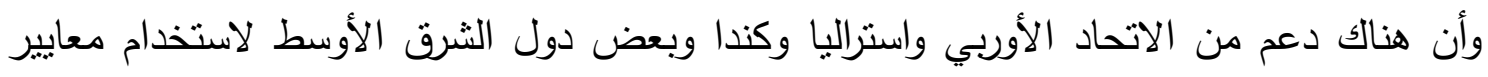

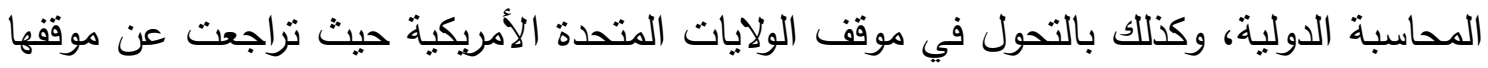
السابق من تبني المعايير الدولية وبدأت الدخول في نادي المعايير الدولية (السهلي، 2010م، ولئ، 
وقد أدركت الهيئة السعودية للمحاسبين القانونين أهمية تبني معايير المحاسبة الدولية

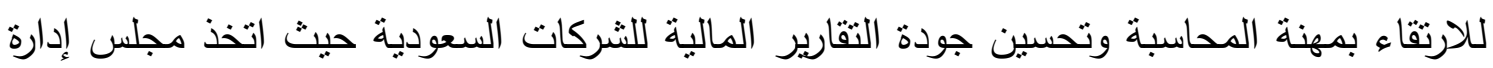
الهيئة السعودية للمحاسبين القانونين قرارا بضرورة الالتزام بمعايير المحاسبة الدولية في حالة عدم هلئه وجود معيار أو رأي مهني صادر عن الهيئة. هذا القرار يعد تحولا كبيرا في نتوجهات الهيئة السعودية للمحاسبين القانونين حيث كانت في السابق تؤكد على أنه يتعين الاسترشاد بمعايير

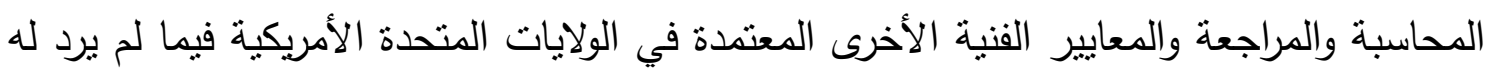
ذكر في المملكة بعد النظر فيها واستبعاد ما لا يتفق وظروف المعلكة.

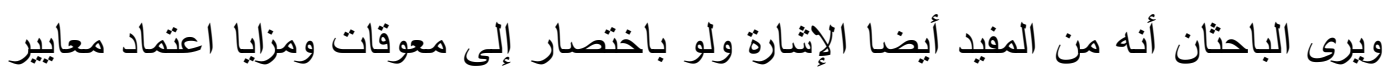

$$
\text { أ- معوقات التوافق الدولي: موحدة في دول العالم وذلك على النحو الأتي: }
$$

من العوائق المهمة التي تقف إزاء التوحيد المحاسبي على المستوى الدولي الآتي:

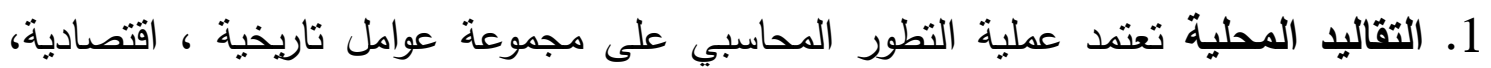

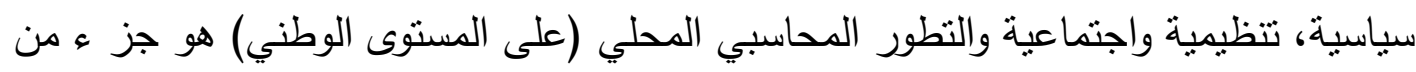

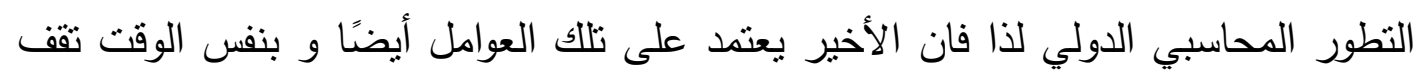

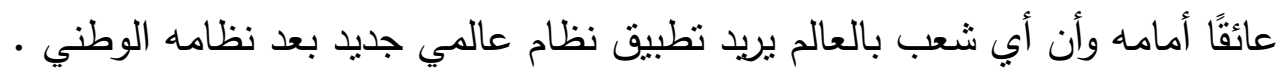

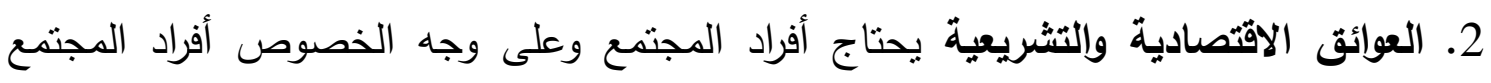

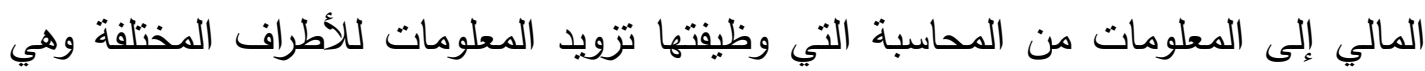
تعمل ضمن نمط اقتصادي معين يفرض عليها اختيار طرق و إجراءات محاسبية. ومن ناحية

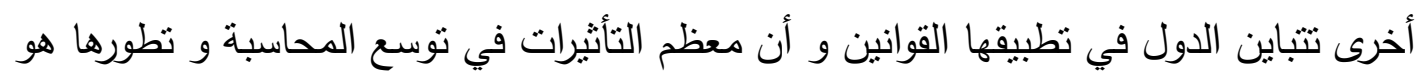
الهيكل التتريعي وهو انعكاس للتقاليد الثقافية الوطنية . 3. الحالة السيادية إذ تثكل عائق أمام التوحيد المحاسبي فالوطنية تقود إلى عدم الرغبة في قبول تسويات تتضمن تغيير الممارسات المحاسبية تفضيلاً لأخرى دولية .

ب-مزايا توفيق معايير المحاسبة المحلية مع معايير المحاسبة الدولية:

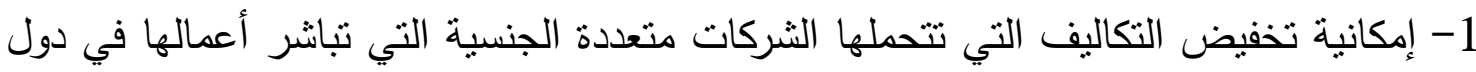
مختلفة و ذلك عند تعديل التقارير المالية لمعالجة الآثار التي تتتج عن اختلاف الممارسات المحاسبية المتعلقة بإعداد التقارير بين الدول المختلفة.

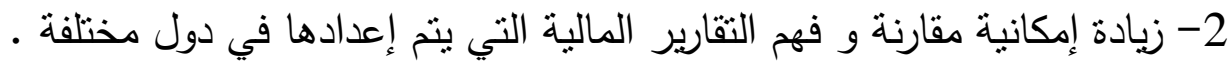


3- إمكانية تطبيق أفضل الممارسات المحاسبية من خلال إتاحة الفرصة للادول التي تتميز ببيئة

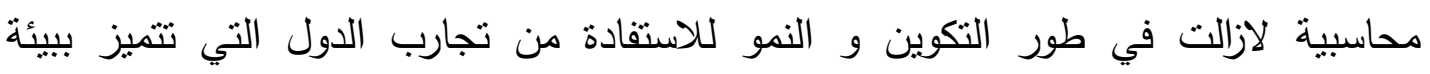
محاسبية متقدمة.

4- إمكانية نوفير التكاليف المتعلقة ببناء المعايير المحاسبية في الدول النامية من خلال تطبيقها للمعايير المحاسبية التي نت تطويرها في دول أخرى أو بواسطة مجلس معايير المحاسبة الدولية

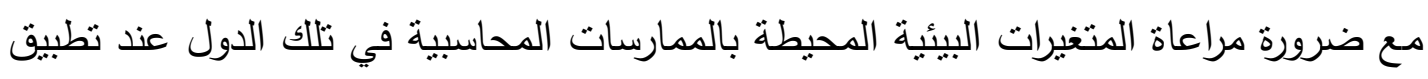
نلك المعايير

3- هيئة معايير المحاسبة الدولية الدية

(IASB)

تأسست هيئة معايير المحاسبة الدولية في عام 1973م بمساهمة من عشر دول الولايات

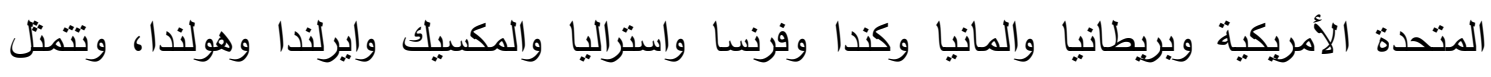
أهدافها الرئيسية في: 1- تطوير مجموعة واحدة من المعايير الدولية لإعداد الثقارير المالية بحيث تكون عالية الجودة ومفهومة وقابلة للتطبيق ومقبولة عالميا. 2- تشجيع الاستخدام والتطبيق الصارم لهذه المعايير. 3- الأخذ في الاعتبار حاجات التقارير المالية للاقتصاديات الناشئة والمؤسسات الصغئن الصغيرة والمنوسطة. 4- تحقيق تقارب بين معايير المحاسبة المحلية والمعايير الدولية لإعداد التقارير المالية لإيجاد حلول ذات جودة عالية. وقد أصدرت هيئة معايير المحاسبة الدولية 41 معيارا محاسبيا بالإضافة إلى 9 معايير دولية للتقارير المالية، وقد تزايدت أهمية تطبيق معايير المحاسبة الدولية عالميا حيث أن هناك

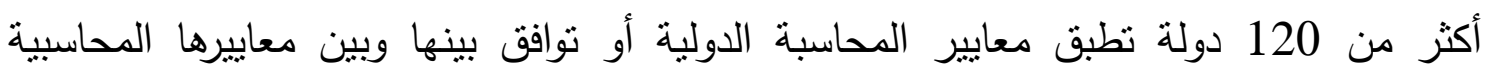
الوطنية.

وبمراجعة معايير المحاسبة الدولية من فبل الباحثين استتنجا أن أهم ما بميز هذه المعايير عن غيرها من معايير المحاسبية الأخرى أنها نركز على التوسع في الإفصاح واستخدام القيمة

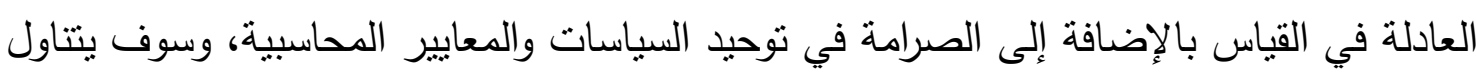
الباحثان بشيء من التفيل هذه الخصائص وذللك على النحو الأتي: 
أ- التوسع في الإفصاح

حدثت في العقدين الماضين تغيرات وتحولات هامة في الاقتصاد العالمي من انساع لدور

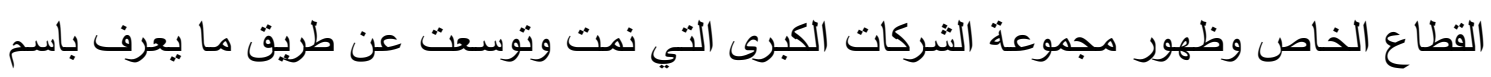

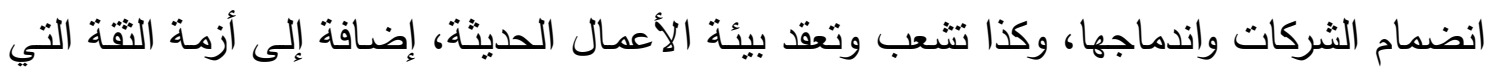

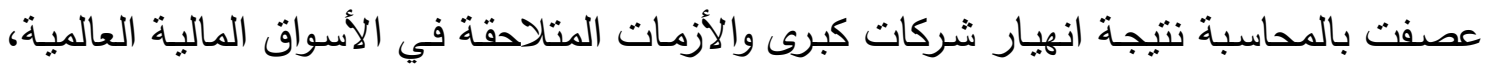
هذه الظروف مجتمعـة وضـعت التوسـع في الإفصـاح والثفافية موضـع اهتمام مجتمـع الأعمال

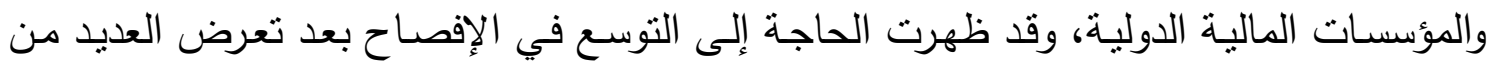

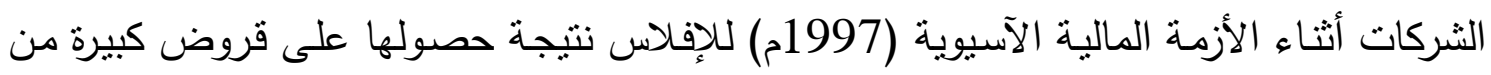
البنوك في شكل ديون قصيرة الأجل وتعسرها في السداد ومحاولة إخفاء هذه الديون من خلال طرق الته ونظم محاسبية أدت إلى عدم معرفة المساهمين، تلتها فضائح انهيار العديد من الثركات الأمريكية

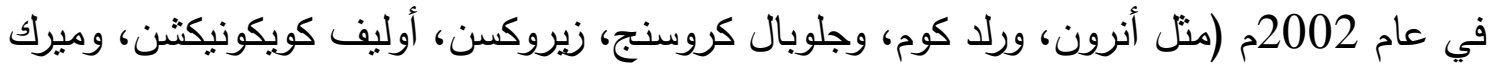

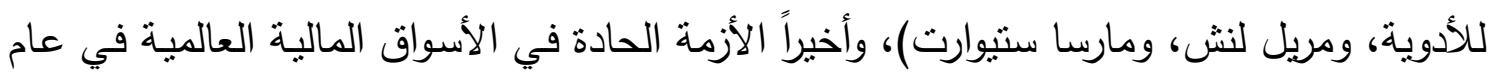

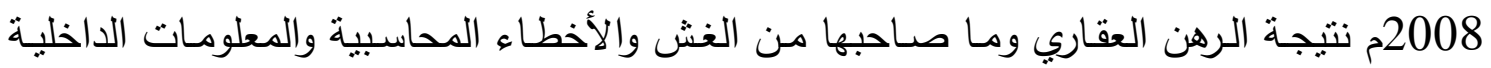

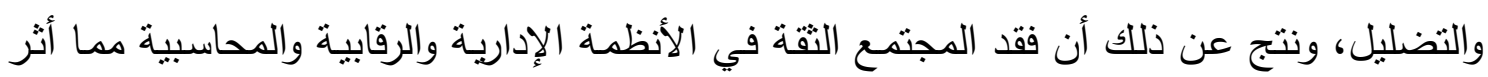

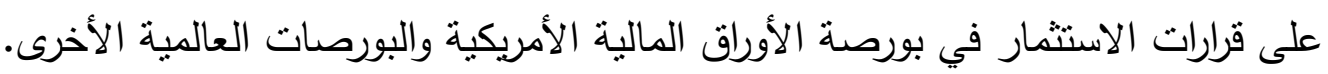

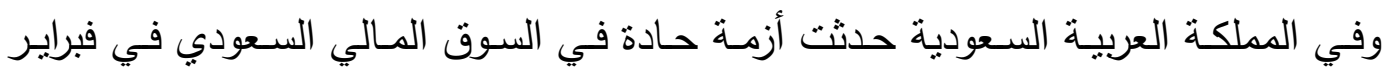
2006م حيث فقد المؤشـر السعودي 6089 نقطـة خـلال 15 يوم (20967-14878) أي أنـهـ تراجع بنسبة تزيد على 29\% خلاد نلك الفترة، ويعد ذلك أسوء تراجع يشهده سوق الأوراق المالية السعودي منذ نشأته، وفي هذه الفتزة مرت بعض الأئام والعروض لجميع الثركات منراكمة وبالسعر

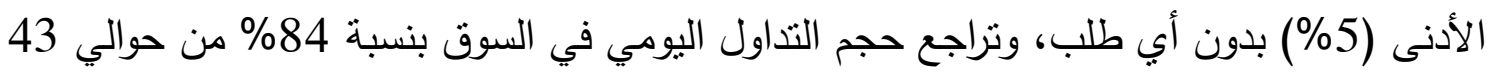

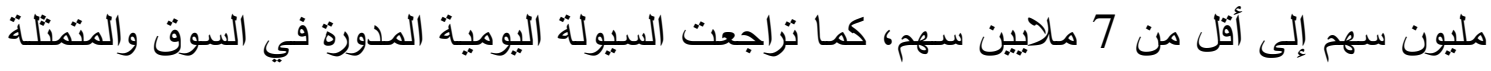

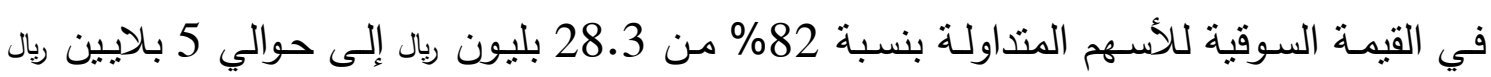

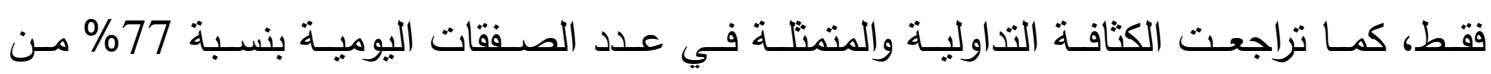
343,918 صفقة إلى 79,135 صفقة (الغامدي، 2006)، وفي نهاية عام 2008م أغلق المؤشر

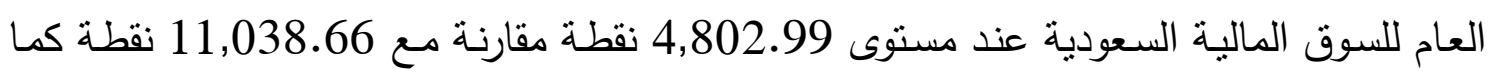
في نهاية عام 2007م منخفضاً 6,235.67 نقطة (56.49\%)، وقد بلغت القيمة السوقية للأسهر

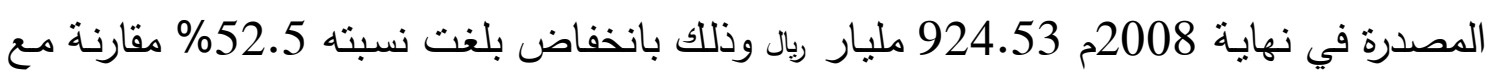


نهاية العام السابق، وبلغت القيمة الإجمالية للأسهم المنداولة خلال عام 2008م نحو 23,962.95

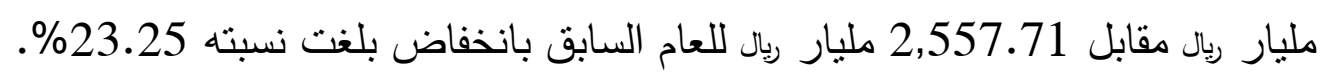
وقد تعالت الأصوات المطالبة بالتوسع في الإفصاح حيث اتضح أن من أهم الأسباب التي

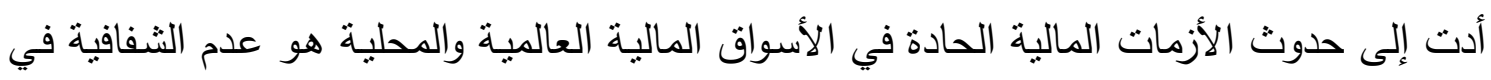

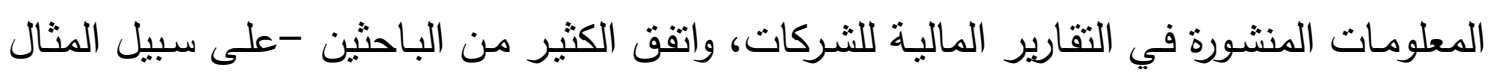
(Mitton, 2002; Groom et al, 2004) المحاسبية وغير المحاسبية التي تنشرها الثركات كماً ونوعاً كلما زادت الثقة في أسواق المال في الني أية دولة، وفي هذا الصدد أثنار (Wen, 2008) إلى أن التوسع في الإفصاح يساعد في تعزيز

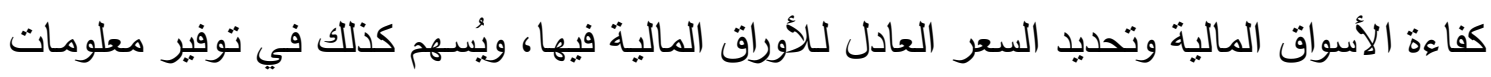

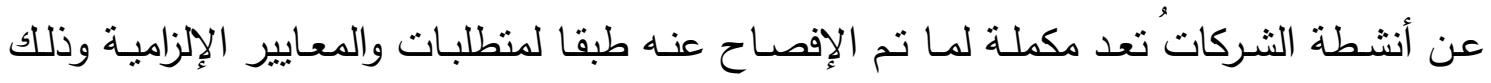
بهدف ترشيد القرارات الاقتصادية.

مـن الناحيـة النظريـة يفترض أن تكون المعلومـات المحاسبية وغير المحاسبية التـي يتن

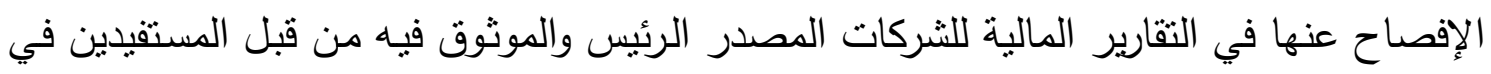

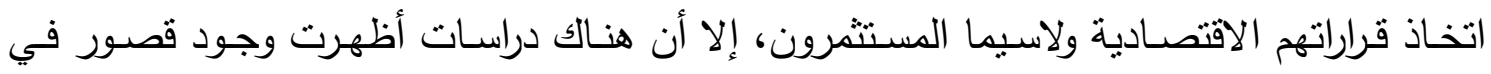

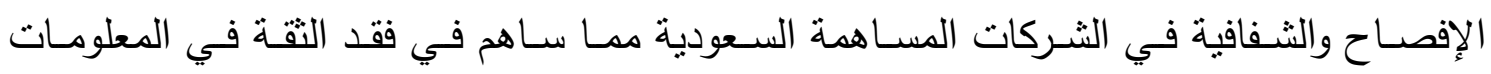

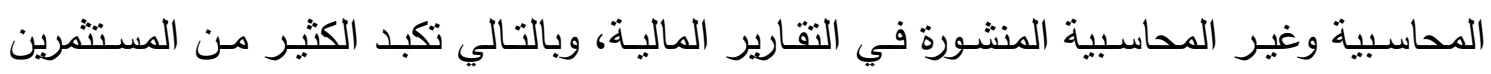

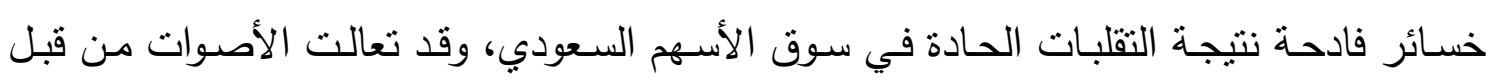
الباحثين والهيئات المهنية والمستثمرين وأصحاب المصالح بالمطالبة بالمزيد من الثفافية والتنوسع الثادئ في الإفصاح.

وقد تم استخدام مصطلح الإفصاح الأمثل في مفاهيم المحاسبة المالية الصادر من الهيئة

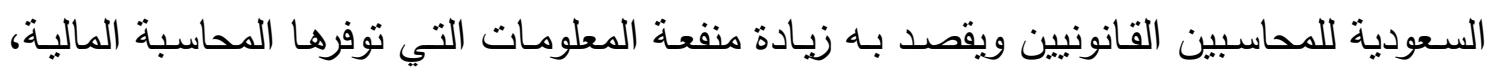
ومن ثم فإن القوائم المالية يجب أن تكثف عن كافة المعلومات التي تجعلها غير مضللة، وهناك الكياك

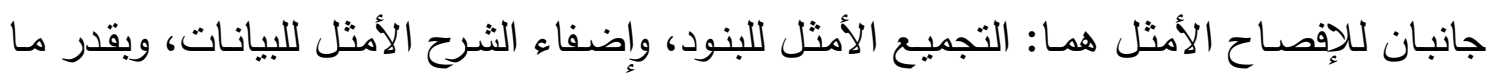

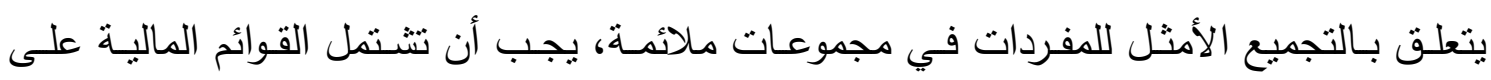

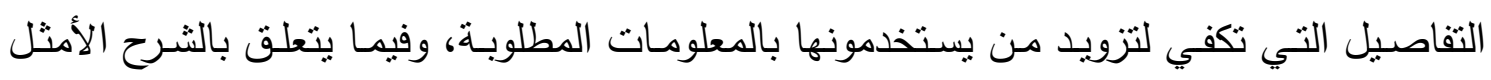


للبيانات يجب إضافة شرح تكميلي للعناوين الرئيسية والفرعية والقيم المالية التي تشملها القوائم بما يكفل توضيح كل منها.

ويشكل الإفصاح أهمية كبيرة بالنسبة للسوق المالي فبواسطته يمكن تقويم عمل الثركات وإعطاء تقويم للأشخاص القائمين عليها، وذلك من خلال النشر والإفصاح عن مجمل العبل العمليات والأنشطة

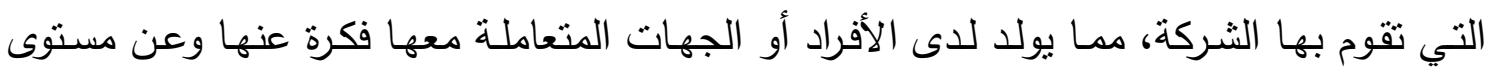

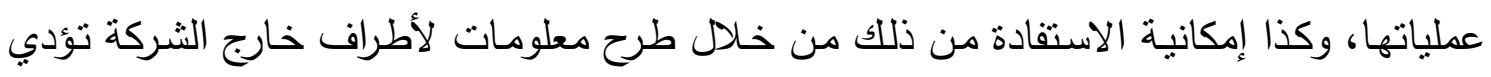

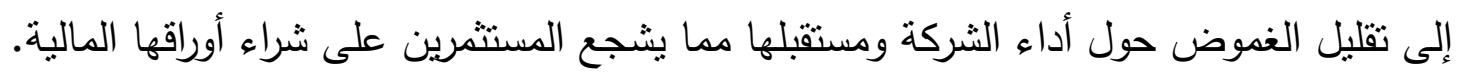

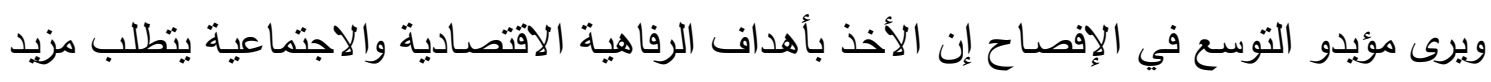

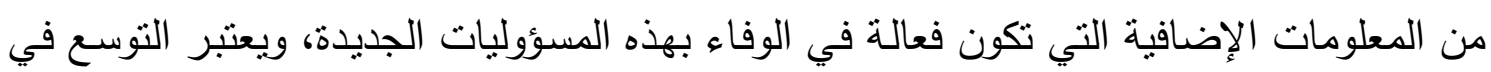
الإفصـاح الحل العملي والمنطقي لمشكلة عدم القدرة على تحديد احتياجات مستخدمي التقارير

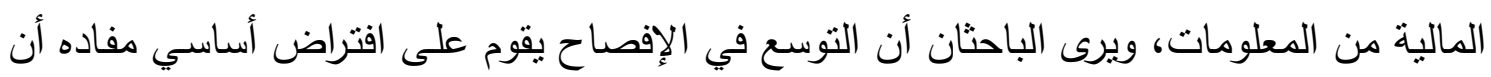

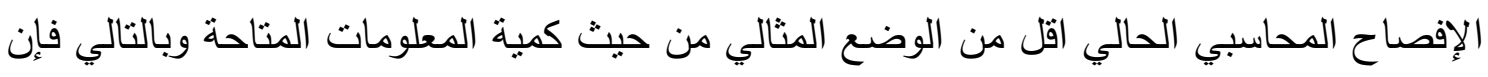

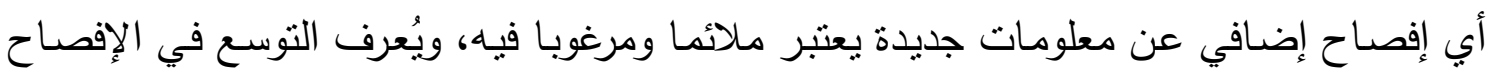

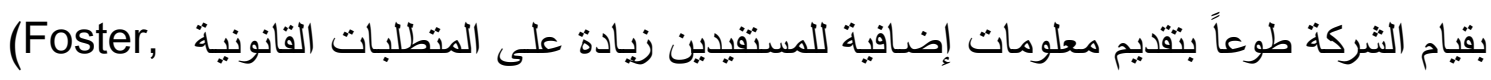

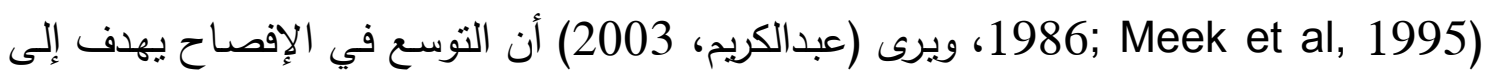

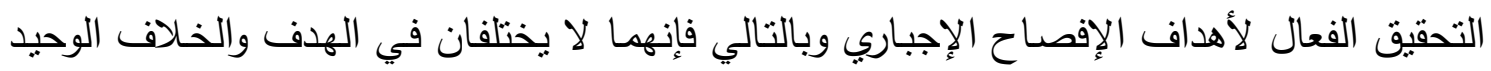

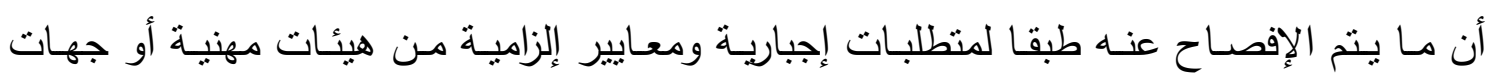

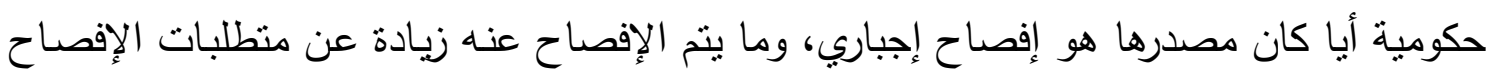

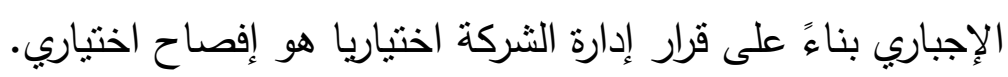

وتأتي أهمية التوسع في الإفصاح عن كافة المعلومات المتعلقة بالوحدة المحاسبية في الحد من محاولات الاستفادة غير المشروعة من المعلومات الداخلية والقضاء على صلى صور التعامل المختلفة

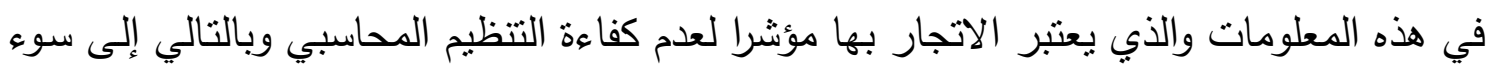

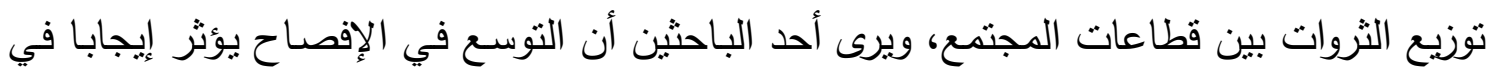

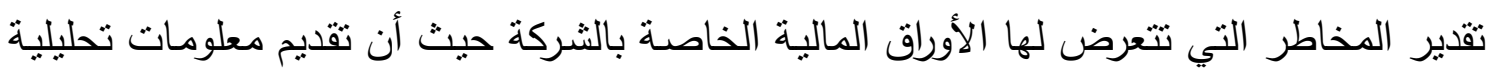

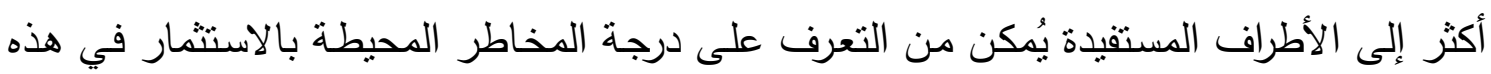

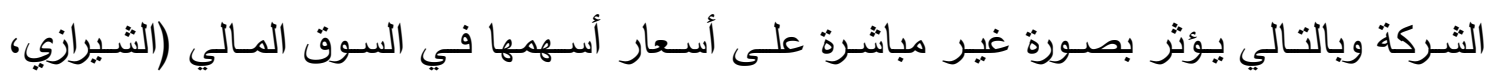

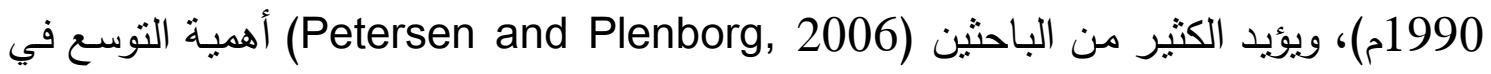


الإفصاح في تخفيض تكلفة رأس المال الذي ترغب الثركة في الحصول عليه وذلك عن طريق

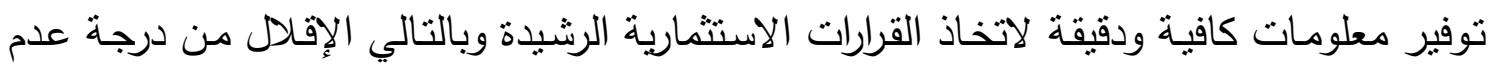
التماتل في المعلومات (Asymmetry Information) بين الإدارة والمستشرين.

وتعتبر ظاهرة عدم تمانل المعلومات من الظواهر التي تعاني منها الكثيرمن أسواق الأوراق المالية

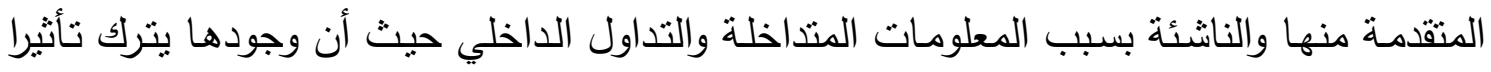
سلبيا على حجم السيولة والتداول وتكلفة رأس المال، ولم تشر أدبيات المحاسبة لوجود تعريف محدد المدات لعدم تماثل المعلومات ولكن وجدت ثلاثة اتجاهات تحمل وجهات نظر مختلفة ومكملة لبعضهـا البعض وهي (السيد، 2005م):

1- أن هنـاك شكلين لعدم تماثل المعلومـات، يتضـن الأول الأول عدم التماثل أو عدم المسـاواة بين

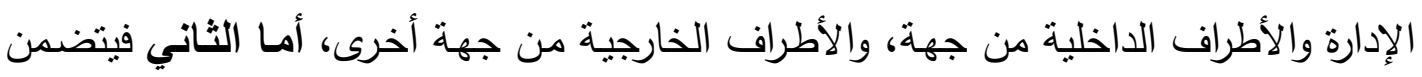
عدم التماثل أو عدم المساواة بين الأطراف الخارجية بعضها البها البعض، مثال ذللك عدم التماثل

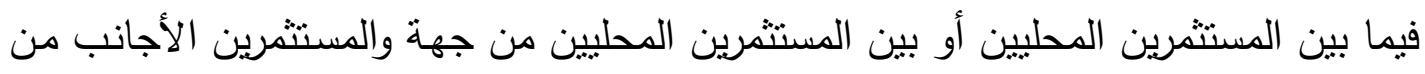
جهة أخرى.

2- أن عدم تماثل المعلومات سلوك متعدد من قبل الأطراف التي تمنلك ميزة معلوماتية بهدف

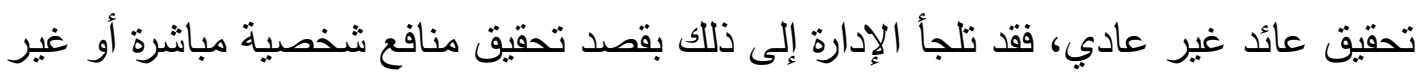

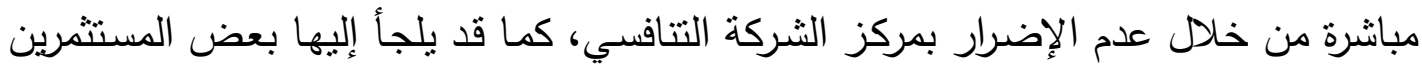

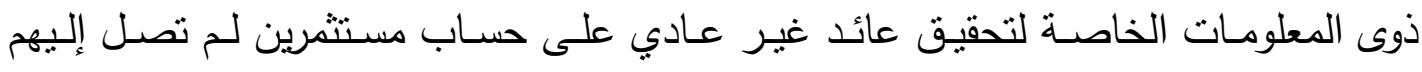

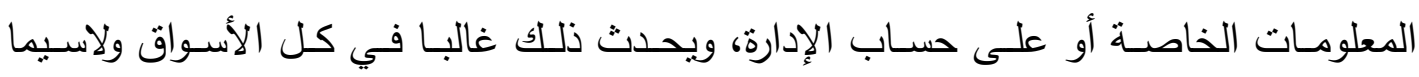

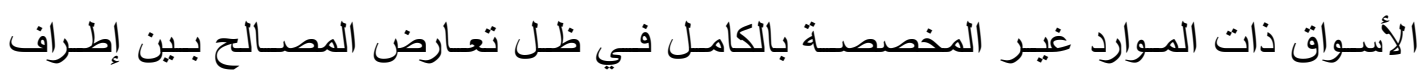
التعاملات التجارية وغياب التوازن في المعلومات التي ينت توفيرها.

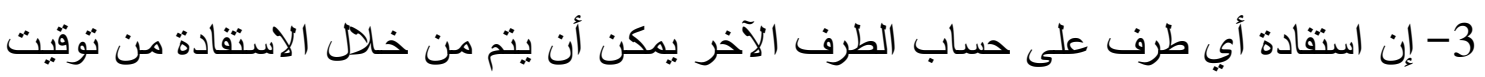

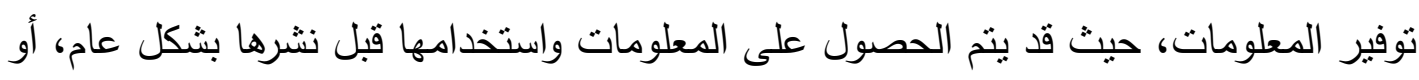

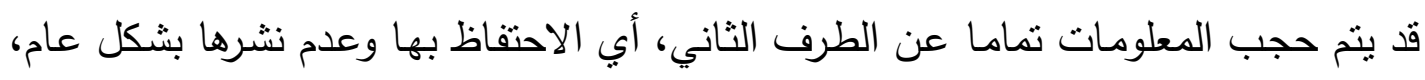

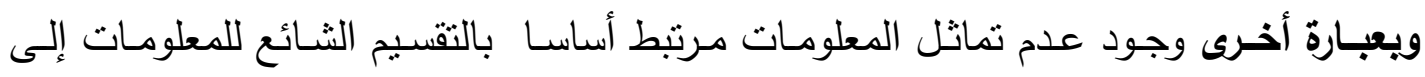
معلومات عامة ومعلومات خاصة.

وتتفاوت الآراء بشأن الآثار المترنبة على عدم تماثل المعلومات والتي يمكن تقسيمها إلى ألى

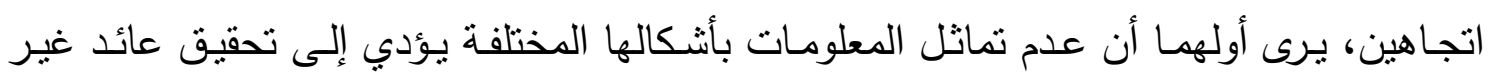


عادي لبعض الأطراف على حساب أطراف أخرى من خلال معرفتهم المبكرة بمعلومات عن أداء

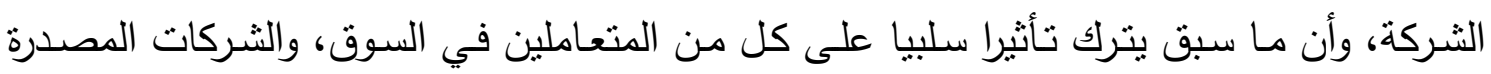

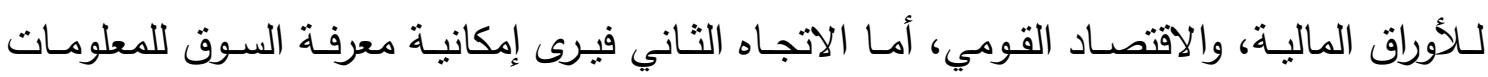

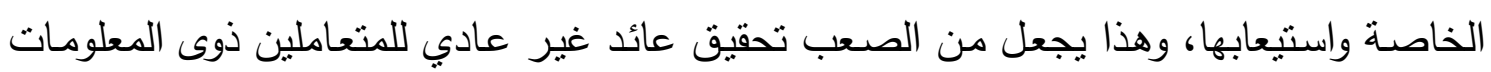

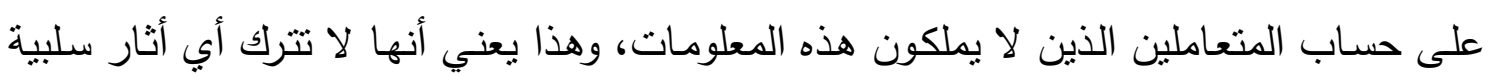

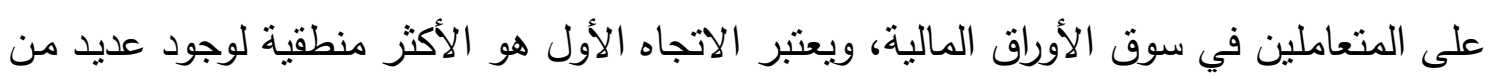

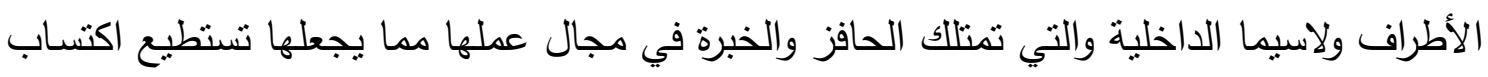

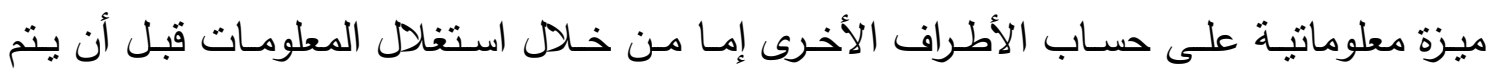

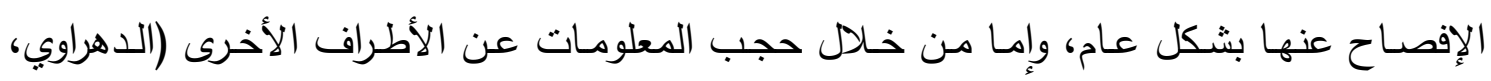

ويعتبر التوسع في الإفصاح المحاسبي وهو ما تتضمنه الكثير من معايير المحاسبة الدولية

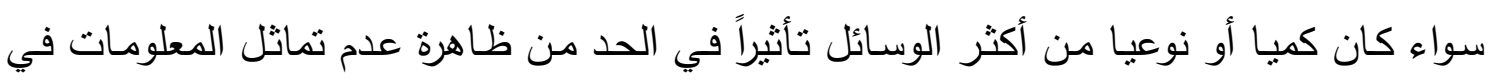

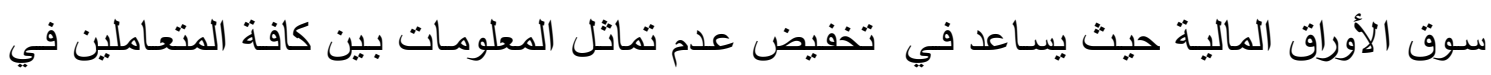

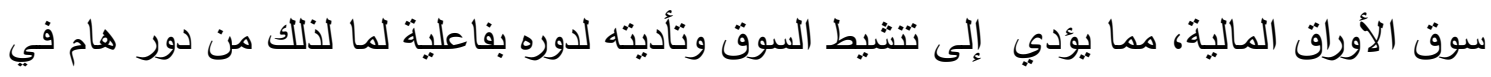

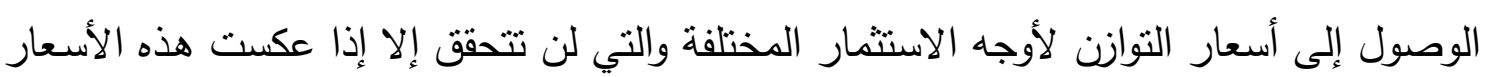

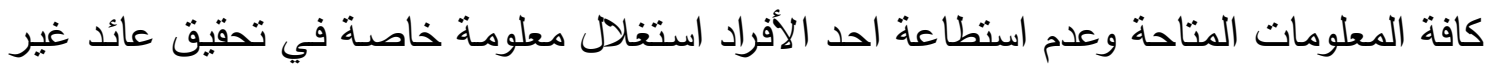
عادي، ونتيجة لذلك فإن التوسـع في الإفصـاح يساعد في التأثنر ايجابيا على كلا من (السيد، :2005

1- الثركات المصدرة للأوراق المالية، حيث تنم زيادة درجة السبولة للأوراق المالية وما يترتب

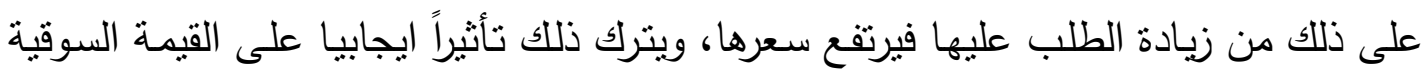

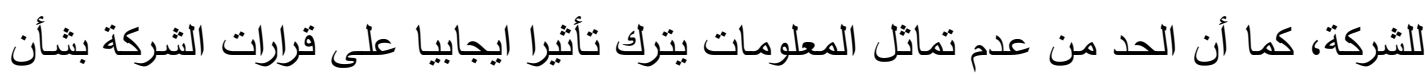
الاستثمار والتمويل . 2- المتعاملون في الأوراق المالية، حيث بساعد التوسع في الإقصـاح على الوصول إلى تتبؤات عالية الدقة للمحللين الماليين وهذا يحقق منافع لكل من المستثمرين وأصحاب المصالئ عالح.

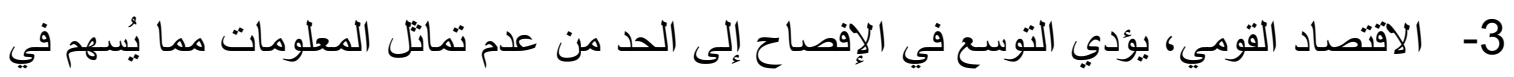

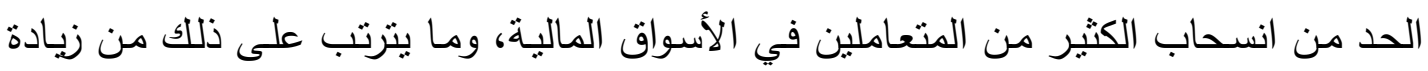


عدد المتعاملين ومن ثم زيادة حجم التداول وانخفاض تكلفة رأس المال، والذي ينعكس في النهاية على تخصيص كفء للموارد الاقتصادية وبالتالي زيادة معدلات التتمية الاقتصادية.

\section{ب-القيمة العادلة}

تتأرجح الددارس الفكرية المحاسبية، منذ فترة بعيدة، بين استخدام كل من نموذجي التكلفة

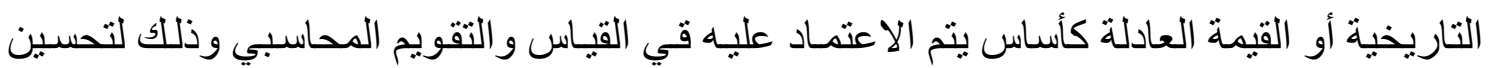

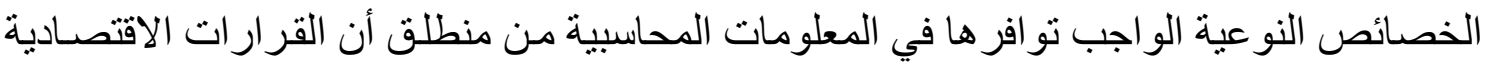
وبشتى أثكالها و أنو اعها تعتمد وبشكل رئيس على البيانات المفصـح عنها في القو ائم الماليـة، فمن

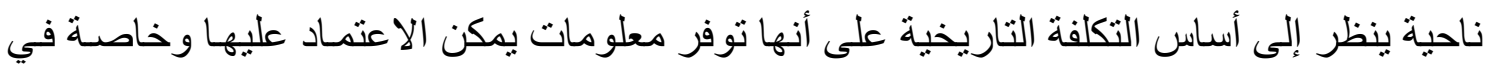

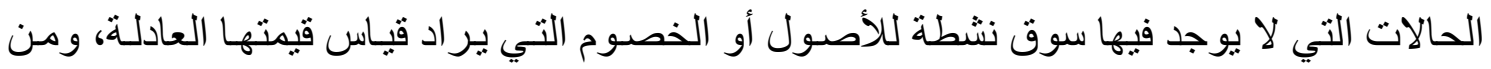

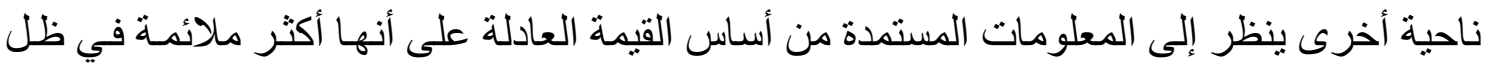
الظروف الاقتصادية السائدة وقت تقديم المعلومات، وبين هاتين الددرستين، ظهرت بعض الآراء التي حاولت أن تقدم نموذج يمزج بين كل من أساس التكلفة التاريخية و القيمة العادلة.

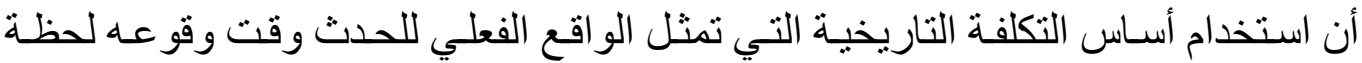
التبادل، لا يثك في دقتها وصحتها لحظة الاكتساب أو التملك، و إنما يظهر التشكيك في سلامة المبدأ

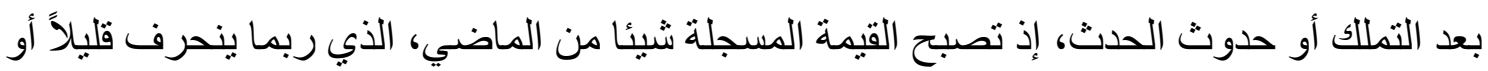

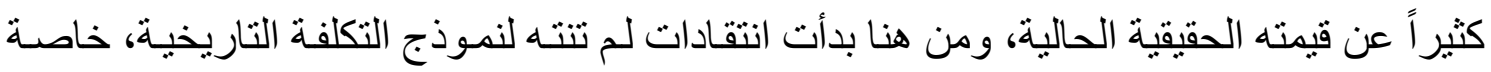

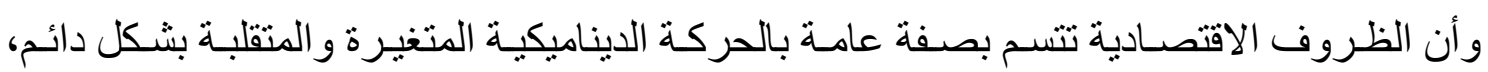

وتتغير القوة الثر ائية لوحدة النقد بتغير هذه الظروف في حالاته المختلفة (دهمش، 2005). أن التوجه الحديث لاستخدام أسـاس القيمة العادلة في العقدين الأخيرين من قبل الهيئات و الهجالس المهنية المحاسبية، ومنها على سبيل المثال مجلس معايير الهحاسبة الدولية (IASB)،

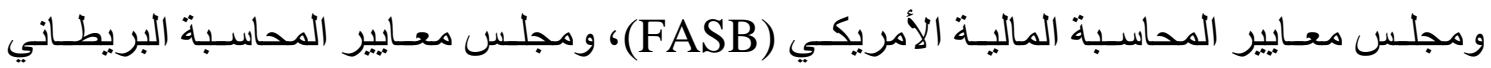
(ASB)، ومجلس معايير الححاسبة الاستر الية (AASB)، و الهيئة السعودية للمحاسبين القانونيين (SOCPA)، من خـلال إصدار وتعديل العديد من المعايير المحاسبية لتعزيز الثفافية وإظهار الوضع المالي ونتائج الأعمـال و التدفقات النقدية وفق الحقائق الاقتصـادية كونها أكثر نفعا وفائدة لمستخدمي المعلومات المحاسبية، حيث بدأت هذه الهيئات و المجالس المهنية بتطبيق أسـاس القيمة 
العادلة على الأدو ات المالية و مـا يشـابهها من بنود كالمشتقات، وتحساول جاهدة تطبيقه على كافة عناصر المركز المالي لتشمل كافة الأصول والخصوم المالية وغير المالية. وتمثل الأصول الثابتـة في المنشـآت الصناعية بأثنكالها النظاميـة المختلفة نسبة عاليـة من مجموع أصولها، وقد أبدت الهيئات و المجالس المهنية الكثير من الاهتمـام بها وصدرت العديد من المعايير التي تناولت القياس و العرض و الإفصساح عنها، ويعد استخدام أساس القيمة العادلة في إعادة تقويم الأصـول الثابتـة بالزيـادة مـن المو اضـيع التي أثـارت جـدلا واسـعا بـين أوسـاط المهنيـين و الأكاديمبين بين المنع و السماح، والترحيب و التحفظ، فبينما نجد أنها تمنع وفقا للمعايير المحاسبية الأمريكية والسعودية، يسمح باستخدامها وفقا للمعايير المحاسبية الدوليـة والبريطانية و الاستر الية و المصـرية والتي ترى أهميـة استخدام أسـاس القيمـة العادلـة والمعالجـات المحاسبية لإعـادة تقويم الأصول الثابنة بالزيادة و أثر ذلك على جودة المعلومات المحاسبية.

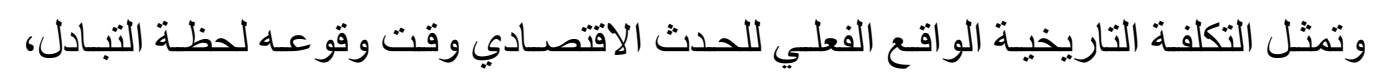
وتمتـاز كأسـاس للقباس المحاسبي بالموضـوعية النسبية، ولكن يؤخذ عليهـا افتر اض ثبـات القوة الثرائية لوحدة النقد وتجاهل التغير ات في الأسعار السوقية للأصول مما يثير إلى أن التمسك بمبدأ التكلفة التاريخية قد ينتج أرقاما لا معنى لها أو ليس لها دلالة في الفتر ات التي تلي التملك أو حدوث التهاث الحدث، وتعد التكلفة التاريخيـة الأسـاس المتبع لتقويم الأصسول الثابتـة ويتم قيـاس هذه التكلفة على لـى أساس السعر النقدي المتفق أو ما يعادله للحصول على الأصل، بالإضافة إلى أي مصروفات أخرى الخى

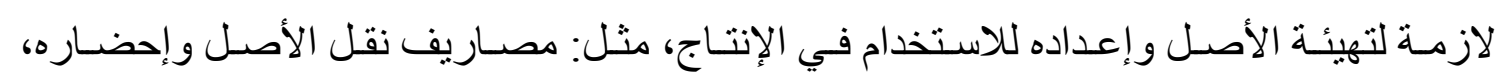
و التأمين عليه، وتكلفة التركيب والتدريب.......الخ. ويوجد اتفاق في الفكر المحاسبي في قياس أي الإ. بند من بنود الأصـول الثابتـة عند الاعتر اف بـه كأصل ثابت على أسـاس التكلفة، أمـا في الفترات اللاحقة بعد الاعتر اف الأولي فهناك مدرستان في الفكر المحاسبي تتبنى الأولى الاستمرار في لهـي استخدام التكلفة التاريخية في تقويم الأصول الثابتة للاعتبار ات التالية: 1-كون التكلفة التاريخية تمثل التكلفة الحقيقية وقت الحصول على الأصل.

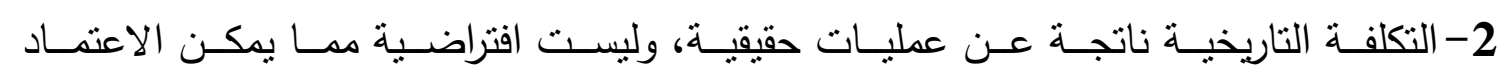




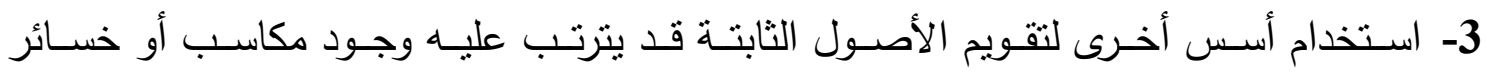

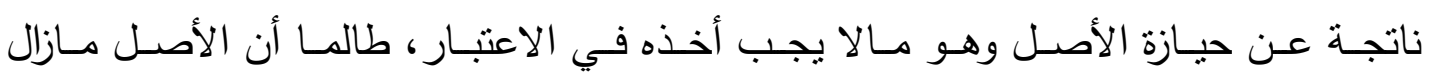

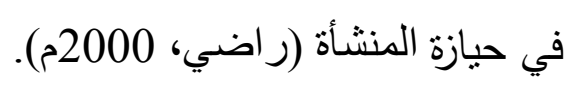

وتتبنى الددرسـة الثانيـة (على سبيل المثنال هيئة معايير المحاسبة الدوليـة) مـن الفكر

المحاسبي إعادة تقويم الأصول الثابتة لكي تقترب من قيمتها العادلة وذلك للاعتبارات التالية:

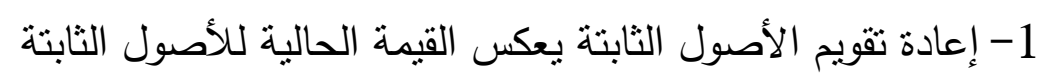

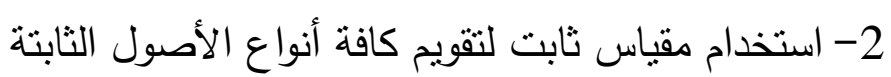

3- يقدم معلومات دقيقة عن العائد على حقوق الملكية.

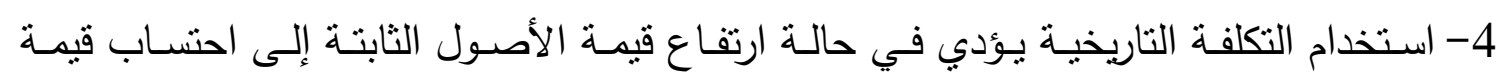

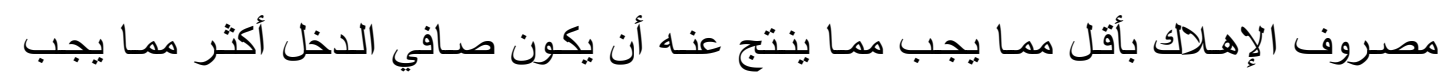

$$
\text { وبالتالي قد تكون توزيعات الأرباح مبالغ فيها. }
$$

5- تحسين نسبة الديون إلى إجمالي الأصسول بما يحقق الزيادة في الطاقة الاقتراضية للمنشأة،

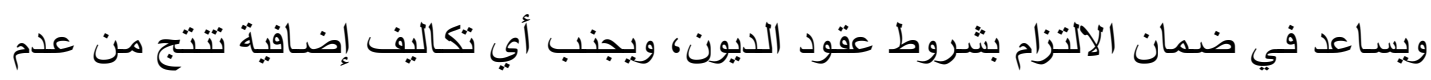

$$
\text { الالتزام بهذه الثروط. }
$$

6- يعزز إمكانية المقارنة بين القوائم المالية للمنشآت ولنفس المنشأة خلال فنرات زمنية مختلفة.

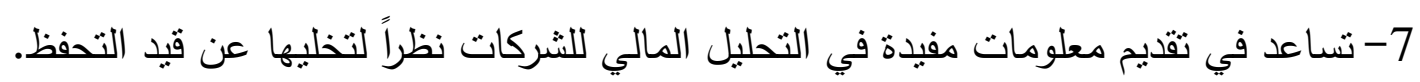

8- تساعد في تقديم معلومات ملائمة لاتخاذ القرارات الاقتصادية الرشيدة.

\section{ج- التوافق والتوحيد}

من أهداف التقارير المالية تقديم معلومات مفيدة تساعد مستخدميها كالمستثرين الحاليين

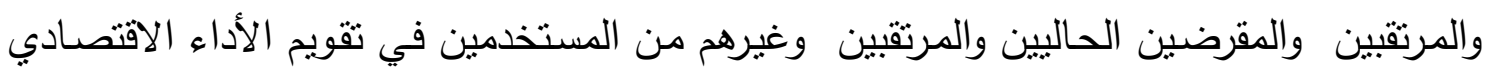

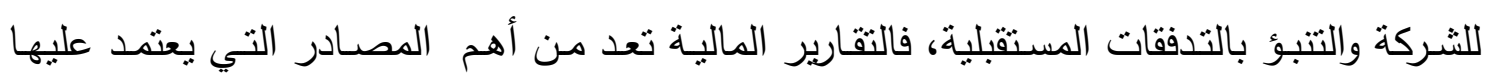

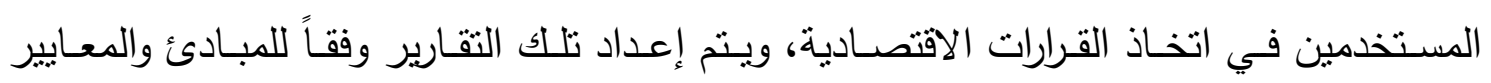

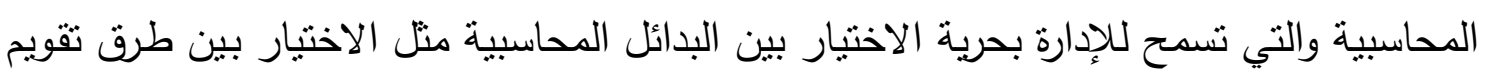

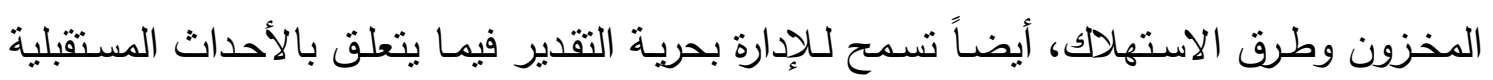
والتي تتطلب نوعاً من الثقدير الثخصي مثل تقدير مخصص الديون المشكوك فيها.

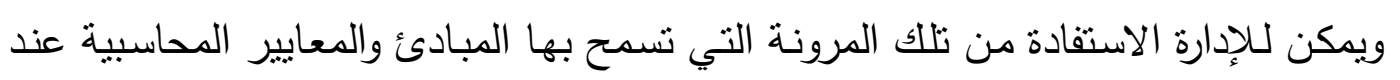

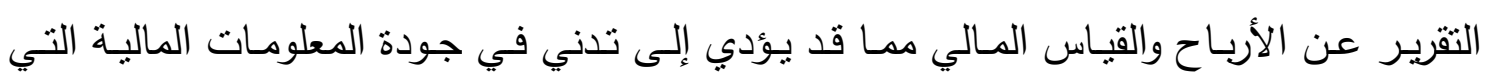


تتضمنها التقارير المالية (Makar et al. 2000)، إن هذه المرونة تعطي الإدارة الخيار في

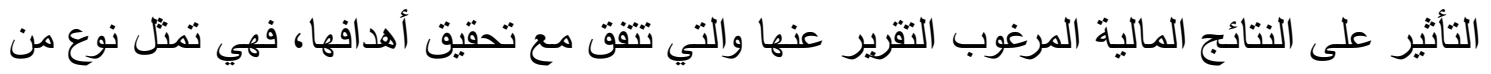
اغتتام الفرص لتحسين صورة أداء الثركة، إلا أنه لها تأثثر على مصداقية وعدالة القوائم المالية

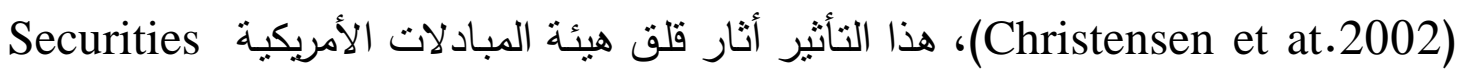
حيث صرح رئيسها السابق آرثر ليفيت في خطابه الثهير لعبة الأرقام المالية عن قلق SEC من تأثير إدارة الأرباح على مصداقية التقارير المالية واعتبارها لعبة تتعارض مع المبادئ ذاتها التي تقف وراء قوة السوق (Livett 1998).

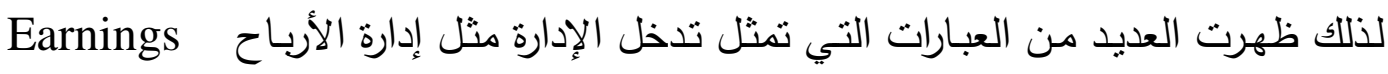
management وتمهيد الدخل Income smoothing والتلاعب Manipulation والمحاسبة الإبداعية Creative accounting والاستحمام Big bith، وساهم ذللك في ظهور العديد من الفضائح المحاسبية والتي أدت إلى انهيار مجموعة من الثركات الكبيرة مثل شركة أنرون للطاقة وساقة

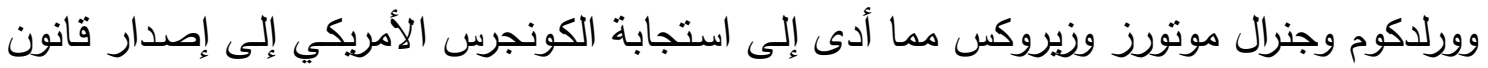

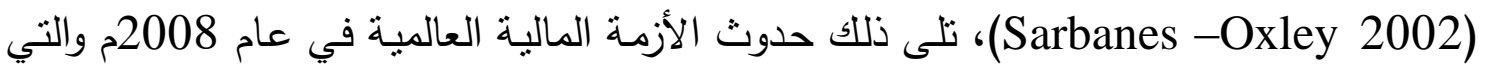

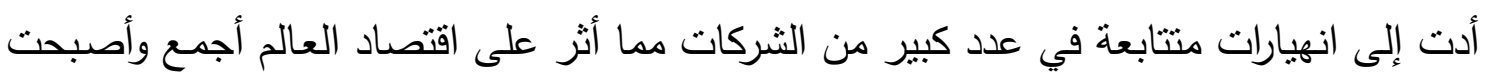

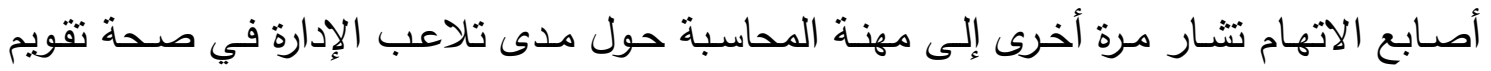
الرهونات العقارية وعدم التطبيق السليم للمبادئ والمعايير المحاسبية.

وإذا كانت هذه الانهيارات والفضائح المالية قد حدثت في الدول المتقدمة التي تتمتع بييئة مهنية عالية في المحاسبة والمراجعة فان دول العالم النـامي ليست بمنائ عن تلك الانهيارات والفضائح المالية حيث أن المهنة لازالت قيد التطوير والتحسين فضلاً عن الأسواق المالية النانشئة، لذا زاد الاهتمام بموضوع تبني معايير محاسبية موحدة وتتاولته العديد من الدراسات، وتوجد في التي الفكر المحاسبي مدرستان تتاولت الاولى التوفيق بين المعايير المحاسبية بين مختلف دول العالم

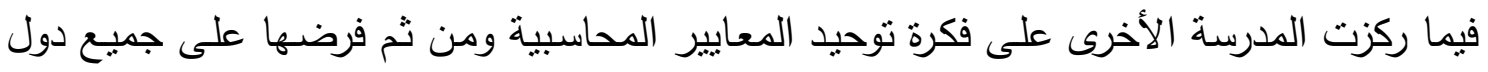
العالم، وسيتناول الباحثان باختصار شرح معنى التوافق والتوحيد في المعايير المحاسبية.

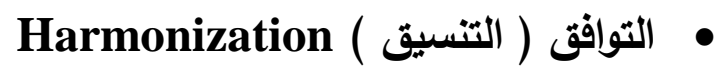
وردت في الفكر المحاسبي مجموعة من التعريفات المتعلقة بمفهوم التوافق الدولي ومنها على سبيل المثال Wolk \& Francis \& Tierney الذي عرف التوفيق بأنه درجة من التتسيق أو التماثل فيما بين مجموعات مختلفة من المعايير والطرق وأثكال التقارير المالية. ومن الملاحظ أن الن الناله 
هذا التعريف قصر التوفيق على درجة معينة من التتاسق أو التماثل بين مجموعة مختلفة من

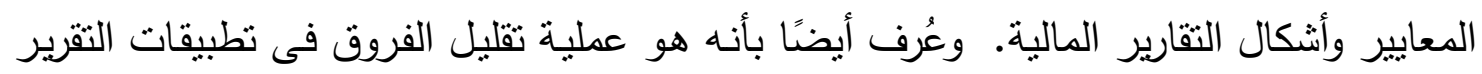

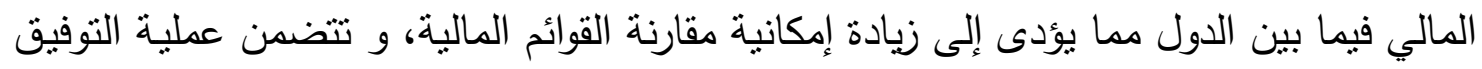
تطوير مجموعة من معايير المحاسبة الدولية الواجب تطبيقها فى مختلف دول العالم و ذللك لزيادة لئه عالمية أسواق رأس المال. و يُلاحظ أن هذا التعريف ركز على تقليل الفروق فى تطبيقات التقرير

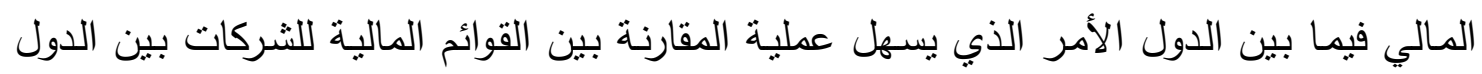

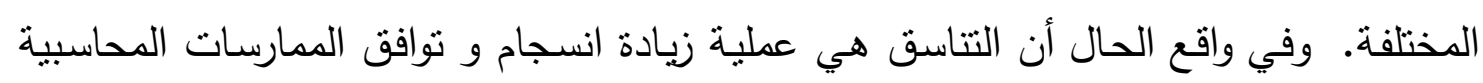

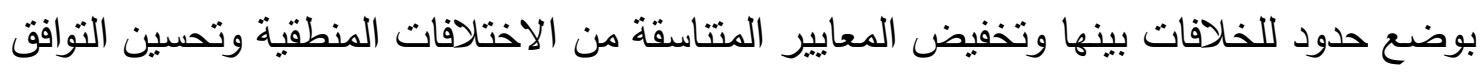

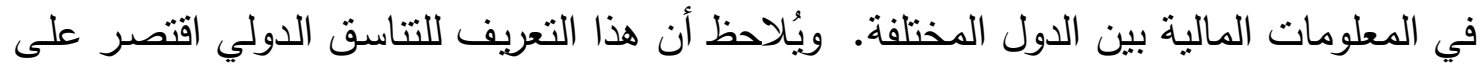

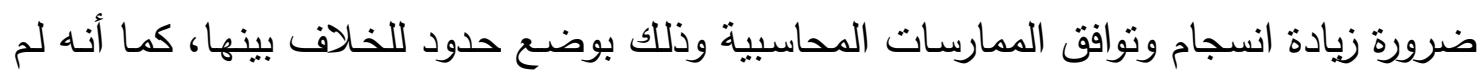

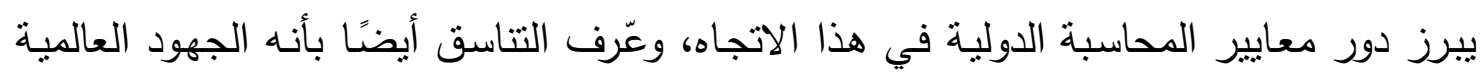

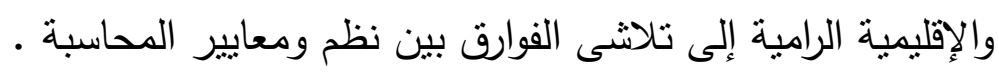
ويهدف النوفيق المحاسبي على المستوى العالمي إلى تلبية احتياجات المستثمر الدولي نئي

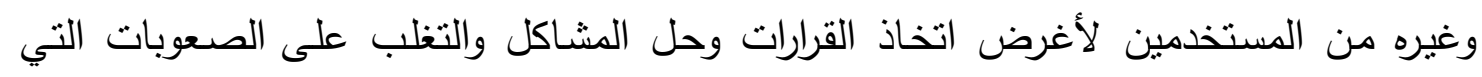
يواجهها المستثمرون الدوليون والثركات متعددة الجنسيات وشركات الدحاسبة والمراجعة الدولية. نُلخص مما سبق، إلى أن التوافق الدولي يعنى محاولة تتسيق و تقريب الممارسات و الطرق

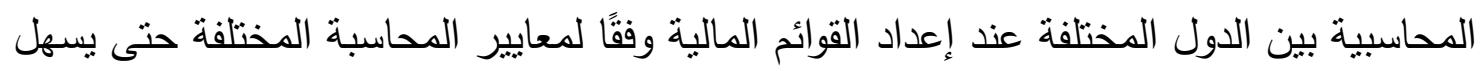

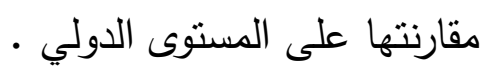

\section{• التوحيا Uniformity}

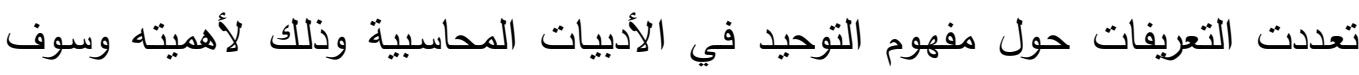

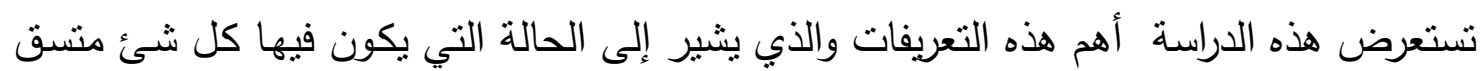
ومتجانس أو غبر منباين فهي تحتوى التماثل الذي يعنى أن تكون كل المبادئ والممارسات

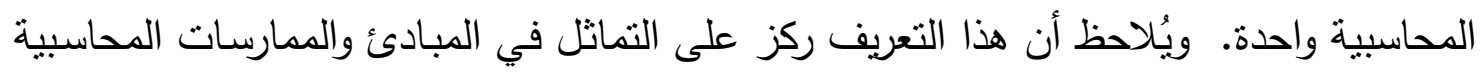

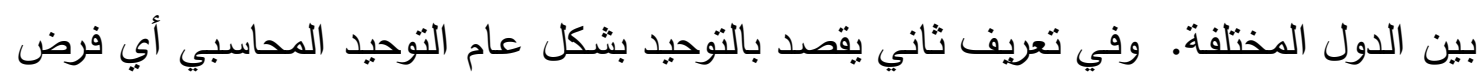

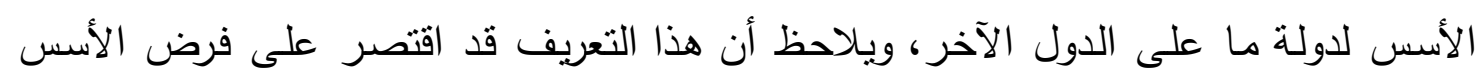

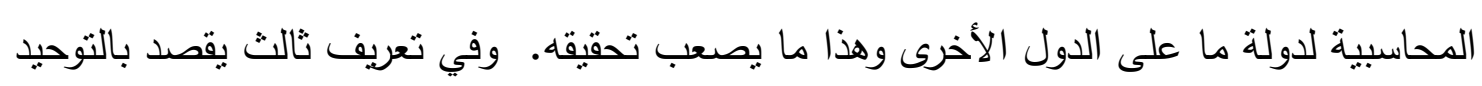

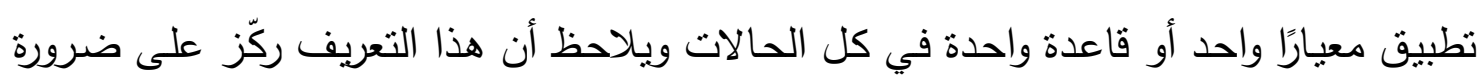


توحيد المعايير المحاسبية. ومما تقدم نلخّص إلى أنه يقصد بالتوحيد المحاسبي توحيد السياسات

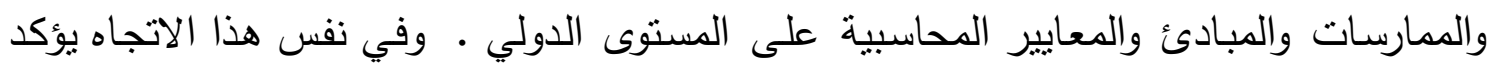
Dawid Tweedie

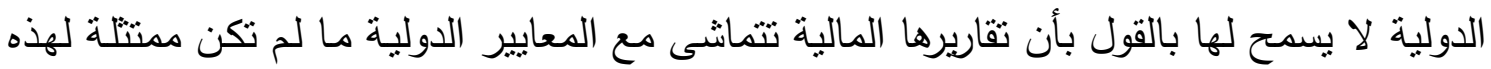

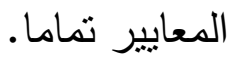

4- أثر توفيق معايير المحاسبة السعودية مع معايير المحاسبة الدولية على جودة المعلومات

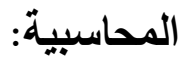

أ أ- الملائمة Relevance

يقصد بملائمة المعلومات المحاسبية قدرتها على التأثير في اتخاذ القرارات، بمعنى أن تكون هذه المعلومات لها القدرة على إجراء اختلافات في القرارات، وبالتالي فإن المعلومات التي لا تؤخذ في الحسبان نظراً لعدم قدرتها على التأثير في القرارات تعتبر معلومات غير ملائمة، ولكي تكون

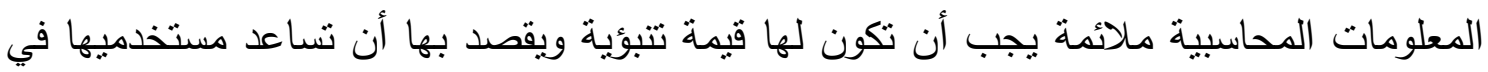

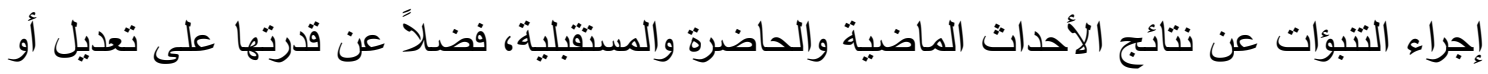
تصحيح التوقعات السابقة، أي تكون لها القدرة على تقديم التغذية العكسية التصحيحية والتقويمية

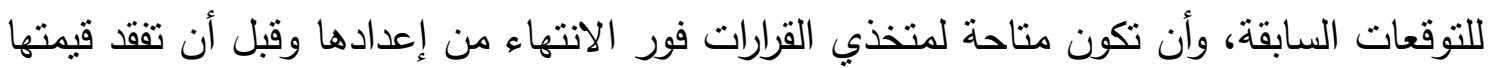

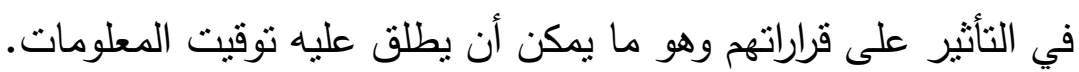
وتنتير الدراسات السابقة - ومنها على سبيل المثال , Barth and Clinch, 1998) Easton et al., 1993, Aboody, et al. 1999)

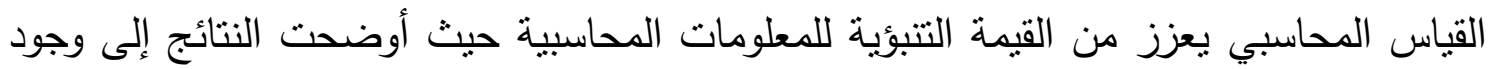

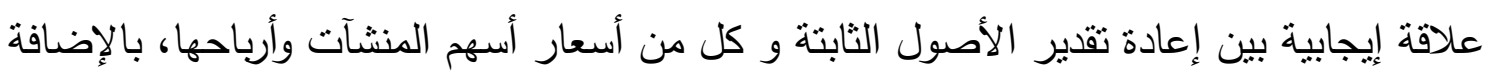
إلى أن المعلومات المحاسبية المقدمة بواسطتها تساعد متخذي القرارات الاقتصادية على التتبؤ بالأرباح المستقلية للمنشآت وتنساعد على معرفة القيمة الثرائية للمنشأة وهو ما لا يقدمه استخدام التكلفة التاريخية إلا في حالة تصفية المنشأة وانتهاء عملها.

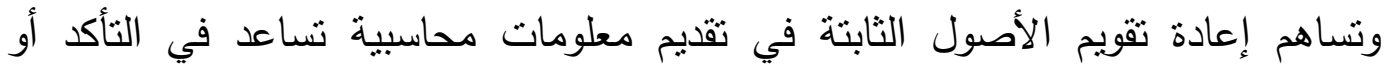

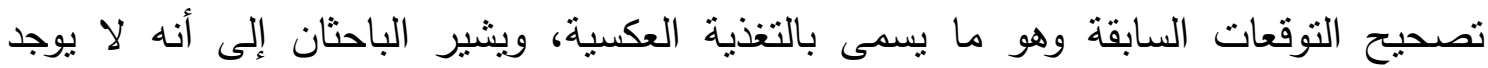

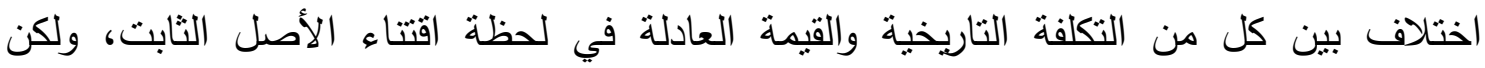
الاختلاف بينهما في الفترة التالية لتملك الأصل، حيث يتم نوفير معلومات محاسبية ملائمة يتم 
بواسطتها التأكد أو تصحيح التوقعات السابقة لمتخذي القرارات الاستثارية أو التمويلية بصورة

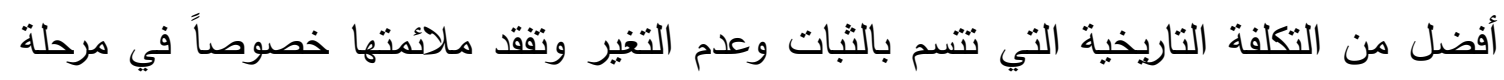

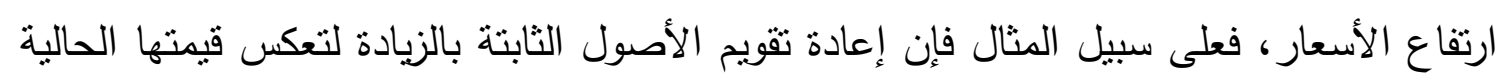

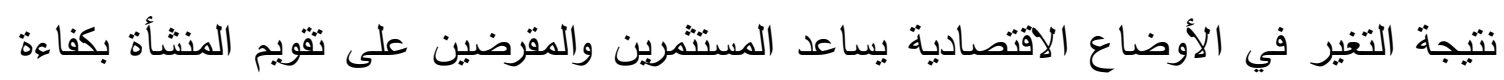

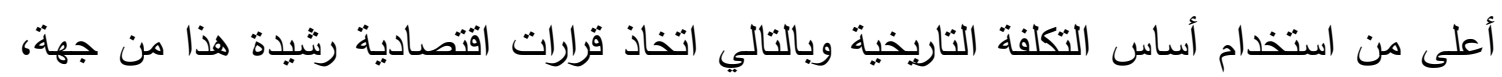

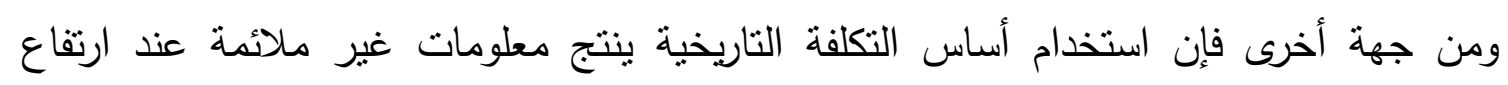

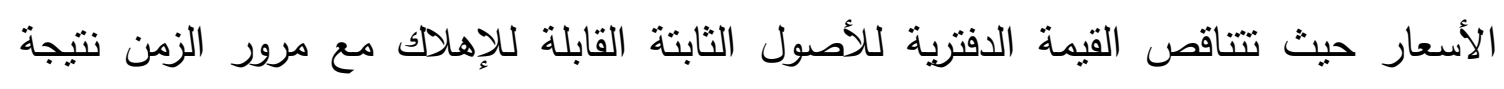

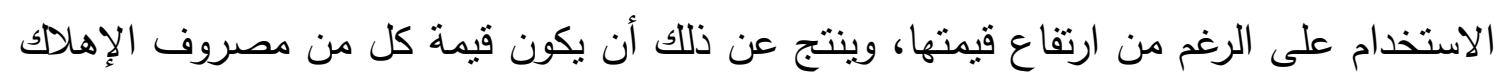

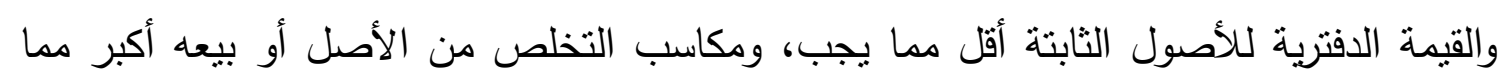

ويعزز إعادة تقويم الأصول الثابتة من ملائمة المعلومات المحاسبية حيث يوفر معلومات

في الوقت المناسب لاتخاذ القرارات الاقتصادية الرشيدة وذلك قبل أن تفقد قيمتها ونأثيرها في اتخاذ

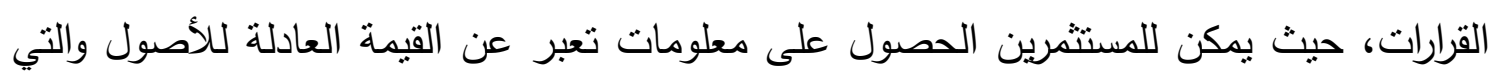

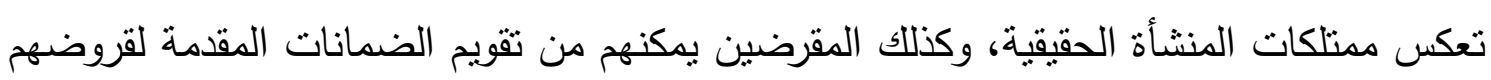

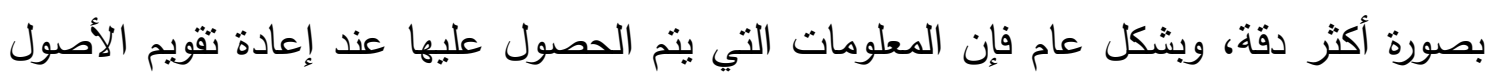

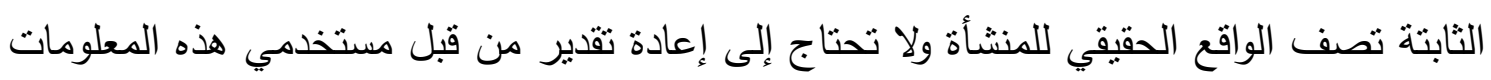
وما ينتج عنه من ضياع الوقت والجهد كما هو متبع عند استخدام أساس التكلفة التاريخية.

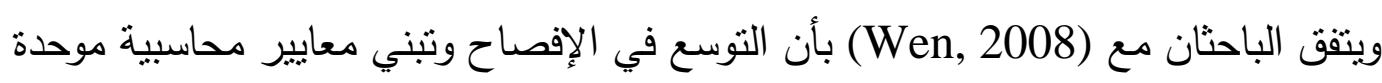

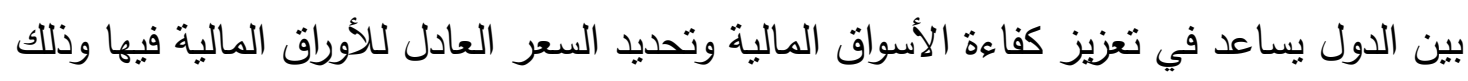

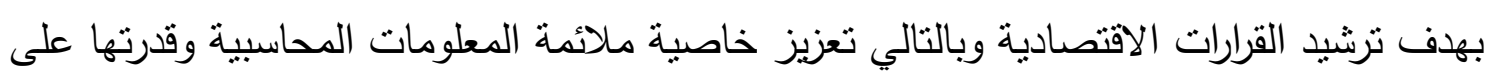
التأثنير في اتخاذ القرارات.

\section{ب-إمكانية الاعتماد عليها Reliability}

تعتبر المعلومات المحاسبية مفيدة ونافعة للمدى الذي يمكن لمستخدميها الاعتماد عليها

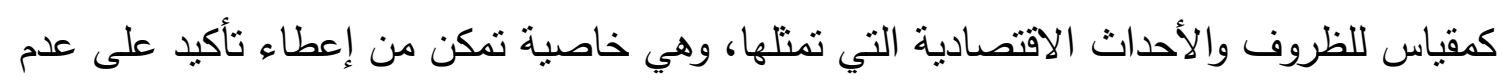

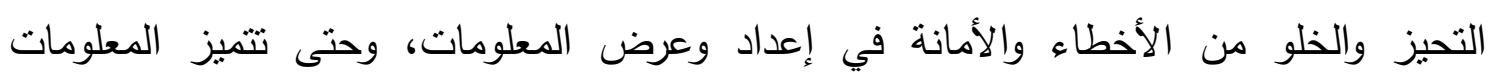

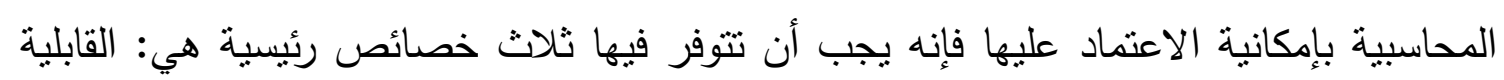

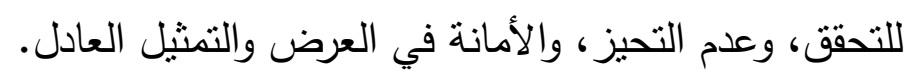


وتعني القابلية للنحقق وجود درجة عالية من الاتفاق والإجماع بين عدد من الآراء المستقلة

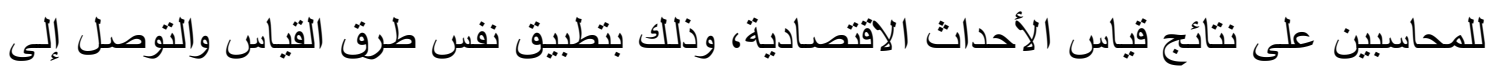

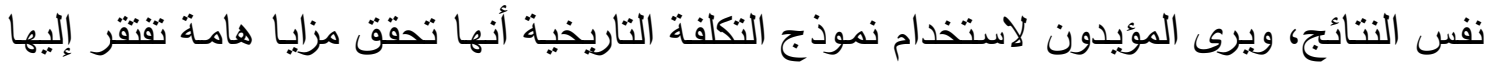

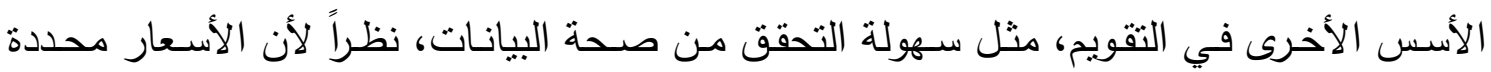

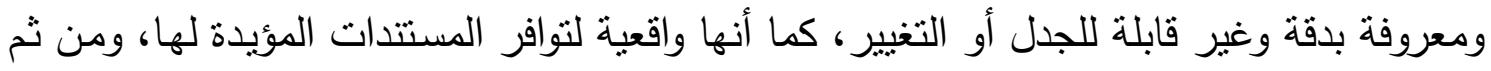
تستند إلى أساس موضوعي وحقيقي. ويرى الباحثان أن التكلفة التاريخية أساس ملائم يمكن التحقق منهه في حالة خاصـة مثل قياس وإثبات الأصل الثابت مقابل النقد بقصد استخدامه في المنشأة، ويتوقف تطبيق أساس التكلفة

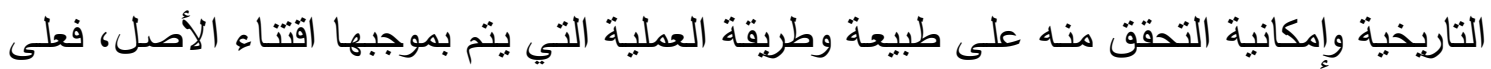

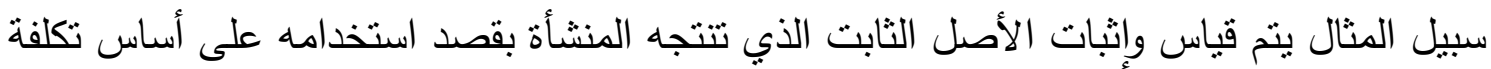

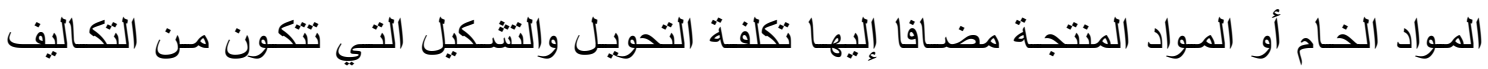
الصناعية المباثرة وغير المباثرة والتكاليف الأخرى اللازمة ليصل الأصل إلى المكان المحدد له

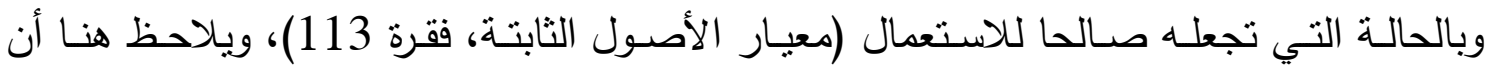
التكلفة الصناعية الغير مباشرة المخصصـة للأصل وكذللك تكاليف التمويل التي يتعين رسملتها تعتمد في جوهرها على التقويم الثخصي للمحاسب، وهنا يبرز التساؤل عن إمكانية التحقق من هذه

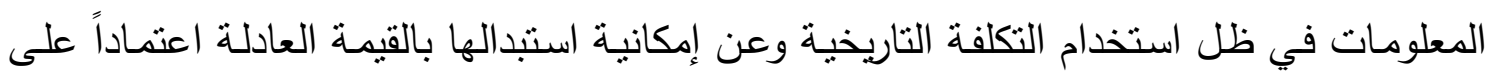
تقويم عادل ومستقل.

ومـن القضـايا ذات الصـلة بموضـوع إمكانيـة التحقـق مـن المعلومـات انضـــام المنشـآت الاقتصادية بأسبابه وأثنكاله المتعددة، حيث اصبح ظاهرة ملحوظة في قطاع الأعمال نظراً للمزايا الاقتصادية العديدة لانضمام المنشآت بعضها إلى بعض وتكوين منشآت كبرى تهدف إلى خلق القان وحدات اقتصـادية ضخمة تسبطر على مصادر الثروة وتمكن من تحقيق الوفورات الاقتصادية

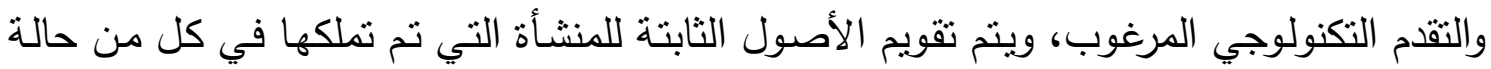
الاندماج أو السبطرة بالقيمة العادلة وهو أمر مقبول في ظل مبدأ التكلفة التاريخية، وهنا يتساءل

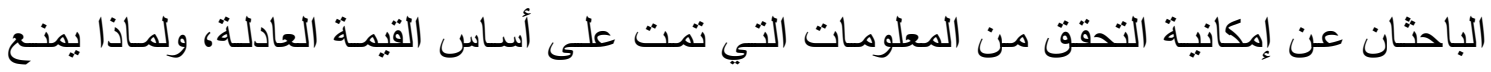

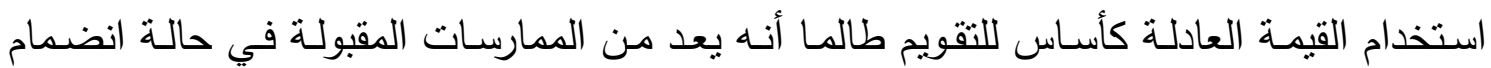

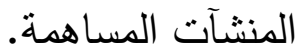


ويلفت الباحثان النظر هنا إلى استبدال نموذج التكلفة التاريخية بالقيمة العادلة في العديد من

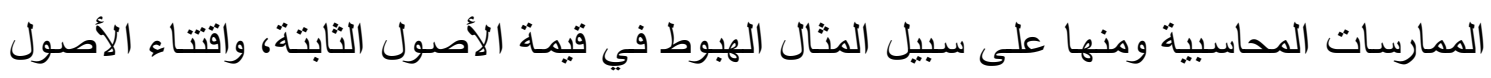
الثابتة عن طريق عمليات غير تبادلية، واقتتاء الأصول الثابتة مقابل أصول ثابتة أخرى، واقتناء

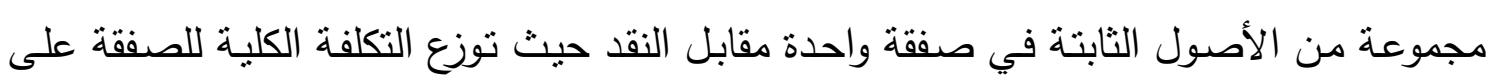

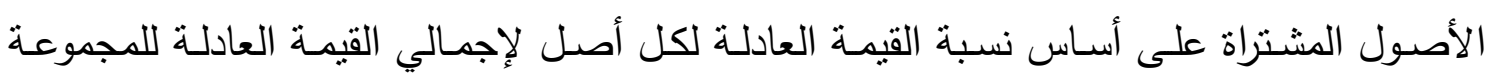

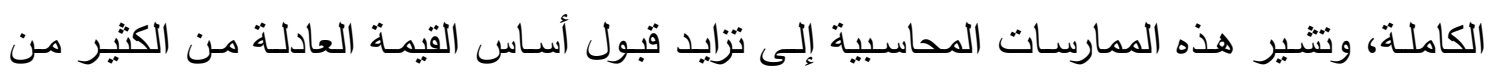

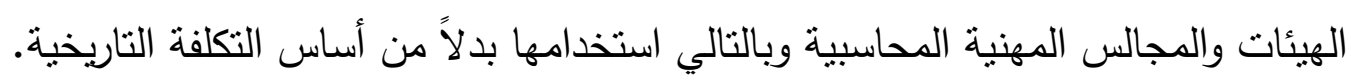

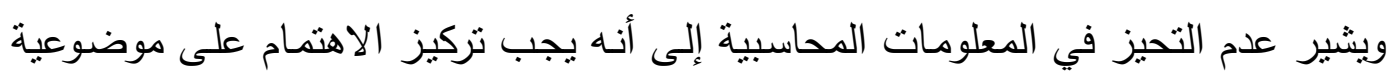

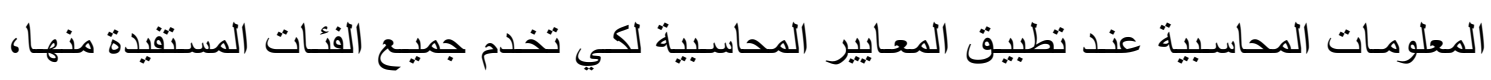
فالمعلومات المحاسبية تكون غير متحيزة عندما تخلو من التحيز المقصود لتحقيق نتائج محددة مقدماً، أو للتأثثر في سلوك متخذي القرارات في اتجاه معين، وباستخدام هذا المفهوم لعدم التحيز

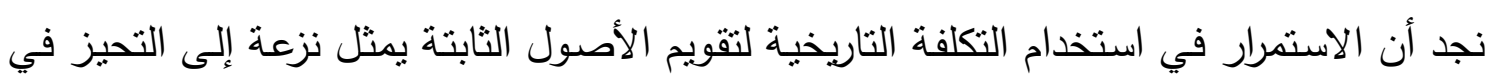
تطبيق قيد التحفظ المحاسبي الذي يتطلب اختيار القيمة التي يترتب عليها عدم زيادة قيمة الإخل

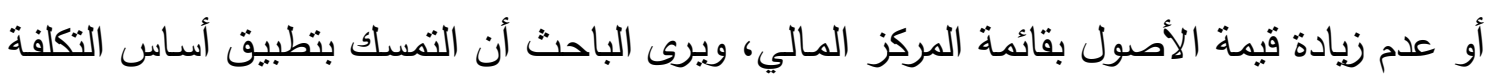

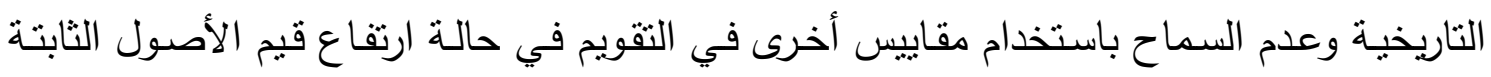

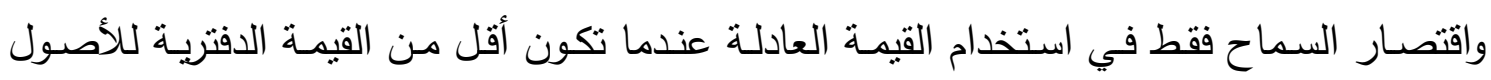

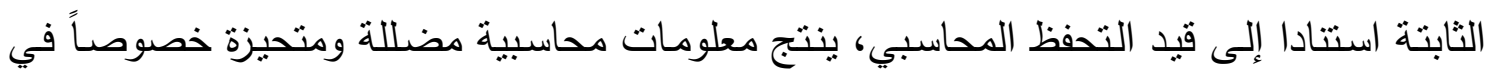
ظل وجود التضخم وانخفاض القيمة الثرائية للنقود.

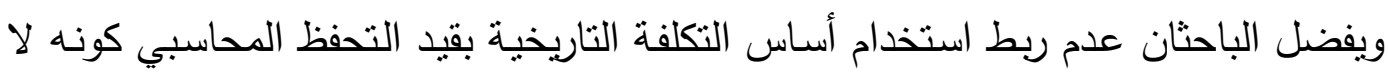

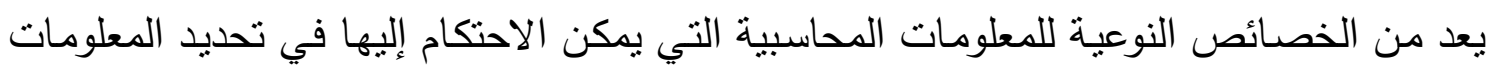

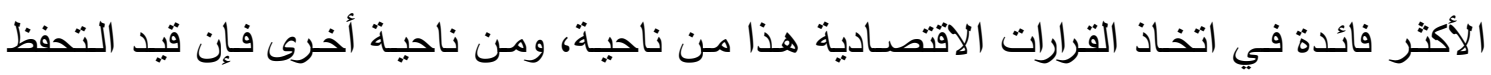

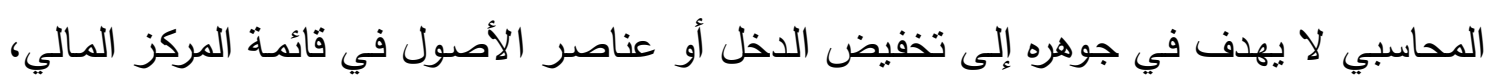

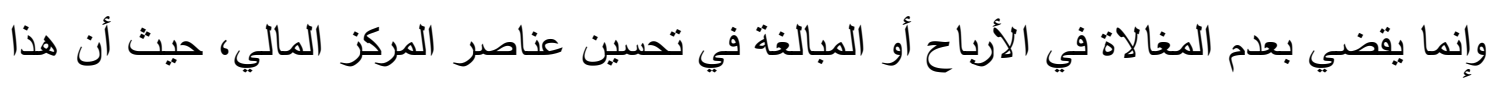

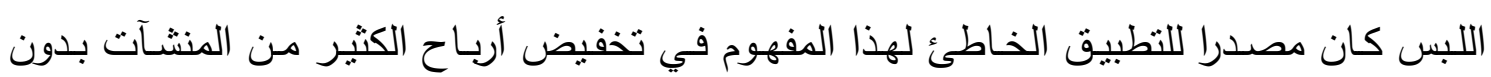

ويقصــ بأمانــة العرض والتنثيـل العـادل للمعلومـات المحاسبية أن تعكس بصـدق طبيعـة

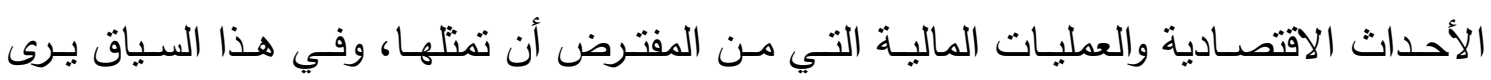


(Foster and Upton, 2001) أن استخدام أساس التكلفة التاريخية يقدم معلومات محاسبية تتصف بالتمثيل الأمين والعادل للحدث الاقتصادي ليس لأنه يعبر عن القيمة المدفوعة لاقتتاء القاء

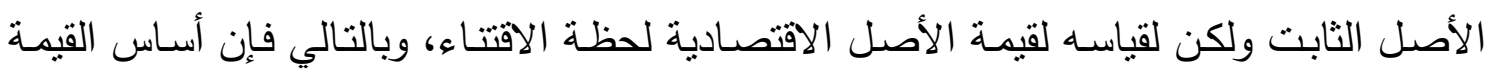

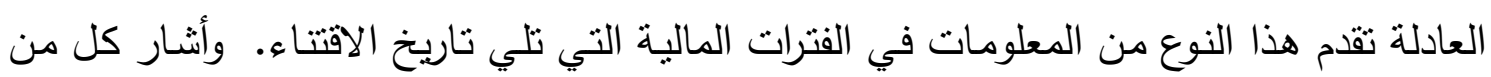

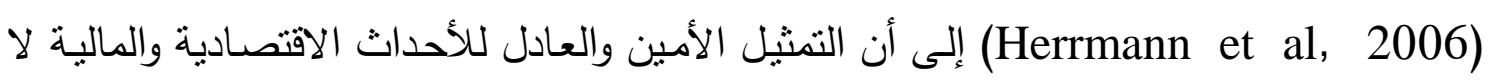

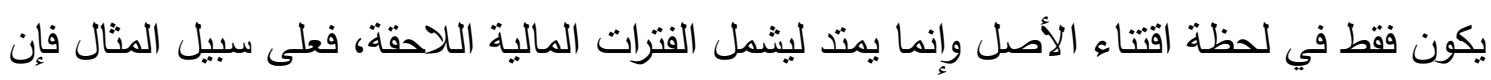
أهمية التسويات الجردية التي تتم في نهاية كل سنة مالية تكمن في تقديم معلومات تتصف التصل بالعدالة

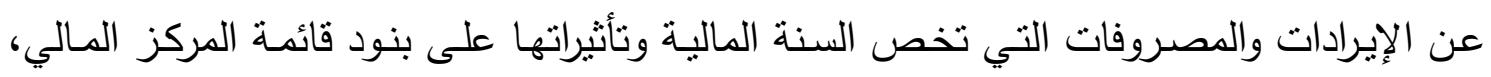

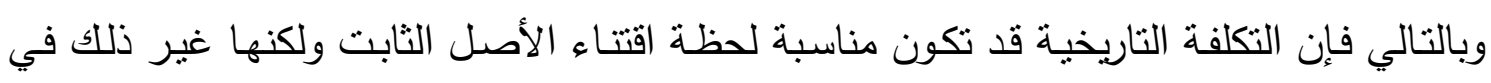

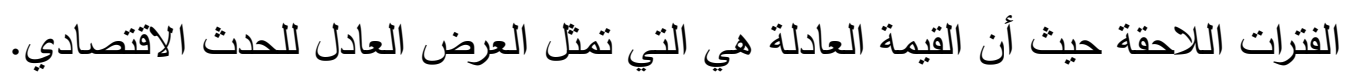

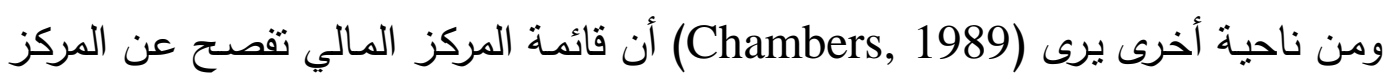

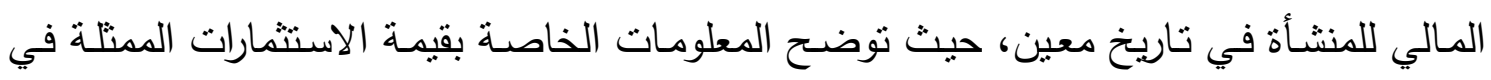
الأصول، ومصادر هذه الاستثمارات الممتلة في الالتزامات وحقوق الملكية، وحيث أنه يتم الاعتماد

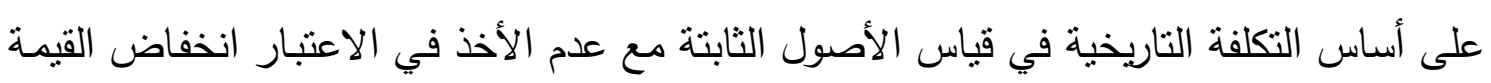

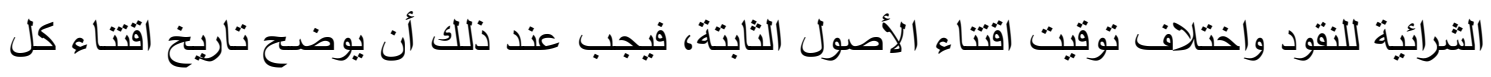

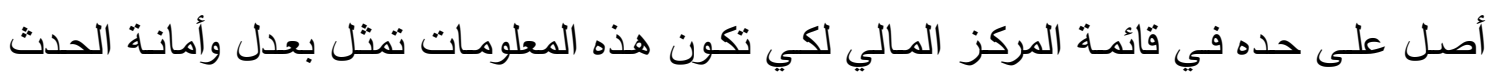

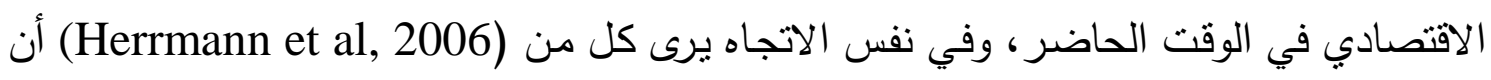

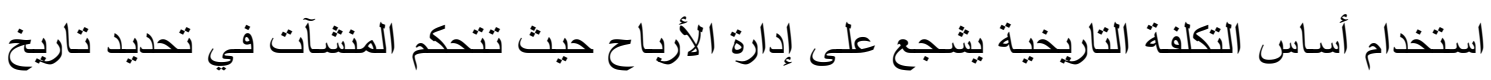

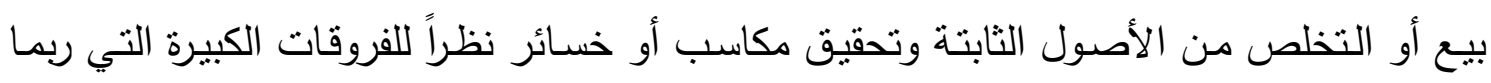
تحدث بين القيمة الدفترية للأصول والقيمة البيعية لها.

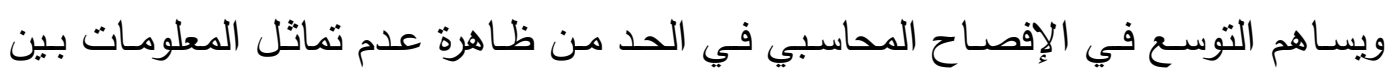

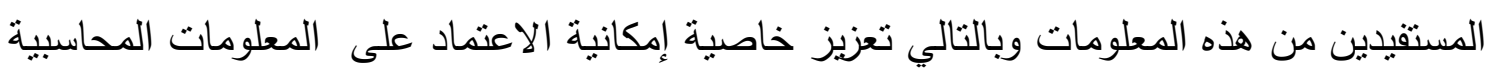

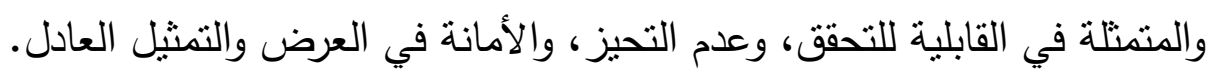

\section{ج- القابلية للمقارنة Comparability}

يقصد بإمكانية المقارنة القدرة على قياس الأحداث الاقتصادية والمالية والثقرير عنها بصورة

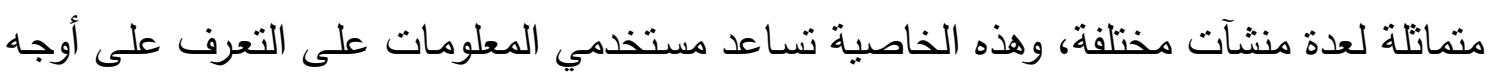

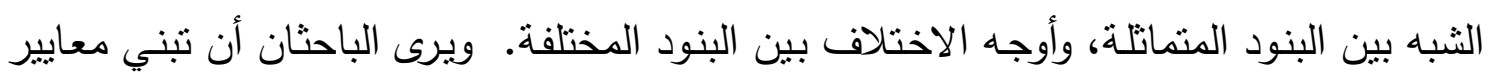


المحاسبة الدولية وما يترتب عليه من التوسع في الإفصاح واستخدام القيمة العادلة سوف يساهم قي تقديم معلومات محاسبية تتوافر فيها خاصية إكانية المقارنة بين التقارير المالية المعدة وفقا لتلك في الكا المعايير وذلك ليتمكن المستفيدون من استخدام معلومات هذه التقارير في قراراتهم الاستثمارية.

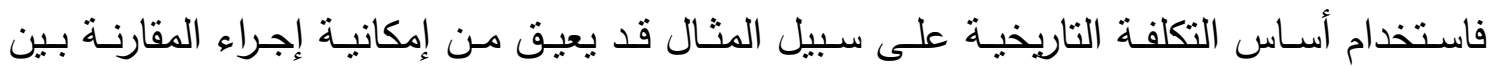

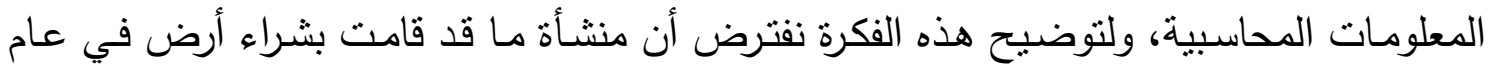

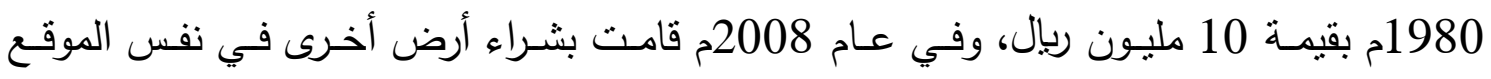

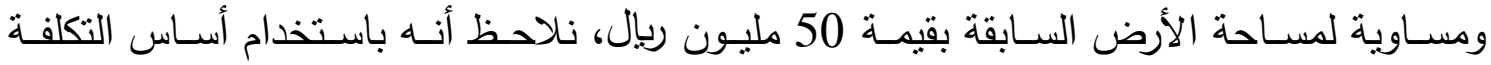
الثاريخية صعوبة إجراء المقارنة بين أصلين متتـابهين في كل الخصائص نظراً لاختلاف القيمة

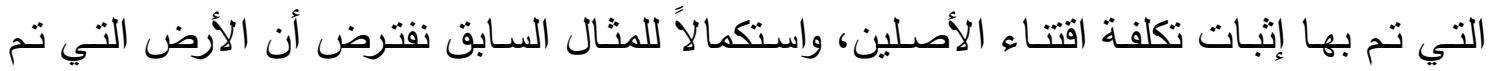

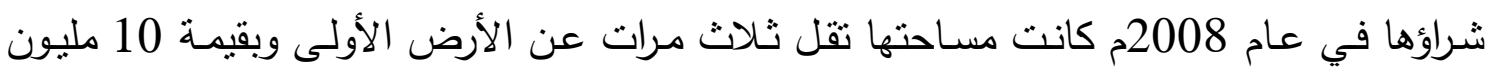

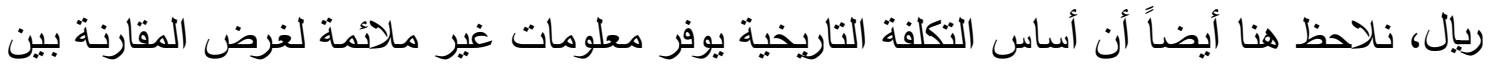
أصلين يختلفان في الخصائص على الرغم من أن القيمة التي يتم التعبير عنهما في قائمة المركز المالي منساوية (Herrmann et al, 2006).

ويثدد الباحثان هنا إلى أن اختلاف القواعد المحاسبية المستخدمة بين المنشآت يفقد خاصية

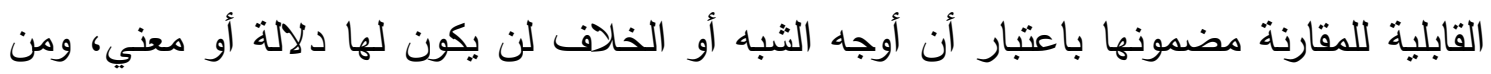
هذا المنطلق يؤدي السماح في المعيار المحاسبي الدولي رقم 16 بإعادة نقويم الأصول الثادئ الثابتة

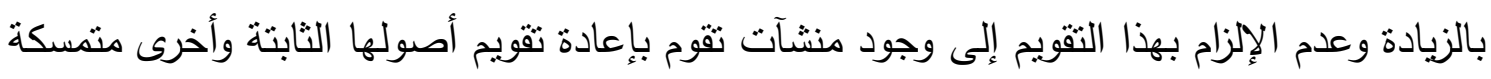
باستخدام أساس التكلفة التاريخية، مما ينتج عنه صعوبة في إجراء المقارنة بين المعلومات المحاسبية في ظل استخدام طرق متعددة في القياس والتقويم.

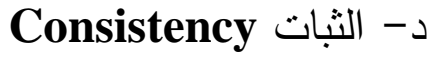
يتوفر الثبات في المعلومات المحاسبية عند قيام المنشأة بتطبيق نفس السياسات والقواعد

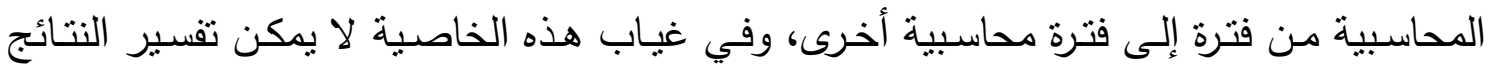

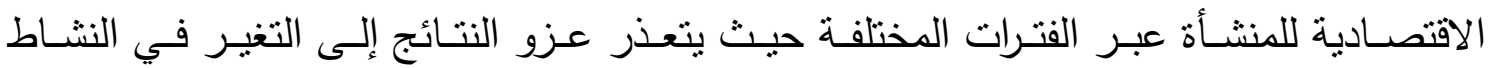
الاقتصادي للمنشأة أو الاختلاف في السياسات والقواعد المحاسبية المطبقة، ولتحقيق الثبات في المعلومات المحاسبية يعتقد الباحثان بأهمية تبني معايير محاسبية موحدة تؤدي إلى إعداد نقارير

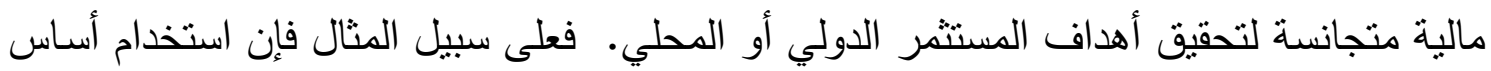

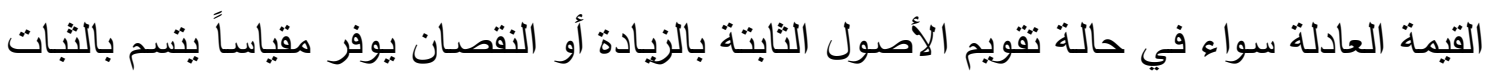


في معالجته لكل الحالات على العكس من أساس التكلفة التاريخية الذي يسمح باستخدام أكثر من

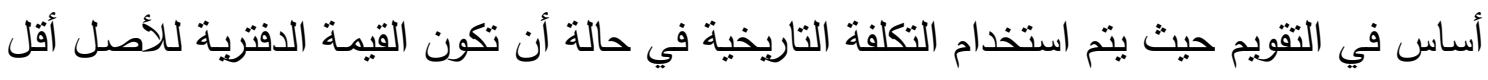

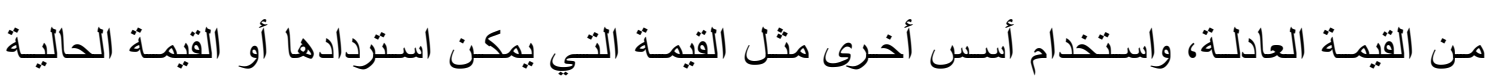
للتدفقات النقدية في حالة زيادة صافي القيمة الدفترية عن القيمة العادلة. 


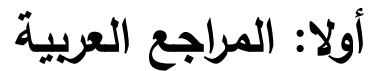

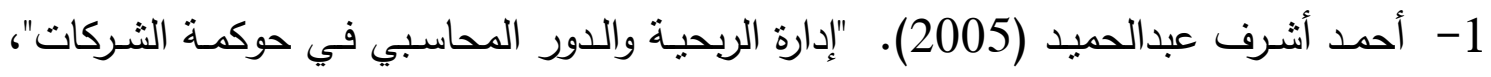

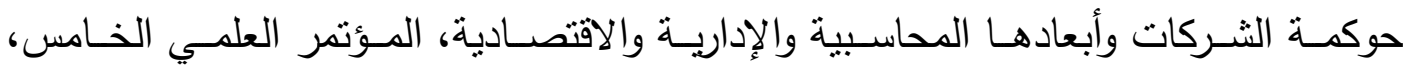
الإنكندرية.

2- أسامة فهد الحيزان (2005). "نظام وإدارة ومراقبة المنشآت (الحوكمة) حالة هيئة المحاسبة

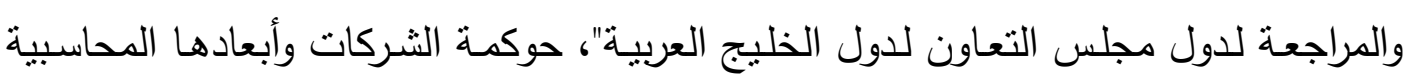
والإدارية والاقتصادية، المؤتمر العلمي الخامس، الإسكندرية.

3- حازم الخطيب، وظاهر القثي (2004). "توجه معايير الدحاسبة نحو القيم العادلة والدخل

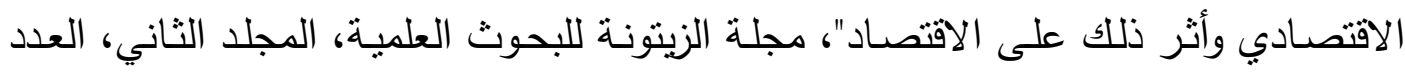

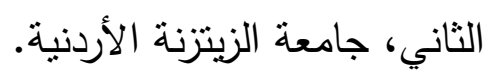

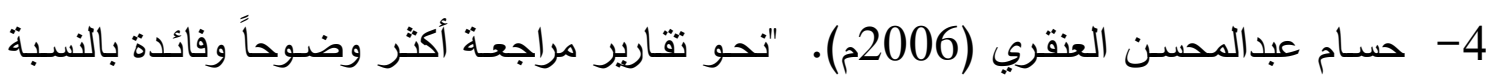

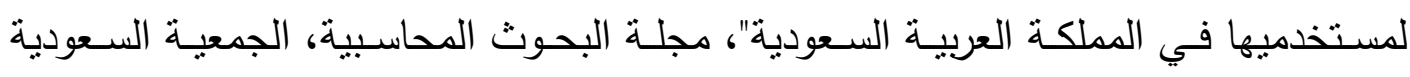
للاسبة، الرياض، المجلد 7، العدد 1، ص ص: ص: 3-48.

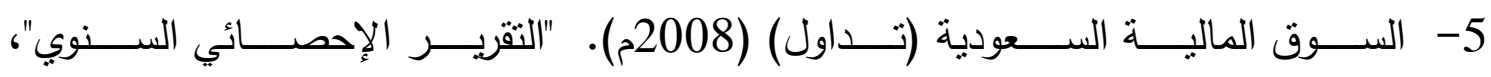
.www.tadawul.com.sa 6- سعد محمد مارق (2009م). "قياس مستوى الإفصاح الاختباري في الثقارير المالية المنشورة

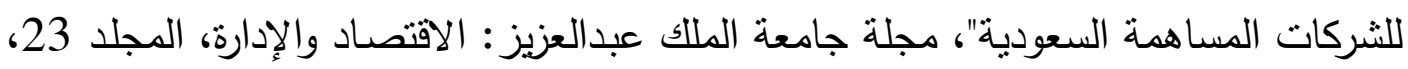
العدد الأول، ص ص: 131-174، جدة:جامعة الملك عبدالعزيز.

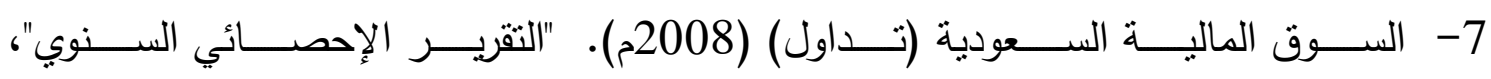
www.tadawul.com.sa

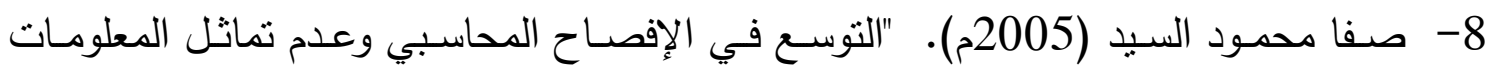

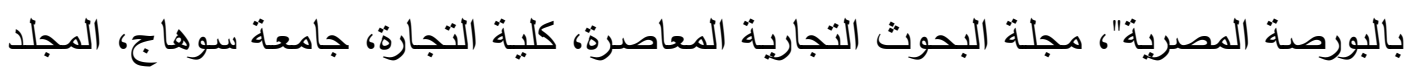

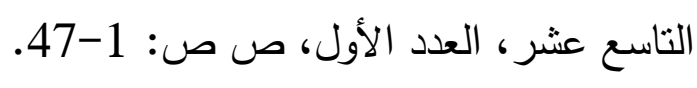


9- عـارف عبداللـة عبدالكريم (2003م). الإفصـاح المحاسبي الاختبـاري مـع دراسـة ميدانيـة

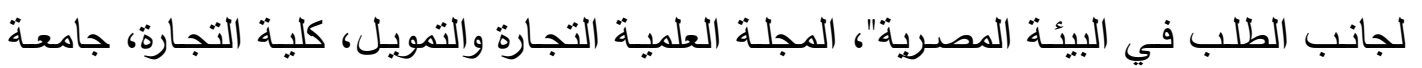

$$
\text { طنطا، العدد الأول، ص ص: 248-316. }
$$

10-عبـاس مهـدي الثـيرازي (1990م). "نظريــة الدحاسـبة"، ذات السلاسـل للطباعــة والنشـر

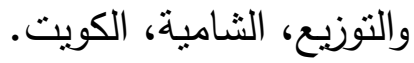

11- عبدالسلام سعيد الغامدي (2006م). "أهمية الأداء المالي للشركة المساهمة في ظل انهيار

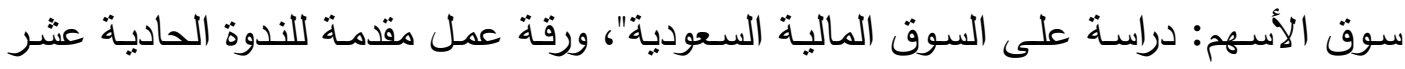
لتطوير المحاسبة "المعلومات وسوق الأوراق المالية."

12-عبدالناصـر محمد سيد درويش (2003). "دور الإفصـاح الهحاسبي في النطبيق الفعـال لحوكمة الثركات- دراسة تحليلية ميدانية-"، مجلة الدراسات المالية والتجارية، كلية التجارة، بني سويف، جامعة القاهرة، العدد الثاني. 13-عبيد سـعد المطيري (2003). "تطبيق الإجراءات الحاكمـة للشـركات في المملكة العربيـة السعودية"، المجلة العربية للعلوم الإدارية، مجلد 10، عدد 3.

14-كمال الدين مصطفى الدهراوي (1994م). "دور الإفصاح المحاسبي في تخفيض عدم تماثل

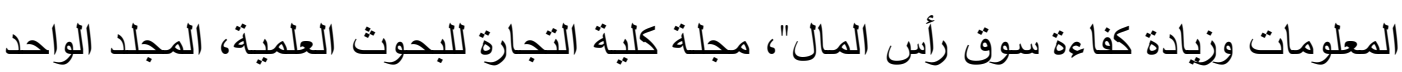

$$
\text { والثلاثون، العدد الثاني، ص صنوم: 43-88. }
$$

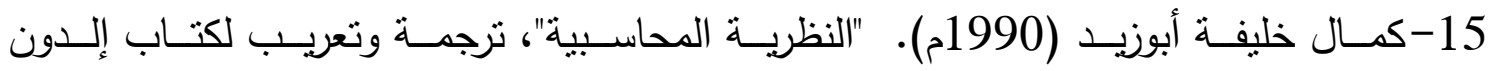

$$
\text { وهندريكسن. }
$$

16-محمــ سـامي راضـي (2000). " "المحاسبـة المتوسـة"، الجزءء الأول، إصـدارات الجمعيـة السعودية للمحاسبة، الإصدار السابع عشر ، الطبعة الثانية. 17-محمد عبدالحميد طاحون (2001). "إعادة تقييم الأصول الثابتة بالزيادة بين السماح والمنع:

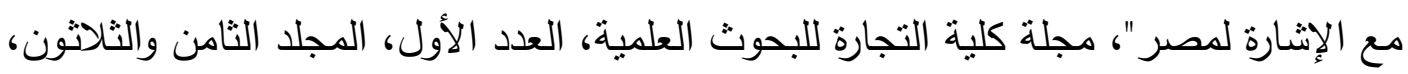
مارس، كلية التجارة، جامعة الإسكندرية. 
18-محمد عبدالعزيز محمد خليفة (2003). " "إطار مقترح لتفسير سلوك الوحدات الاقتصادية في

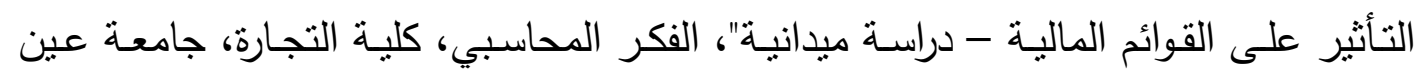
شمس، العدد الثاني، السنة السابعة.

19-محمد عبدالفتاح محمد إبراهيم (2005). "إطار محاسبي مقترح لدور حوكمة الثركات في

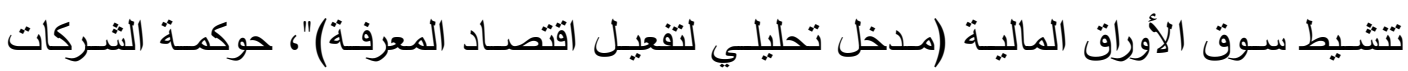
وأبعادها المحاسبية والإدارية والاقتصادية، المؤتمر العلمي الخامس، الإسكندرية. 20- هلال عبدالفتاح عفيفي (2008م). "العلاقة بين تطبيق حوكمة الثركات ومسنوى الإفصاح

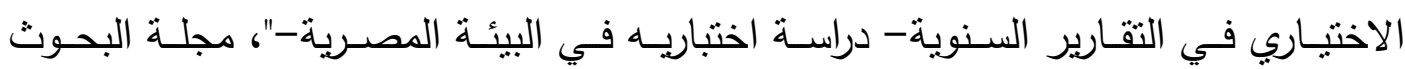

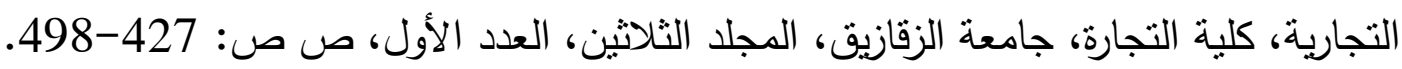
21- هيئة السوق المالية (2006). "لائحة حوكمة الثركات في المملكة العربية السعودية"، القرار رقم 1-212-2006، -2006، الرياض. 22- هيئة السوق المالية (2008). "لائحة حوكمة الثركات في المملكة العربية السعودية"، القرار رقم 1-36-2008، تاريخ 1429/11/12هـ. 23- هيئة المحاسبة والمراجعة لدول مجلس التعاون لدول الخليج العربيـة (2003م). الإطـار

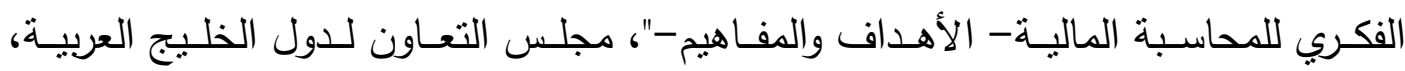
.www.gccaao.org

24-الهيئـة السـعودية للمحاسـبين القـانونيين (2007م). "مفـاهيم المحاسـبة الماليـة"، معـايير المحاسبة المالية، لجنة معايير المحاسبة، المجلا الأول، المملكة العربية السعودية، الرياض. 25-الهيئة السعودية للدحاسبين القانونيين (2007). "معيار الأصول الثابتة"، معايير المحاسبة المالية، لجنة معايير المحاسبة، المجلد الثاني، المملكة العربية السعودية، الرياض. 26- الهيئة السعودية للمحاسبين القانونيين (2007). "معيار محاسبة الهبوط في قيمة الأصول

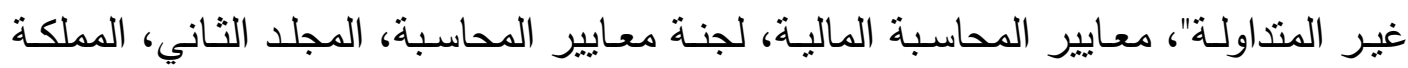
العربية السعودية، الرياض. 
27- هيئة المحاسبة والمراجعة لدول مجلس التعاون لدول الخليج العربيـة (2003م). الإطـار

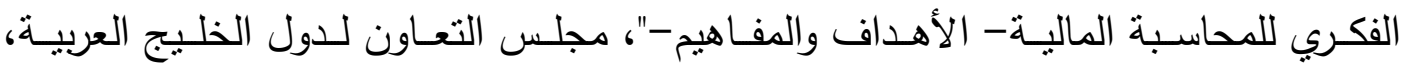

.www.gccaao.org

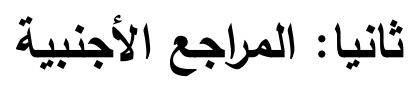

28- Aboody, D., Barth, M.E., and Kasznik, R. (1999). "Revaluations of fixed assets and future firm performance: Evidence from the UK", Journal of Accounting and Economics, 26, pp. 149-178.

29- Accounting Standards Board (ASB) (1998). "Financial Reporting standard 11: Impairment of Fixed Assets and Goodwill", London: Institute of Chartered Accountants in England and Wales.

30- Accounting Standards Board (ASB) (1999b). "Financial Reporting standard 15: Tangible Assets", London: Institute of Chartered Accountants in England and Wales.

31- Australian Accounting Standards Board (AASB) (1999). "AASB 1010: Recoverable amount of non-current assets", Melbourne.

32- Australian Accounting Standards Board (AASB) (2001). "AASB 1041: Recoverable amount of non-current assets", Melbourne.

33- Barth, M.E., and Clinch, G. (1998). "Revalued financial, tangible, and intangible assets: Associations with share prices and non-market-based value estimates", Journal of Accounting Research, 36, pp. 199-233.

34- Brown, P., Izan, H., and Loh, A. (1992). "Fixed asset revaluations and managerial incentives", Abacus, 28, 1, pp. 36-57.

35- Boesso, G., and Kumar, K. (2007). "Drivers of corporate voluntary disclosure: A framework and empirical evidence from Italy and the United States", Accounting, Auditing \& Accountability Journal, 20(2), pp. 269-296.

36- Celik, O., Ecer, A., and Karabacak, H. (2006). "Disclosure of forward looking information: Evidence from listed companies on Istanbul 
Stock Exchange (ISE)", Investment Management and Financial Innovations, 3(2), pp. 197-216.

37- Christensen, H., and Nikolaev, V. (2008). "Who uses fair -value accounting for non-financial assets following IFRS adoption?", Social Science Research Network.

38- Chau, G., and Gray, S. (2002). "Ownership structure and corporate voluntary disclosure in Hong Kong and Singapore", The International Journal of Accounting", 37, pp. 247-265.

39- Courtney, S., and Cahan, S. (2004). "The Impact of debt on market reacation to revaluation of noncurrent assets", Pacific-Basin Finance Journal, 12, pp. 219-243.

40- Dye, R. (2001). "An evaluation of essays on disclosure and the disclosure literature in accounting", Journal of Accounting and Economics, 32, pp. 181-235.

41- Easton, P.D., Eddey, P.H., and Harris, T.S. (1993). "An investigation of revaluations of tangible long-lived assets", Journal of Accounting Research, 31, pp. 1-38.

42- Eng, L., and Mak, Y. (2003). "Corporate governance and voluntary disclosure", Journal of Accounting and Public Policy, 22, pp. 325-345.

43- Foster, G. (1986). "Financial Statement Analysis", Englewood Cliffs, N.J., Prentice-Hall.

44- Freeman, R. (1984). "Strategic Management: A Stakeholder Approach", Pittman Publishing, Marshfield, NA.

45- Groom, C., Du, S., Qu, W, and Sims, R. (2004). "Accounting Regulation and Corporate Governance in China's Listed CompaniesAn Examination of The Changing Environment and Current Issues", paper Presented at the 2004, Beijing Conference. 
46- Gull, F., and Leung, S. (2004). "Board Leadership, outside directors' expertise and voluntary corporate disclosure", Journal of Accounting and Public Policy, 23, pp. 351-379.

47- Herrmann, D., Shahrokh, M., and Thomas, W. (2006). "The quality of fair value measures for property, plant, and equipment", Accounting Forum, 30, pp. 43-59.

48- International Accounting Standards Committee (IASC0) (2003). "International Accounting Standard No. 16, Property, plant, and equipment", IASC.

49- International Accounting Standards Committee (IASC0) (1998). "International Accounting Standard No. 36, Impairment of assets", IASC.

50- Key, S. (1999). "Toward A New Theory of The Firm: A Critique of Stakeholders Theory", Management Decision, 37(4), pp. 317-348.

51- Leventis, S., and Weetman, P. (2004). "Impression management: dual language reporting and voluntary disclosure", Accounting Forum, 28, pp. 307-328.

52- Mitton, T. (2002). "A Cross Firm Analysis of The Impact of Corporate on The East Asian Financial Crises", Journal of Financial Economics, 64(2), pp. 215-241.

53- Meek, G., Robert, C., and Gray, S. (1995). "Factors Influencing Voluntary Annual Report Disclosure by US, UK and Continental European Multinational Corporation", Journal of International Business Studies, 26, pp. 555-572.

54- Nasser, K., and Nuseibeh, R. (2003). "Quality of financial reporting: evidence from the listed Saudi nonfinancial companies", The International Journal of Accounting, 38, pp. 41-69.

55- Omaima, A., Romilly, P., Giorgioni, G., and Power, D. (2009). " The value relevance of disclosure: Evidence from the emerging capital 
market of Egypt", The International Journal of Accounting, In Press, Corrected Proof, Available online.

56- Orens, R., and Lybaert, N. (2007). "Does the Financial analysts' usage of non-financial information influence the analysts' forecast accuracy? Some evidence from the Belgium sell-side financial analyst", The International Journal of Accounting, 42, pp. 237-271.

57- Petersen, C., and Plenborg, T. (2006). "Voluntary disclosure and information asymmetry in Denmark", Journal of International Accounting, Auditing and Taxation, xxx, pp. xxx.

58- Robb, S., Single, L., and Zarzeski, M. (2001). "Nonfinancial disclosure across Anglo-American countries", Journal of International Accounting, 10, pp. 71-83.

59- Ross, S. (1979). "Disclosure regulation in financial markets: Implications of modern finance theory and signaling theory", In. F. Edwards, Issues in Financial Regulation, McGraw-Hill.

60- Warne, R. (2008). "The Effect of Non-Financial Asset Fair-Value Recognition on Nonprofessional Investors' Judgments", Social Science Research Network

61- Watson, A., Shrives, P., and Marston, C. (2002). "Voluntary Disclosure of Accounting Ratios in the UK", British Accounting Review, 34, pp. 289-313.

62- Wen, X. (2008). "Voluntary Disclosure and Investment", Electronic copy available at: http://ssm.com/abstracl, pp. 1-39.

63- Whittred, G., and Chan, Y. (1992). "Asset revaluation and the mitigation of under-investment”, Abacus, 28, 1, pp. 58-74. 


\section{أثر تطوير معايير المحاسبة السعودية على جودة المعلومات المحاسبية (دراسة ميدانية)}

ملخص

هدفت الدراسة إلى توثيق الوضع الحالي لمهنة المحاسبة في المملكة العربية السعودية وذلك

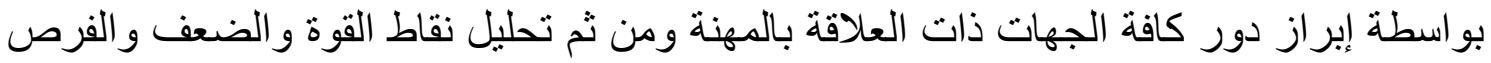
والمخاطر في معايير المحاسبة في المملكة العربية السعودية وذلك لاستكثاف الفرص المتاحة و الأفاق المستقلية التي يمكن الاستفادة منها لتطوير معايير المحاسبة في المملكة العربية السعودية. وعملت الدراسة على تحقيق ذلك من خلال الاستقراء النظري بهدف استقراء وتصنيف كل ما توصل إليه الباحثان من مراجع ومؤتمرات وأبحاث بهدف الوصول إلى إطار نظري شامل لموضوع الدراسة، إضافة إلى القيام بتحليل محتوى معايير المحاسبة في المملكة العربية السعودية، ومن ثم صياغة واختبار مجموعة من الأسئلة كأساس للار اسة الميدانية والتي نم إجر ائها باستخدام أسلوب الاستبيان، والذي تم توزيعه على الدحاسبين القانونيين الممارسين للمهنة والأكاديميين

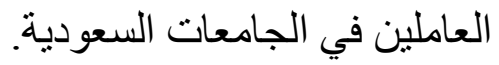

الكلمات الافتتاحية المعلومات المحاسبية، معايير المحاسبة السعودية، الهيئة السعودية للمحاسبين القانونيين، معايير

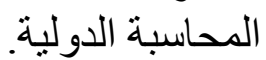
Accounting information, Saudi Accounting Standards, Saudi Organization for Certified Public Accounting, International Accounting Standards. 


\section{Summary}

The Impact of development of Accounting Standards in Saudi Arabia on the Qualitative Characteristics of Accounting Information (Field Study)

Saudi Arabia is one of the largest economies in the Middle East. It has witnessed several changes in its accounting system in the last two decades. This study aims to provide an analysis of the Saudi accounting system in terms of its development, with special focus on the development of the accounting standards. In addition, this study suggests recommendations that can help reform accounting standards in Saudi Arabia. To achieve that, a structure questionnaire is designed to meet these objectives and to respond to the research questions. The final questionnaires are distributed to the target groups that included a simple of external auditors and academics. 